\title{
LIFBAK SPINAL LOAD REDUCTION EXOSKELETON COMMERCIALISATION PROJECT REPORT.
}

BY

PAUL DOWD

A thesis submitted to the Victoria University of Wellington in fulfilment of the requirements for the degree of Master of Innovation and Commercialisation

Victoria University of Wellington 2018 


\section{Abstract}

This research investigates the product and market development requirements for building a medical device intended to assist patients rehabilitating from back injuries. It looks at the competitive landscape, potential customers segments, path to market, research and development requirements, and funding requirements. This document provides background research for the included business case which will be presented to my project partner, Lifbak. Lifbak is developing a device for customers seeking to accelerate their rehabilitation from a back injury.

\section{Acknowledgements}

I would like to acknowledge several people who have supported me as I researched and wrote this report.

Jenny Douché, thank you for tirelessly working to build a programme I believe is essential to the future of job creation in New Zealand. Your unwavering support and positivity throughout the program is very much appreciated. I would also like to thank all of the participants of the programme who made the experience more enjoyable, and valuable.

Siah Hwee Ang, thank you for supervising me. And, crucially, helping me through navigating the suspensions and extensions I needed to fit my study around my work. Your expertise, experience, and guidance has helped me demand more of myself and strive to higher research standards.

Mark Hildesley is the original inventor of the Lifbak device, and the person whom the business case is written for. Your input, support, and time at critical stages is much appreciated. I sincerely hope that Lifbak gains the required funding and builds New Zealand's next unicorn business.

Finally, my wife Camila. You stood by me through this entire process; suffering my ups, and downs with strength and patience. Without your support, encouragement, and understanding I could not have finished. Thank you. 


\section{Table of Contents}

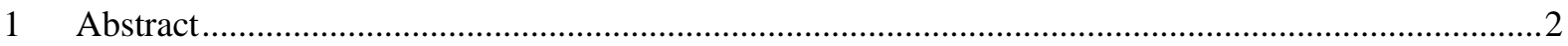

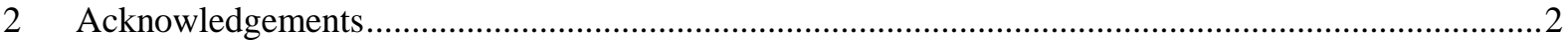

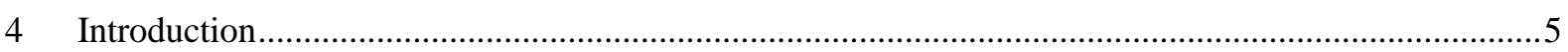

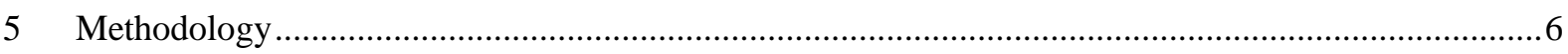

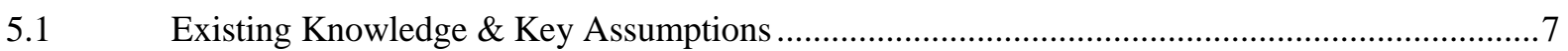

5.2 Market segmentation analysis and beachhead market identification............................................

5.2.1 Step One: Market Segmentation Analysis ………….............................................................

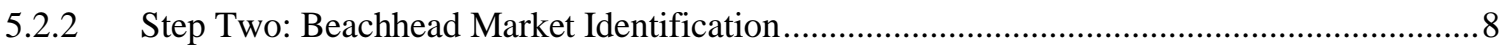

5.2.3 Steps 3, 4, and 5: Problem Interviews to reach Customer/Problem Fit...................................

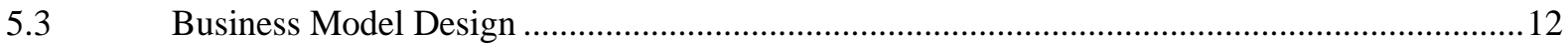

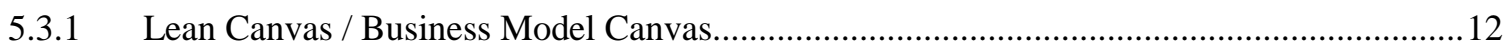

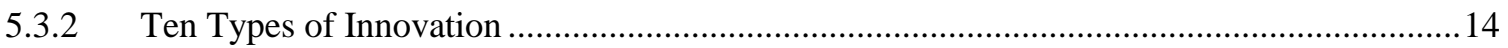

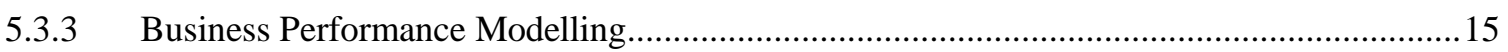

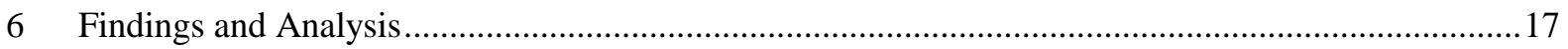

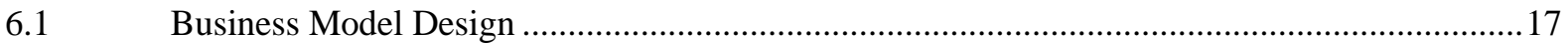

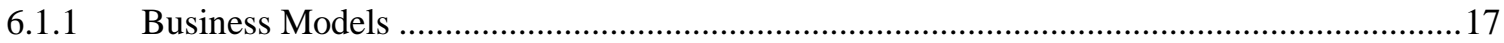

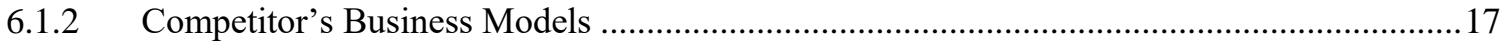

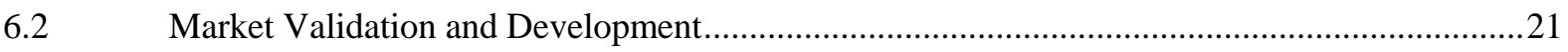

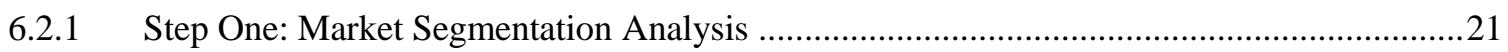

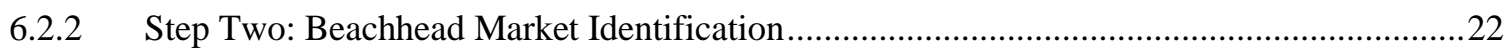

6.2.3 Step Three: Surveying and Problem Interviews......................................................................

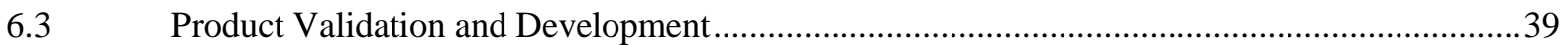

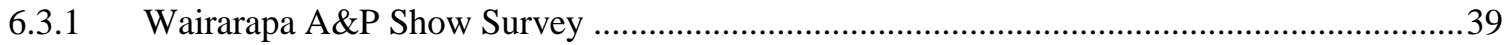

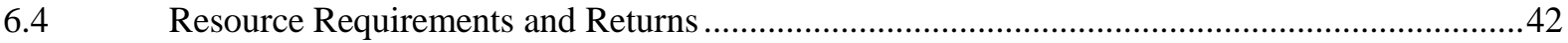

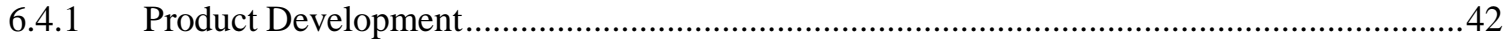

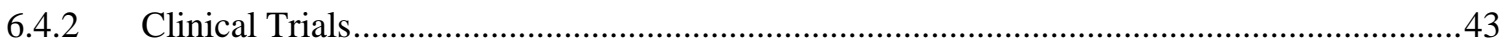

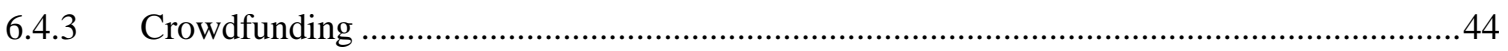

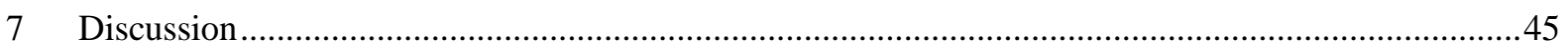

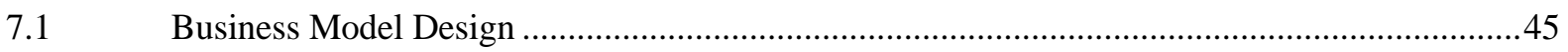

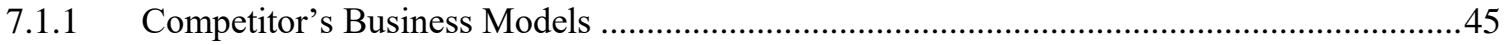

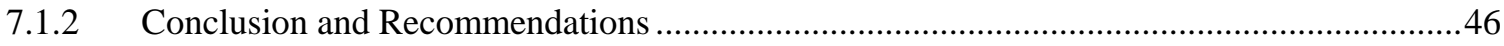

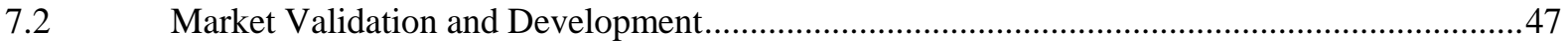

7.2.1 Market Segmentation Analysis ..........................................................................................

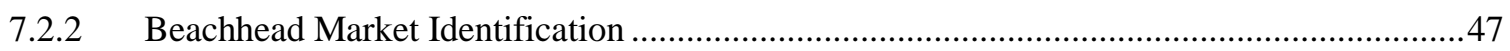

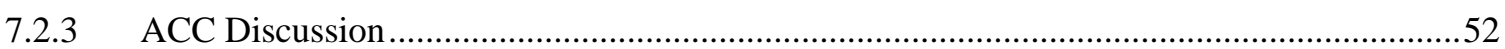




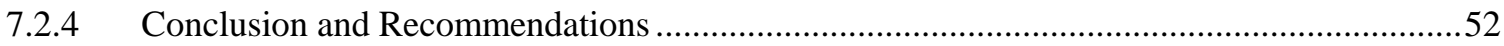

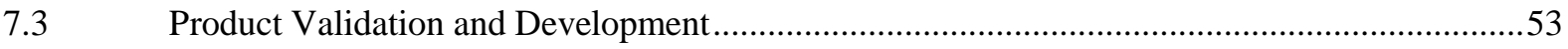

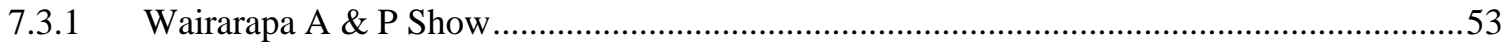

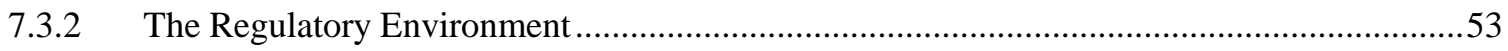

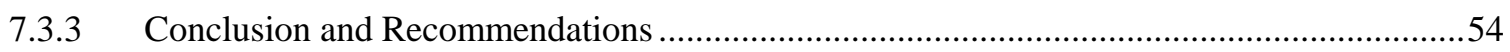

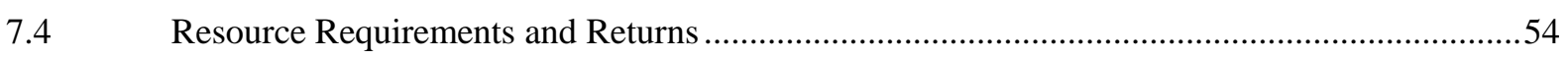

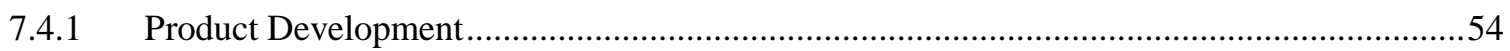

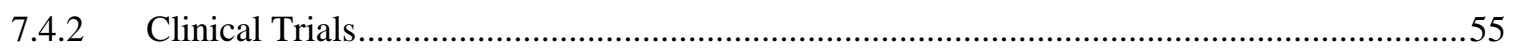

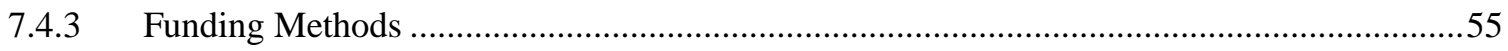

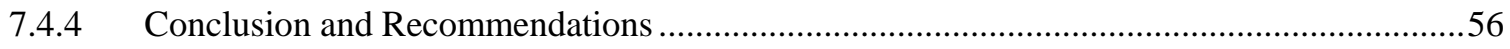

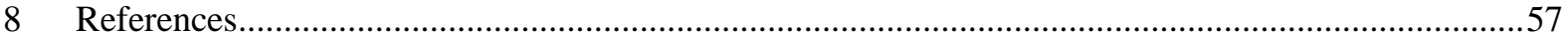

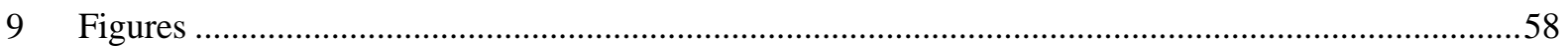

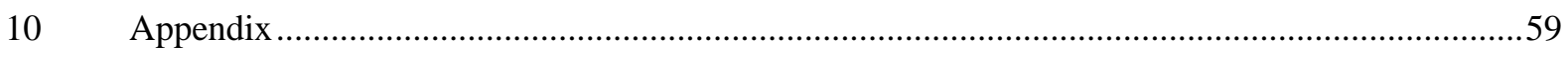

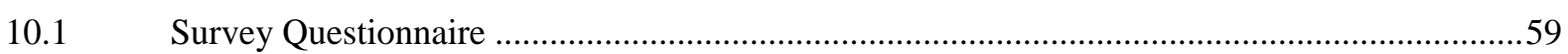

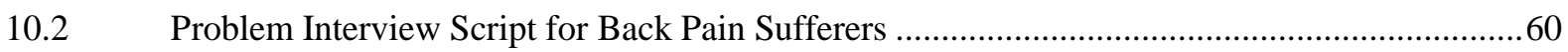

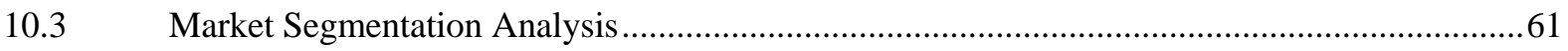

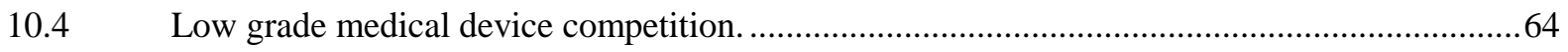

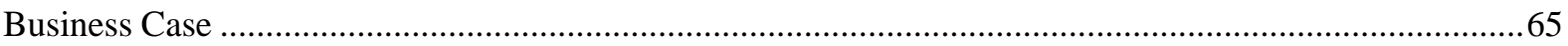




\section{Introduction}

Low back pain (LBP) is a global health problem that is reaching epidemic proportions, with $80 \%$ of adults expected to suffer at some point in their lifetime. LBP and the spinal injuries and conditions leading to LBP pose a significant economic burden on health systems and economic productivity, with estimates suggesting LBP causes $40 \%$ of employment absenteeism, and cost the economy approximately $1 \%$ of Gross Domestic Profit. Frustratingly, $80 \%$ of causes of LBP are not accurately attributed to a diagnosis and are bundled under the non-specific category. This poses difficulty when assessing the true personal and economic impact of certain injuries and conditions. LBP is particularly apparent in developed nations.

In New Zealand, the most common back injury, a lumbar sprain, has seen exponential incidence increase rates (196,733 active claims in 2012 to 243,792 in 2015), and cost increases $(\$ 110,417,759$ in 2012 to $\$ 173,745,244$ in 2015); far outstripping population increase rates lower than $2 \%$, and leading me to project that by $2020,320,000$ New Zealanders will receive compensation for a lumbar sprain that year. ACC's cost for treatment is rising faster than the incidence rate. These increases in both incidence and cost puts significant pressure on limited health system funding.

Despite the commonality of LBP, the treatment methods available today are little changed from those available 50 years ago. There are expensive innovative solutions being developed to treat major conditions where patients have lost significant function, but the lower end appears to lack new clinical options. There is a significant opportunity for research and development for innovative ideas focused on helping patients experience faster recovery times and an increased quality of life, leading to a reduced burden of LBP on economies.

Lifbak has developed a load reduction exoskeleton designed to accelerate and support the rehabilitation of patients with LBP. Clinical trials are yet to be undertaken, therefore we do not understand exactly what injuries and/or conditions Lifbak's device will best treat. This report looks to provide direction to Lifbak on what conditions they should design, develop, and run trials for, markets to enter, and the capital required to bring the device to market.

Lifbak will need to raise at minimum $\$ 340,000$ in capital to fund the future research, development, and trials required to develop a product has proven efficacy and will meet the needs of consumers and economic buyers. 


\section{Methodology}

To research and develop the recommendations for this commercial opportunity I have taken a "lean startup" approach, specifically using the methods espoused by Bill Aulet and Ash Maurya. I have taken the first four process steps from Bill Aulet's Disciplined Entrepreneur: 24 Steps to a Successful Start Up (Aulet, 2013) and supplemented them with the interview methods presented in Ash Maurya's Running Lean (Maurya, 2012).

Lean start-up is an entrepreneurial movement built around the principles of validated learning. The goal is to reduce both the opportunity and financial risk associated with developing new businesses/products, and bringing them to market (Ries, 2011). This approach to entrepreneurship relies on continuous experimentation, trying to remove risk from the endeavour with the least possible cost, whilst generating validated learning that is taken forward to inform the next experiment. The method places a higher priority on validating the customer, problem, and market, over building the solution/product.

I have completed research directed at informing two areas of discussion and recommendations: discovering a beachhead market for Lifbak to enter and that market's requirements/needs (section 5.2), and building the business model and strategy Lifbak can use to build the business and enter the market (section 5.3).

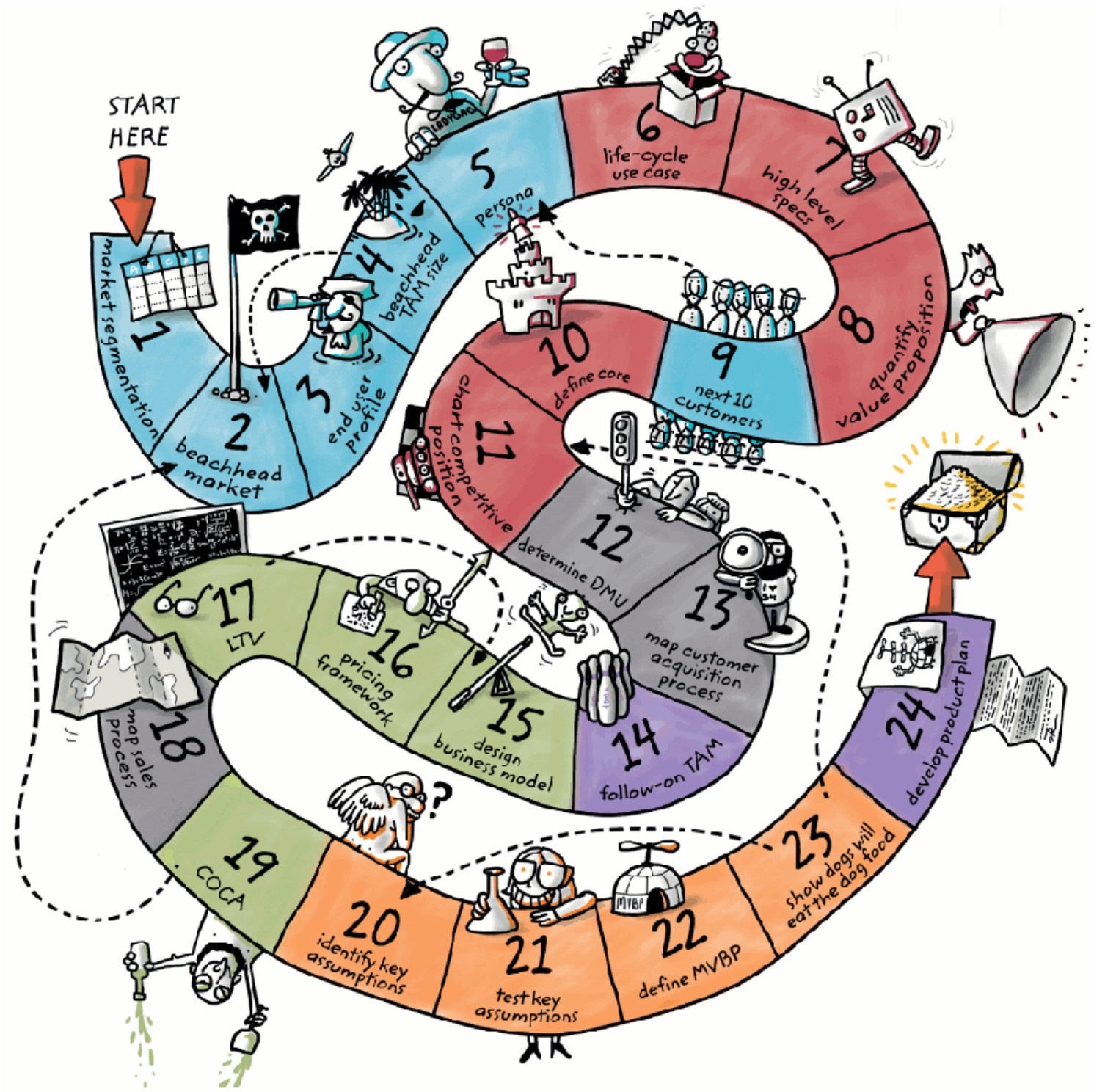

Figure 1 - 24 Steps to a successful startup. (Aulet, 2013) 


\subsection{Existing Knowledge \& Key Assumptions}

Having worked in and around start-ups and early stage companies throughout my working career I have first-hand knowledge of the challenges they face, and experience in implementing some of the solutions which help founders overcome these challenges. My own knowledge is based around the Lean Start-up methodologies and it is that which I'll be most closely following throughout this project.

I work from the perspective that we should have no assumptions, and as such I will be completing multiple rounds of research in order to test and prove different areas of the business model. However, there are always some assumptions in place in order to start testing. These are:

1. Customers have back pain and discomfort for which they are seeking better / different solutions.

○ Tested through Customer/Problem Fit research.

2. The Lifbak device works and will provide a benefit to the user if load reduction would help them reduce discomfort.

- Tested through Problem/Solution Fit research.

3. The Lifbak device prototype is currently undesirable to customers. This is based on feedback where customers have expressed a desire for it to be more invisible by fitting under clothing and being more comfortable to wear.

- Tested through Problem/Solution Fit research.

Bill Aulet, the Managing Director of the Martin Trust Center for MIT Entrepreneurship, gives us 24 steps to a successful start-up. I have selected from these steps and added them to Ash Maurya's advice in Running Lean to form a strong methodology for building and validating the Lifbak business.

\subsection{Market segmentation analysis and beachhead market identification.}

The purpose of the market segmentation analysis step is to discover all of the potential markets for our product, narrow those results to six probable viable markets, and then gather primary research on all of the viable markets to give us a strong view of the marketplace.

The purpose of the Select a Beachhead Market step is to analyse the top market opportunities from the Market Segmentation step and select a single opportunity to pursue. That opportunity may then be further segmented to get a highly focussed beachhead market segment for the business to target.

\subsubsection{Step One: Market Segmentation Analysis}

We all know that you never really have a business until you have a paying customer. However, just having some customers doesn't mean you have a good business.

"In order to have a good, sustainable business, you will need to gain enough customers paying enough money within a relatively short period of time so you do not run out of capital, but instead, become profitable." (Aulet, 2013, p. 25)

It is expected that Lifbak will be creating and entering a market that doesn't yet exist. This creates complexity and cost for the business as Lifbak must build the market, convincing target customers that this new type of product will solve their problem, and at the same time discover and build the solution that this new market will adopt. (Thiel \& Masters, 2015) 
Market Segmentation involves brainstorming all of the potential market segments into as many individually identifiable segments as possible. The intent is to get as specific as possible and always be segmenting until you get to segments which are broadly homogeneous and which you can build a strong customer profile around. We then narrow down our list of potential segments to 6 options based on the answers to the following questions (Aulet, 2013):

1. Is the target customer well-funded?

2. Is the target customer readily accessible to your sales force?

3. Does the target customer have a compelling reason to buy?

4. Can you today, with the help of partners, deliver a whole product?

5. Is there entrenched competition that could block you?

6. If you win this segment, can you leverage it to enter additional segments?

7. Is this market consistent with the value, passions, and goals of the founding team?

Once we have narrowed our market segments we engage in further more detailed research to identify (Aulet, 2013):

1. End user profile

2. Application

3. Benefits

4. Lead customers who can influence the greater market segment

5. Market characteristics

6. Partners/Players we need to work with

7. Size of the Market

8. Competition, real or perceived

9. Complementary products or services our customer would require (if any)

\subsubsection{Step Two: Beachhead Market Identification}

The purpose of this step is to analyse the results of the Market Segmentation Analysis to determine our beachhead market. We can then move onto the next steps with clear focus knowing exactly who we are targeting.

Once we've selected a beachhead market it is possible that further segmentation is needed to get a sufficiently focussed market segment whilst still maintaining a total addressable market size sufficient for a sustainable business. The three conditions we will use for this purpose are (Aulet, 2013):

1. Do the customers within the market all buy similar products.

2. Do the customers share sales cycles and methods. Will our marketing and sales people be effective across the segment.

3. Is there word of mouth within the segment to encourage traction. 


\subsubsection{Steps 3, 4, and 5: Problem Interviews to reach Customer/Problem Fit}

As I move towards achieving customer/problem fit I will be conducting problem and solution interviews.

\subsubsection{Problem Interviews}

Problem Interviews are all about validating my hypotheses around the customer-problem pair. We are seeking deep knowledge to resolve product risk (what problem are we solving for the customer), market risk (how do they currently solve it), and customer risk (is this a viable beachhead market). (Maurya, 2012)

The interview uses the following structure:

\section{PROBLEM INTERVIEW SCRIPT DECONSTRUCTED}
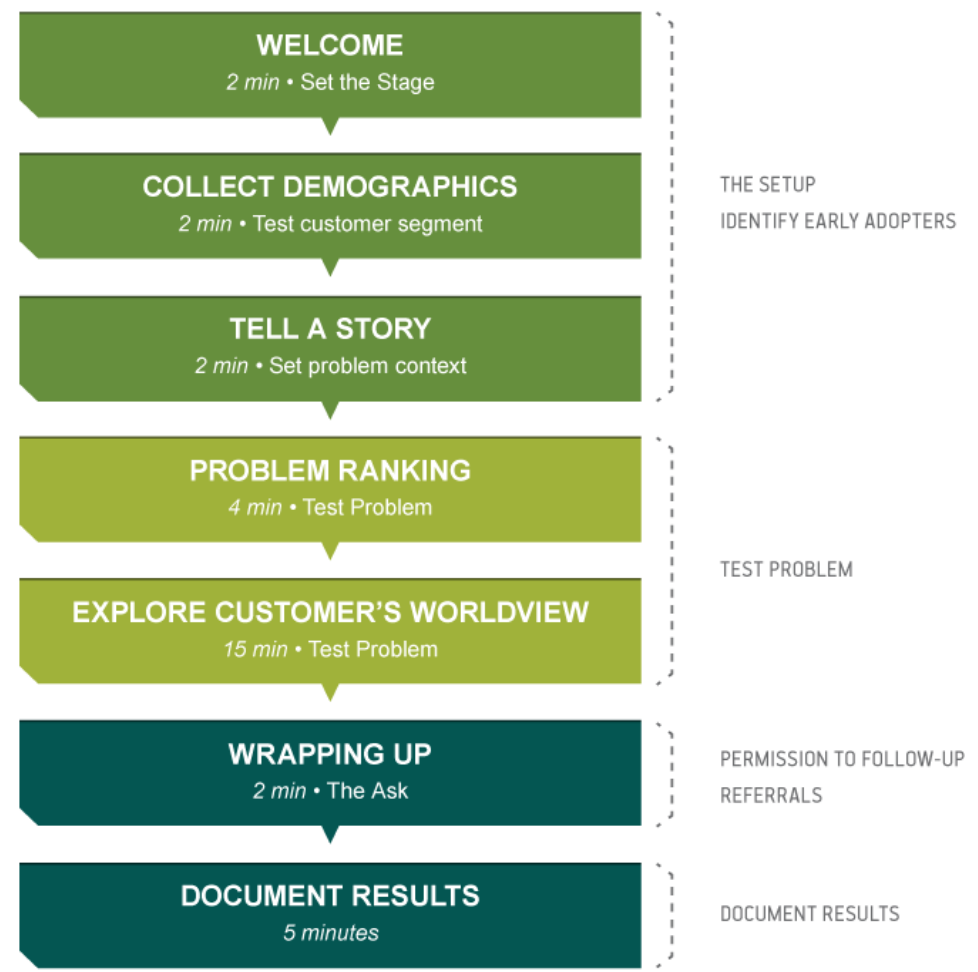

REFERRALS

DOCUMENT RESULTS

Figure 2 - Problem interview script deconstructed (Maurya, 2012, p. 85)

\section{The Setup:}

The first three stages of the interview set the stage of what the interview is about, allow us to collect some data that was unavailable through other means, and then tell a story about the problem to give context to the problem questions we test in the next step.

Test Problem:

In this step, we state the top three problems that we are seeking to address and then ask the interviewee to rank them. To avoid bias these questions will be stated in random order. This step is followed by an exploration of the customers' worldview. Examples of the information we will seek in this step are current 
solutions and other problems they have. We will look at both responses and body language to garner a robust indication of how much pain the experience and whether our solution is likely to be a "must have", "nice-to-have", or "don't need" offering.

\section{Conclusion:}

In these steps, we are looking to hook the interviewee to secure a follow up interview once we are ready to present a solution and to gather referrals for future interviews. Finally, we need to spend some time (5 - 10 minutes) documenting the interview while it is still fresh in our minds.

\section{Specific method for this use case:}

I found and took an opportunity to reach my target audience by running a stall at the Wairapara Agricultural and Pastoral Show held in October 2016. Because the market segment Mark and I chose to pursue was farmers, this was an important event where we could get access to a large number of attendees who otherwise are distributed across a wide area. Due to this opportunity, I took the modified approach to the Problem Interview step to make the most use of the event. I decided to run a short survey of willing attendees with three aims: to learn about their back pain and its impact on their life, their opinion on a prototype of the device, and collecting contact details for respondents who were willing to participate in a follow up interview. The follow up interview is the full version of the Problem Interview, with the survey providing additional evidence for/against this market.

I received 22 responses at the A\&P Show, with 13 of those indicating a willingness to have a follow up interview. Of the 13, only 3 responded to communications after the event and were interviewed. I found an additional person to interview, bringing the total number of problem interviews to 4 . Problem interviews were held either at neutral locations, such as a café, or at the interviewees' home/office.

See Appendix: Survey Questionnaire for the survey questionnaire. See Appendix: Problem Interview Script for Back Pain Sufferers for the Problem Interview questions. When looking at where The Problem Interview fits amongst academic qualitative interview methods, it most closely matches standardised openended interviews, in that the interview is extremely structured with accurate wording used across all participants with an ability to gather deep detail from open discussion. (Turner, 2010)

The results from my surveying and interviews in this section provides the foundational knowledge used to discuss, and make recommendations on, in the three Market Validation and Development sections of this report.

\subsubsection{Solution Interviews}

\section{Solution Interviews to reach Problem/Solution Fit}

In the solution interview, we demonstrate a Non-functional Prototype (NFP) $)^{1}$ or Minimum Viable Product $(\mathrm{MVP})^{2}$ to qualified leads who ideally were qualified through the Problem Interview stage. The purpose here is to test a possible solution and the lowest possible cost, thereby reducing risk. It is important to

\footnotetext{
${ }^{1}$ A NFP allows the user to experience using the solution without there being any functioning software behind the experience. E.g. a cardboard cut-out demonstration of a mobile phone app, or a webform that looks like an automated system but actually has a person in the background doing the search manually.
}

${ }^{2} \mathrm{~A}$ MVP is the minimum product that the customer will accept as solving their problem and will use and pay for. 
make sure the demonstrated product is realistic (we can build it), real (the interviewee doesn't need to take a leap of faith to understand the solution), and is able to be iterated on. (Maurya, 2012)

The Solution Interview looks like the following:

\section{SOLUTION INTERVIEW SCRIPT DECONSTRUCTED}

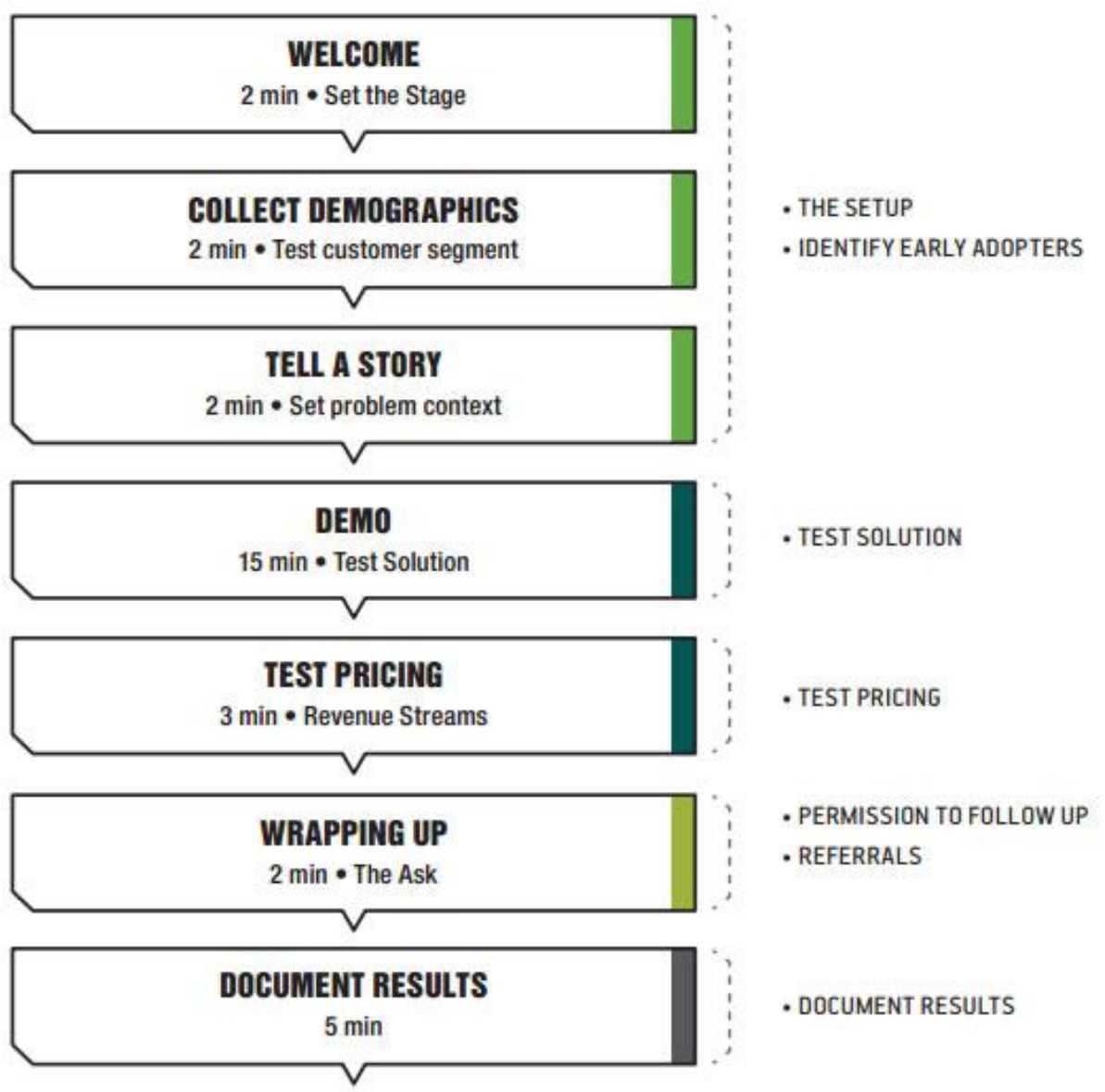

Figure 3 - The Solution interview script deconstructed (Maurya, 2012, p. 103)

\section{The Setup}

We welcome and thank the interviewee for taking the time to meet with us, collect demographic data that we haven't previously recorded, and set the context of the interview by telling a story about the problem we are seeking to solve.

\section{$\underline{\text { Test Solution }}$}

This is the core of the interview. We will demonstrate and test the solution with the interviewee to show how it solves the problems we are addressing. We then seek to discover what most resonated with the interviewee, what features should be prioritised for them, and what features might be missing.

Test Pricing

"Usually the right price is the one the customer accepts, but with a little resistance." (Maurya, 2012, p. 106)

In this step we will test the price with the interviewee by describing how the solution will be offered and suggesting a starting price. It is important that we set a price rather than ask the interviewee to suggest a price. 


\section{$\underline{\text { Conclusion }}$}

Once the main part of the interview has been completed we will seek either a concrete commitment from the interviewee to purchase the solution (if one is ready), or more likely, seek permission to contact them once the solution has been launched. We will also request referrals for additional interviews.

Finally, we spend some time documenting the results of the interview while they are fresh in the mind.

Specific method for this use case:

I did not run formal solution interviews with the target market due to the market pivot identified during the problem interviews and surveys.

To answer questions on the product so that I could discuss, and make recommendations, for the product validation and development sections of the report I did two things: asked questions about the product during the A\&P Show survey, and ran several of interviews with experts in key areas important to market discovery and development, and product development and clinical trials.

\subsection{Business Model Design}

When choosing what business modelling tools to use as an entrepreneur there can be confusion as the user is confronted by a dizzying array of options. As long as the tool covers the main business areas then I favour using what is familiar to me and makes the most sense to me. Ultimately it is the implementation of the model that makes a successful business, so the modelling tools shouldn't be considered for too long. To this end I've chosen three tools I am familiar with and have used previously:

- Ash Maurya's Lean Canvas (Maurya, 2012) as the primary business modelling tool,

- Doblin's Ten Types of Innovation (Keeley, Walters, Pikkel, \& Quinn, 2013) to dig deeper into the model and define a more concrete innovation model, and

- Key Metrics Modelling to model the key performance metrics of the business. ${ }^{3} 4$

These tools will primarily be used to inform and frame the recommended strategy and tactics presented in the business case.

\subsubsection{Lean Canvas / Business Model Canvas}

The Lean Canvas, an adaptation of Alex Osterwalder's Business Model Canvas, is a one-page business plan used to rapidly model the fundamental parts of a business model. A Lean Canvas allows the entrepreneur to outline multiple business models in a single day, far shorter than the time it takes to write a traditional business plan. The entrepreneur can then evaluate the various models before testing and settling on the one with the highest probability of success. A side effect of the canvas method is the need to distil ideas into a small space, driving succinctness and precision in the ideas. (Maurya, 2012)

A Lean Canvas consists of nine sections: problem, solution, metrics, unique value proposition, unfair advantage, channels, customers segments, cost structure, and revenue streams. A blank canvas can be seen in Figure 4 - Lean Canvas (Maurya, 2012).

${ }^{3}$ (Taplin, 2011) - http://kpilibrary.com/topics/business-plans-business-models-or-kpi-models

4 (Dowd, 2015) - http://growthdevil.com/key-metrics-modelling-devilish-growth/ 


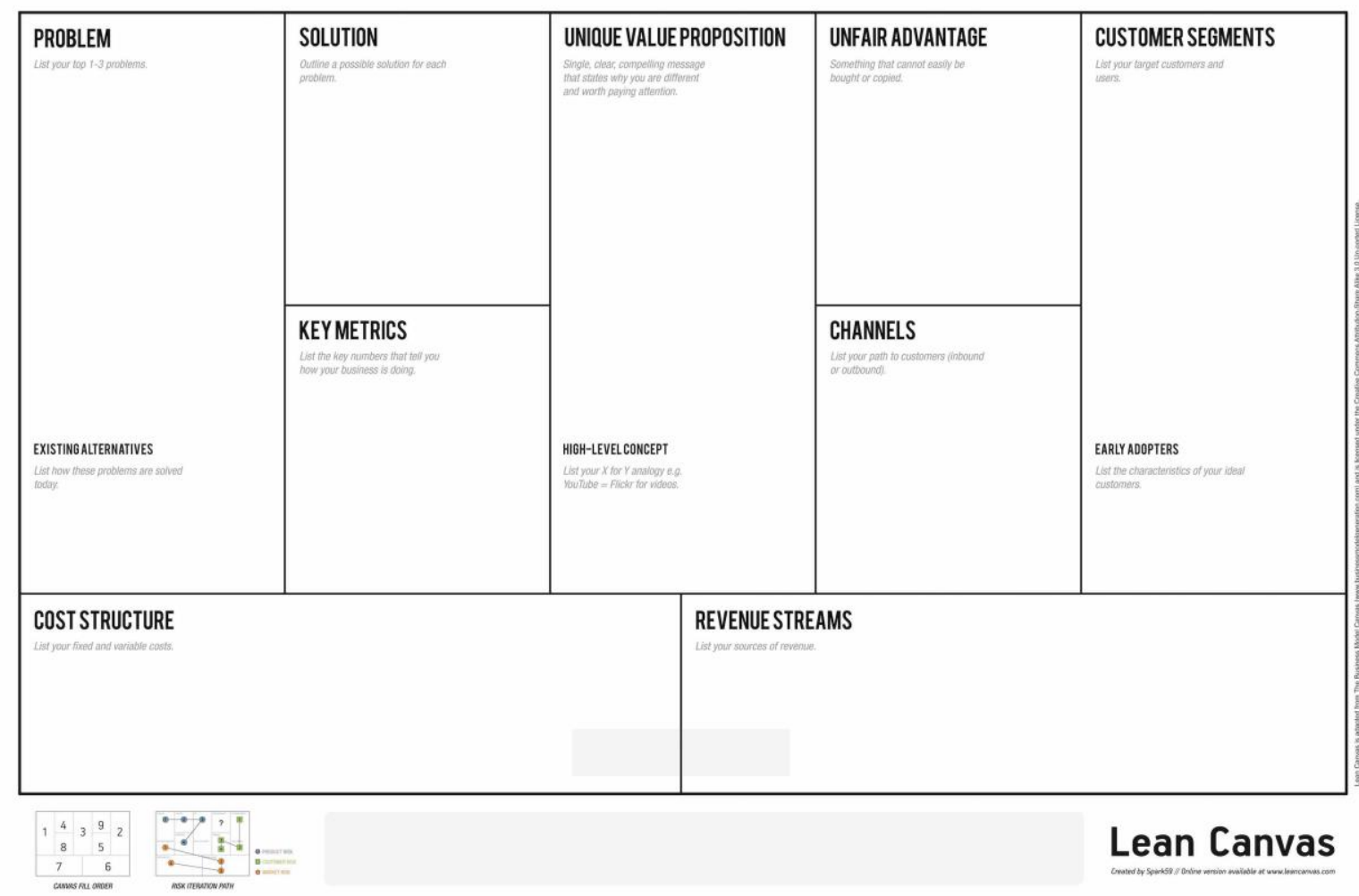

Figure 4 - Lean Canvas (Maurya, 2012)

The Lean Canvas should be filled out, experimented on, and validated, in the following order:

1. Problem

2. Customer Segments

3. Unique Value Proposition

4. Solution

5. Channels

6. Revenue Streams

7. Cost Structure

8. Key Metrics

9. Unfair Advantage

The focus with the Lean Canvas is on the fit between the identified problem and a customer segment that wants that problem solved and is willing to pay for that privilege. The problem-customer segment pair drives the rest of the canvas and should be tackled together, and first (Maurya, 2012, p. 27). Most of the activity in this report is based around the exploration and validation of this pair. This, and the lower validation priority of other sections of the canvas, explains why some elements of the business case have yet to be explored and validated in this report. The following is a brief explanation of the first two sections:

\section{Problem \& Customer Segments:}

A problem is, simply put, anything your customer wants solved. It could be a pain they want to remove, or a gain they need to create. When considering the problem, you also need to perform tasks like a root cause analysis to identify not just the apparent problem your solution will solve, but also the underlying job it is doing for the customer. (Christensen, 1997) 
When considering the customer part of the pair, you need to identify two things: the customer segments who have the problem, and the price threshold at which those customers will pay to solve the problem. You also need to identify a separate early adopter cohort who you'll validate first.

When validating this pair, you are testing how well you understand the problem you're solving, and how well you can identify the customers who have the problem as you understand it. It is expected, that as you learn more and more about the customers you're targeting and the problems they have, that you'll pivot your assumptions, and therefore the solution that you think you need to build.

\subsubsection{Ten Types of Innovation}

Then Types of Innovation is the codification of three decades of work and research by the Doblin consulting firm from Chicago. After analysing nearly 2000 examples of successful innovation, Doblin codified the different methods that firms use to innovate (and differentiate themselves) into over 100 innovation tactics within the 10 overarching types of innovation. Ten Types of Innovation is a toolkit used to drive business model innovation, and organisational differentiation, as opposed to product innovation. (Keeley et al., 2013)

The full table of innovation tactics, under the ten headers, can be seen in Figure 5 - Ten Types of Innovation Tactic Overview.

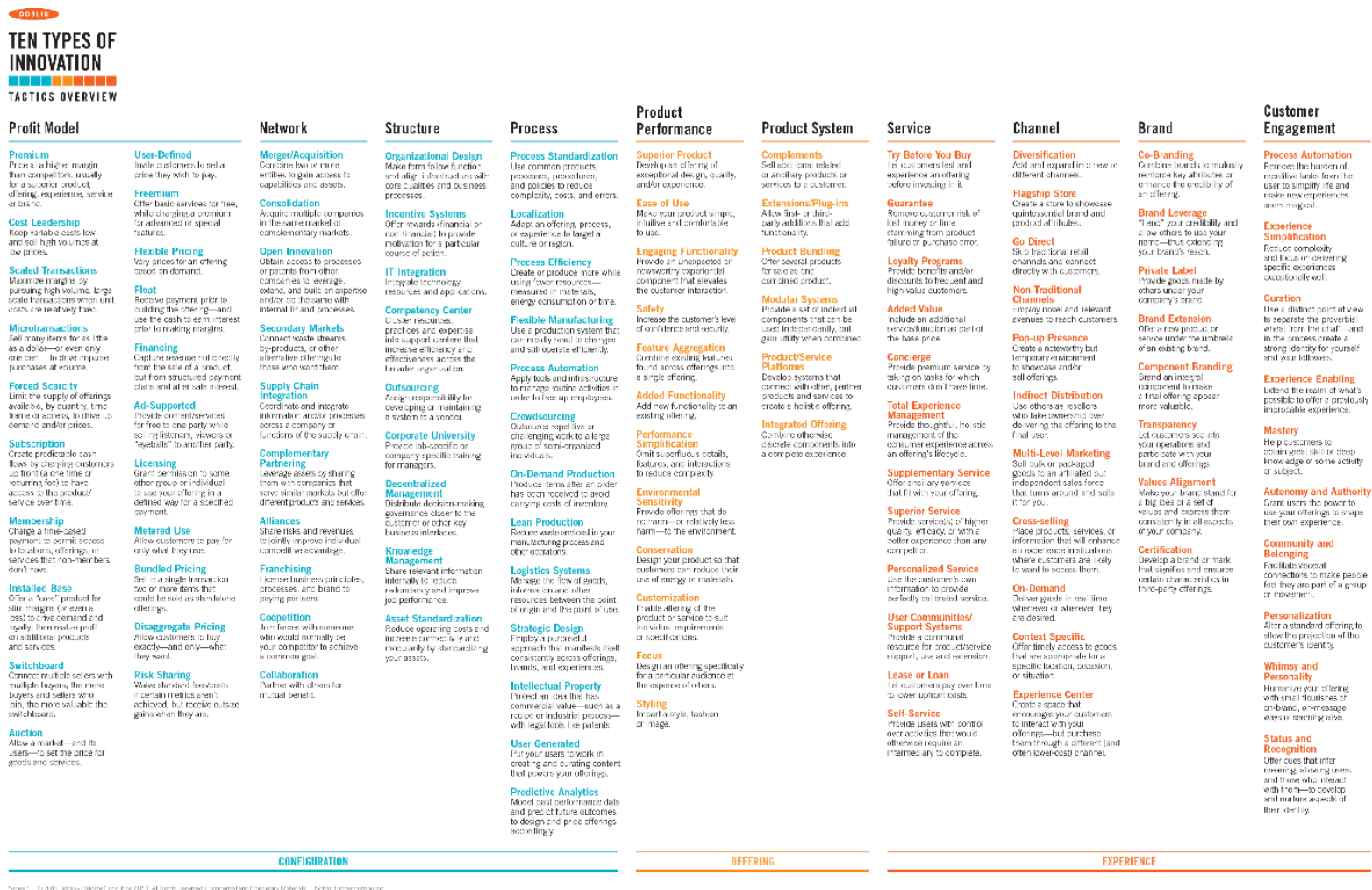

Figure 5 - Ten Types of Innovation Tactic Overview

There are ten overarching areas of a business where they can innovate, grouped into three sections of configuration (how the business works), offering (the core products/services), and experience (the customer facing elements of the business).

1. Profit model - how you make money

2. Network - how you connect with others to increase and create value

3. Structure - the organisation of assets and talent

4. Process - the methods and process the organisation uses to do work 
5. Product Performance - the features and benefits of the offering

6. Product Systems - how individual offerings can be connected to drive greater value

7. Service - how offerings are supported or amplified through customer service

8. Channel - how offerings reach your customer/s

9. Brand - the outward facing representation of the business

10. Customer Engagement - how the organisation builds compelling interactions that go beyond and elevate the offerings delivered.

Definitions of the specific tactics I recommend to drive innovation and marketplace differentiation are included alongside those recommendations in the business case.

\subsubsection{Business Performance Modelling}

As a tool book for this section I am using the Ash Maurya's Traction and Customer Factory (Maurya, 2016) models, and my own Key Metrics Modelling (KMM).

In order to judge the success or failure of our business model we need to first set measurable metrics which we can experiment against. All these metrics should lead to a single metric that informs success for investors and the entrepreneur. This single metric is called traction.

"Traction is the rate at which a business model captures monetizable value from its users. "(Maurya, 2016, p. 26)

All metrics are also mapped on a key metrics model which captures the relationship all of the actions which impacts profitability and performance.

Lifbak has a multisided business model with non-paying users who receive the value of the product, and customers who pay for that value. To build the model we need to assume, and in the future, establish, a derivative currency exchange rate that is used to convert value created for users into captured monetizable value from customers. The diagram below outlines the core value creation and capture elements of the business model. Its shows the basic process of taking an unaware visitor, using our customer factory to deliver value to the user and turn them into a happy user, and then capture monetizable value from happy customers via a derivative exchange rate. The assumption here is that customers, e.g. ACC and health insurers, will pay us an amount based on the value we create for users. In some instances, we may sell direct to users in which case we capture monetizable value directly from the user who has now become the customer. (Maurya, 2016, pp. 33-35)

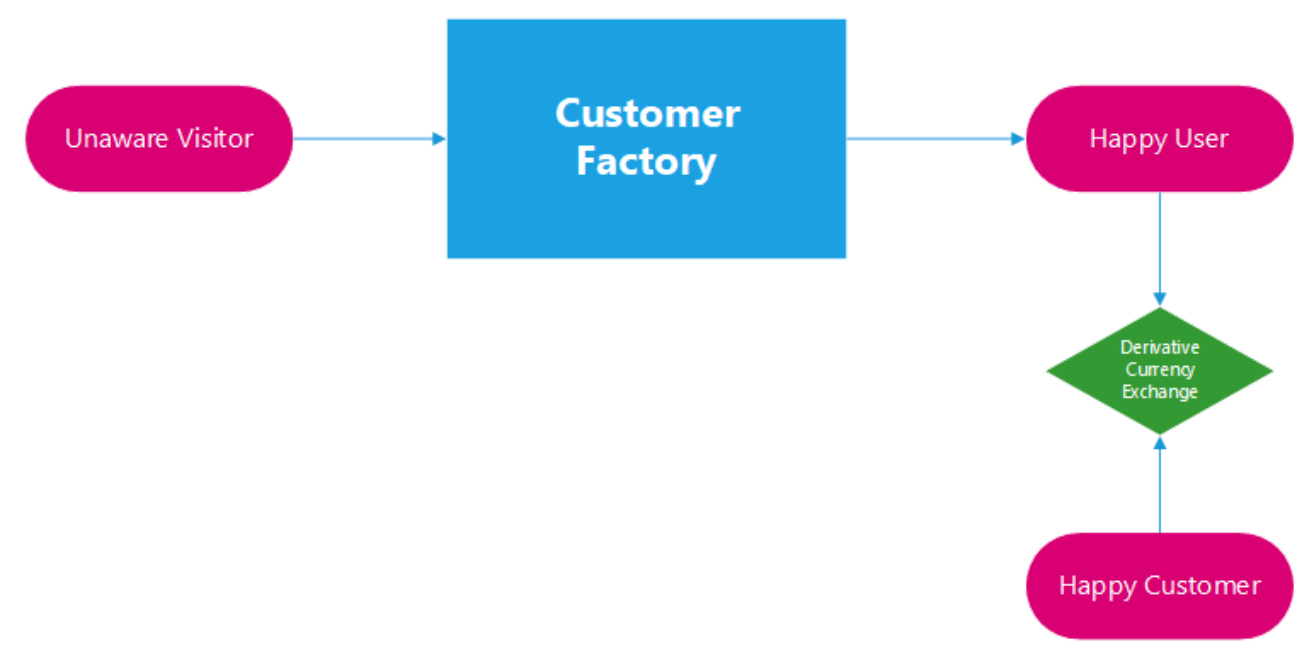


Establishing a derivative exchange rate by establishing the value of certain user outcomes to paying customer will be critical to success of the business as it will be these user outcomes that become the most important metrics in the KMM.

Another term I will reference is throughput, which is the rate that unaware visitors are converted to happy users.

\section{Customer Factory}

A customer factory describes the key inputs and outputs of a business and brings a clear focus onto what helps to drive customer acquisition, conversion, and retention. It doesn't factor in some of the noncustomer facing metrics which are important to know when seeking to build a profitable sustainable business. For these metrics, I use a Key Metrics Model (KMM). A KMM, or sometimes called a Key Performance Indicator Model, shows all of the metrics that influence business performance and the relationships between them. This allows managers to focus on optimising improving individual metrics without losing sight of how those optimisations at the micro level are affecting macro business performance indicators, for example net profit, ROFI, and asset turns, as well as other micro metrics further up the chain.

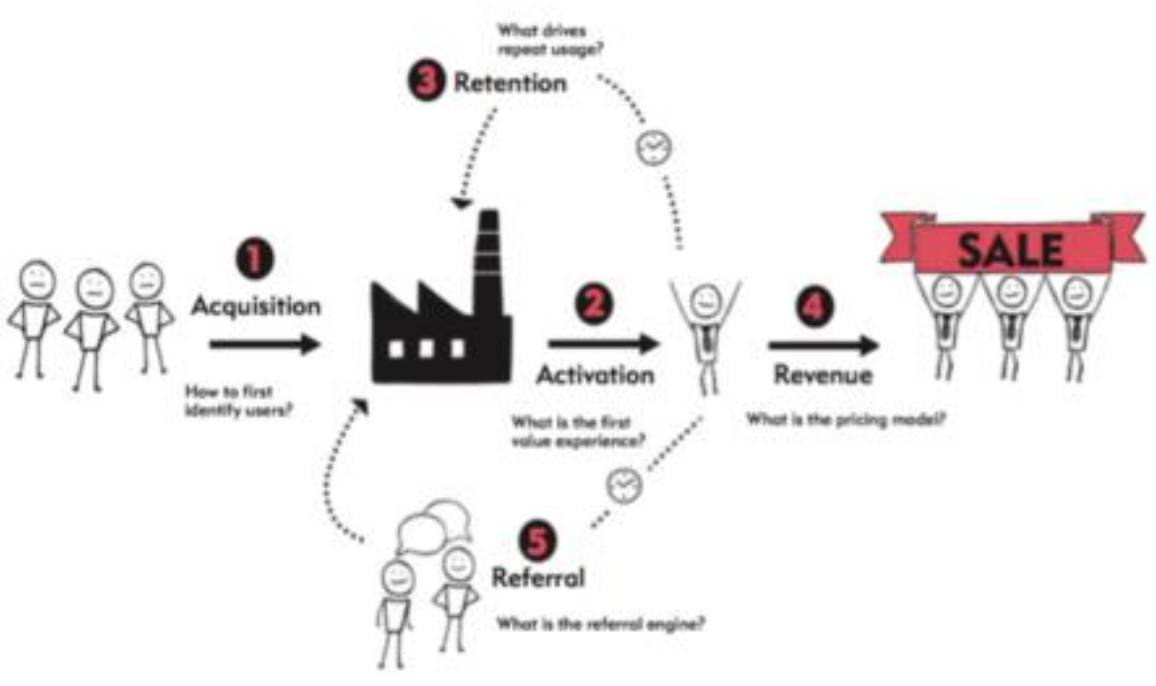

There are five key areas of the customer factory:

1. Acquisition - how we acquire new leads.

2. Activation - how we get new leads to start engaging with our products and services.

3. Retention - how we ensure users repeatedly engage with our products and services so that we can deliver monetizable value.

4. Revenue - how we capture revenue from users.

5. Referral - how we turn happy users into evangelists.

Each of these five areas has metrics that we need to measure and perform against. Marketing and operational tactics focus around one or more of these metrics. 


\section{Findings and Analysis}

\subsection{Business Model Design}

\subsubsection{Business Models}

Every viable business is built upon a sound business model, whether known by the managers of that business or not, and sound strategies and tactics to execute on the business model. A good, innovative, business model isn't enough to dictate success, but a poor one will dictate failure. It is the strategies of an organization that management built and execute that allow companies to successfully implement a viable business model. (Magretta, 2002)

There are many business modelling tools available to the entrepreneur. In fact, as the image below demonstrates, there is an almost inexhaustible supply of them.
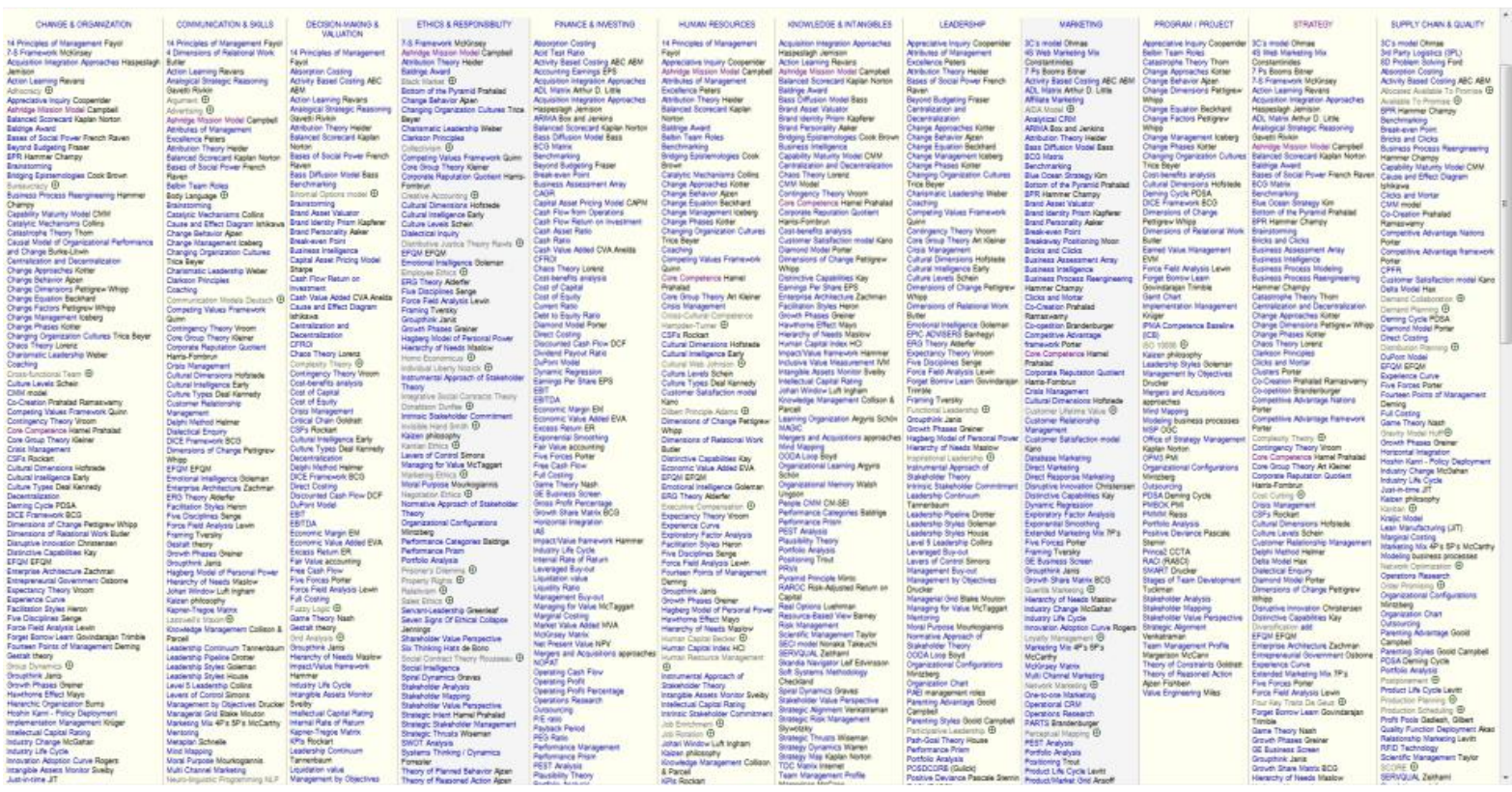

Figure 6 - Lots of business strategy tools ("Strategy. Methods, Models and Theories," 2017)

\subsubsection{Competitor's Business Models}

I have identified the following companies and investigated their business models based on the Lean Canvas method. Their assumed canvases are represented below. As I am unable to see into the companies I'm investigating I am not able to fill in the metrics, cost structure, unfair advantage, channels, and customer segments with a high degree of certainty. Where possible I have included these fields. These companies were chosen as they operate in a medical devices field similar to ours. They might be considered competition of sorts, however Lifbak and my recommendations seeks to minimise this possibility by being highly differentiated from these organisations in key product market areas.

- BackX - http://www.suitx.com/backx

- StrongArm Tech - https://www.strongarmtech.com/

- Ekso Bionics - http://eksobionics.com

- Rex Bionics - http://www.rexbionics.com/ 
The Lean Canvases below describe in simple terms what I've learned about how the organisations approach certain aspects of business strategy by reviewing what they have written about their company and products on their corporate websites. Because most of the Lean Canvas involves outward facing aspects of a business I was able to identify, in simplified terms, how the business operates in that section of their business model. The obviously outward facing sections are: Problem, Solution, and Unique Value Proposition. Occasionally, and in all instances here, we are able to assess the Customer Segments, Unfair Advantage, and Revenue Streams. Less often, we are able to assess Channels, and only very rarely would we get the visibility into company operations required to assess their Key Metrics and Cost Structure.

The information gathered shows key differences about how each company approaches the marketplace, with key differences displayed across the organisations. Because these organisations are already in the market and have significant investment propelling them forward, Lifbak should seek to use the information in these business models to help discover a market gap that Lifbak is best positioned to exploit. The Ten Types of Innovation method is used to build a differentiation strategy based on what is learned from analysing these Lean Canvases.

The main competitors can be grouped into two categories: robotic exoskeletons, and workplace assistance exoskeletons.

backX Lean Canvas ("backX | suitX," 2017)

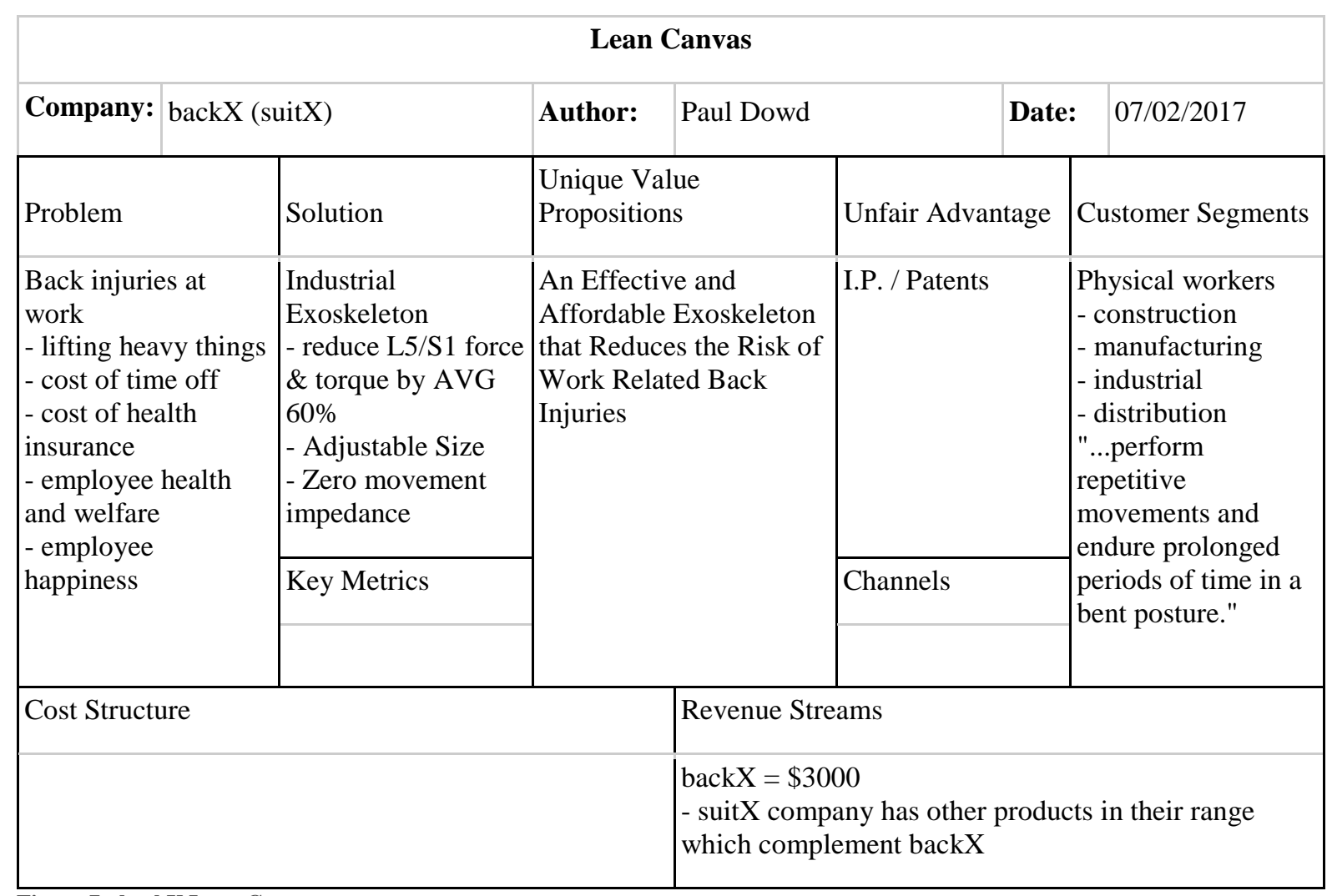


StrongArm Tech ("StrongArm® ${ }^{\circledR}$ Technologies, Inc.,")

\begin{tabular}{|c|c|c|c|c|c|}
\hline \multicolumn{6}{|c|}{ Lean Canvas } \\
\hline Company: & StrongArm Tech & Author: $\mathrm{F}$ & Paul Dowd & Date: & $07 / 02 / 2017$ \\
\hline Problem & Solution & \multicolumn{2}{|l|}{$\begin{array}{l}\text { Unique Value } \\
\text { Propositions }\end{array}$} & Unfair Advantage & $\begin{array}{l}\text { Customer } \\
\text { Segments }\end{array}$ \\
\hline \multirow{3}{*}{$\begin{array}{l}\text { Back injuries at } \\
\text { work } \\
\text { - lifting heavy } \\
\text { things } \\
\text { - cost of time off } \\
\text { - cost of health } \\
\text { insurance } \\
\text { - employee health } \\
\text { and welfare } \\
\text { - employee } \\
\text { happiness }\end{array}$} & \begin{tabular}{|l} 
Ergoskeleton V22 \\
- transfers load from \\
hands to waist \\
$-10 \%$ risk reduction \\
- prevents injury \\
- movement tracking \\
- prevention \\
modelling \\
\end{tabular} & \multirow{3}{*}{\multicolumn{2}{|c|}{$\begin{array}{l}\text { Reduce the cost of } \\
\text { injuries to your } \\
\text { workforce. }\end{array}$}} & $\begin{array}{l}\text { Patents } \\
\text { Analysis \& Risk } \\
\text { Management } \\
\text { forecasting platform }\end{array}$ & \multirow[t]{3}{*}{\begin{tabular}{|l} 
Factory workers \\
Distribution \\
workers
\end{tabular}} \\
\hline & Key Metrics & & & \multirow[t]{2}{*}{ Channels } & \\
\hline & Injuries prevented & & & & \\
\hline \multirow{2}{*}{\multicolumn{3}{|c|}{ Cost Structure }} & \multicolumn{3}{|c|}{ Revenue Streams } \\
\hline & & & \multicolumn{3}{|c|}{$\begin{array}{l}\text { Product sales } \\
\text { FUSE Platform subscription (prevention and tracking } \\
\text { software) }\end{array}$} \\
\hline
\end{tabular}

Figure 8 - StrongArm Tech Lean Canvas

Ekso Bionics ("Ekso Bionics - An exoskeleton bionic suit or a wearable robot that helps people walk again,")

\begin{tabular}{|c|c|c|c|c|c|}
\hline \multicolumn{6}{|c|}{ Lean Canvas } \\
\hline Company: & Ekso Bionics & Author: & Paul Dowd & Date: & 07/02/2017 \\
\hline Problem & Solution & \multicolumn{2}{|c|}{$\begin{array}{l}\text { Unique Value } \\
\text { Propositions }\end{array}$} & Unfair Advantage & Customer Segments \\
\hline \multirow{2}{*}{$\begin{array}{l}\text { Injury leading to } \\
\text { an inability to } \\
\text { walk. } \\
\text { - hard to re-learn } \\
\text { walking } \\
\text { - always need } \\
\text { support } \\
\text { - lost } \\
\text { independence }\end{array}$} & $\begin{array}{l}\text { Robotic exoskeleton } \\
\text { - gait training } \\
\text { - medically } \\
\text { researched, backed } \\
\text { by research } \\
\text { - software controlled } \\
\text { robotic exoskeleton }\end{array}$ & \multirow{2}{*}{\multicolumn{2}{|c|}{$\begin{array}{l}\text { Get patients walking } \\
\text { again. }\end{array}$}} & $\begin{array}{l}\text { Clinical Research } \\
\text { on their device } \\
\text { Distribution } \\
\text { Network } \\
\text { I.P. / Patents }\end{array}$ & \multirow[t]{2}{*}{$\begin{array}{l}\text { Patients who have } \\
\text { lost the ability to } \\
\text { walk. } \\
\text { - Stroke } \\
\text { - Spinal Cord } \\
\text { Injuries }\end{array}$} \\
\hline & Key Metrics & & & Channels & \\
\hline \multirow{2}{*}{\multicolumn{3}{|c|}{ Cost Structure }} & \multicolumn{3}{|c|}{ Revenue Streams } \\
\hline & & & \multicolumn{3}{|c|}{\begin{tabular}{|l} 
Product Sales \\
Software Sales \\
Possible: \\
- Training \\
- Rentals and Services
\end{tabular}} \\
\hline
\end{tabular}

Figure 9 - Ekso Bionics Lean Canvas 


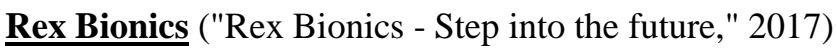

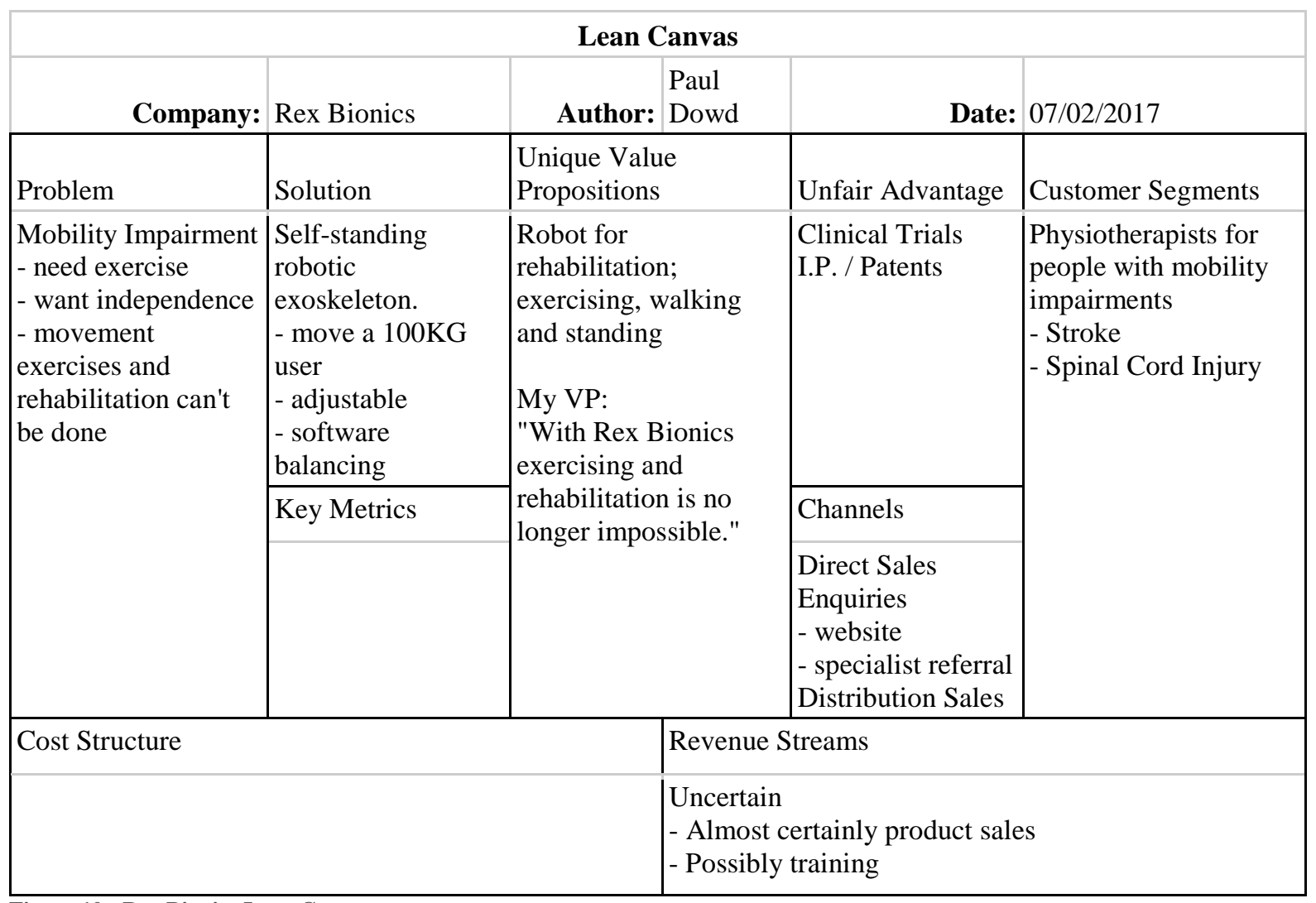

Figure 10 - Rex Bionics Lean Canvas

\section{Other competition:}

Other forms of competition in the marketplace are:

- Our distribution channel partners (Physiotherapists, chiropractors, specialists)

- Exercise programs, exercise sessions, and personal trainers.

- Low grade medical devices such as lower back compression braces that cost below $\$ 100$.

- Inaction (doing nothing about it)

Service providers, such as Physiotherapists are competition because they provide services to help the same problems as Lifbak, to the same customers. However, as Lifbak builds their channel partner network, this competition with significantly reduce as they are turned into customers and channels to market instead.

This research focuses on these

Exercise and training programmes such as yoga and Pilates are complementary methods that are sometimes used by those who have suffered a back injury if they need to rebuild flexibility and strength. I did not research these providers as they are sufficiently differentiated from Lifbak and although they treat the same customers, they will not be able to compete with Lifbak on a level playing field.

Low grade medical devices such as compression belts, as seen in Appendix: Low grade medical device competition., are of dubious quality and efficacy. I didn't hear any of the physiotherapists or specialists I talked to recommend, or even mention, these devices. I don't consider these devices as competition as they are not a currently used device by medical practitioners. Patients who may consider these devices, and who have an injury that the Lifbak device supports, should be able to receive the Lifbak device through 
ACC, insurers, or the public health system once Lifbak has proven efficacy, which further reduces the threat of these devices being true competition.

Inaction, in combination with analgesics to mask the injury and/or pain, will possibly be the hardest form of competition that Lifbak will face. This was apparent through the interview process where some interviewees were content to just bear their condition rather than take additional, inconvenient, steps to help their recovery. (BPS - A. B. C. and D, 2016) This highlighted the need to spend the requisite effort to research and discover the right markets for Lifbak where the combination of injury severity, impact on quality of life, and treatment inconvenience, meets a happy equilibrium where Lifbak's device becomes a viable treatment option that consumers will try. I didn't research this in more detail because with the correct market segments identified the competition from inaction will be removed.

\subsection{Market Validation and Development}

\subsubsection{Step One: Market Segmentation Analysis}

For this process, I used a matrix model whereby the project partner and I rated each of the 21 potential market segments against a range of key indicators. This matrix was then enhanced by adding a weighting multiplier of 0.5 - 5 for each indicator based on what indicators are more important to the founders (or to the success of the business). This helps to improve accuracy of the final results. To force consideration and accuracy when weighing the average of all weights must equal 2.5. The seven key indicators are:

- Is the customer well-funded?

- Is the customer readily accessible?

- Does the customer have a compelling reason to buy?

- Can we deliver a whole product?

- Is there entrenched competition to block us?

- Can we leverage this segment to enter additional segments?

- Is the segment consistent with founder passion and goals?

Each of these indicators was given a rating of $1-5$ with 5 being the best response. Each response is multiplied by its weighting multiplier before all of the responses are added together to get a final value. This additional method of rating and weighting is not in either of the reference books I use, but is a technique used by Growth Devil, a company I have previously worked for, when performing this type of work. The overall method and the questions themselves come from 24 Steps (Aulet, 2013)

The highest value result of this analysis is the market that is most likely to succeed; however, the top 5-8 results are all high potential and are taken through to Step Two for the Beachhead Market Identification stage. You can see the full table of results in Figure 11.

\subsubsection{Results of Analysis}

For full analysis see attached matrix spreadsheet.

\begin{tabular}{|l|l|}
\hline Crushed vertebra & 76 \\
\hline Pinched nerve / Sciatica & 76 \\
\hline Scoliosis & 38 \\
\hline
\end{tabular}




\begin{tabular}{|l|l|}
\hline Truck drivers & 64.25 \\
\hline bus drivers & 55 \\
\hline taxi-drivers / sales people & 46.75 \\
\hline dairy workers & 66 \\
\hline farmers & 66 \\
\hline small aircraft / helicopter pilots & 62.5 \\
\hline government workers & 40 \\
\hline developers / coders & 54 \\
\hline receptionists & 41.5 \\
\hline call-centres & 45.5 \\
\hline Pregnant Women & 58.5 \\
\hline Minor sporting injury. & 67 \\
\hline Sports Clubs (on field re-injury prevention) & 67 \\
\hline Minor work injury & 61.75 \\
\hline HR Managers & 43.5 \\
\hline elderly & 58.25 \\
\hline nursing homes & 41.25 \\
\hline DHBs (rental devices) & 76.5 \\
\hline
\end{tabular}

Figure 11 - Market segmentation matrix

Bright Green $=1$ st Priority

Dull Green $=$ 2nd Priority.

\subsubsection{Step Two: Beachhead Market Identification}

Each of the markets identified in the previous step has been evaluated further to discover:

1. who the end users are,

2. what FDA OR ema requirements we may need to adhere to,

3. whom the economic decision maker is and their motives,

4. specific applications and diagnosis the user may use the device for,

5. the benefits we could expect the user to receive from use,

6. who the lead customers are,

7. any specific market characteristics,

8. partners we need to work with to enter this market in areas ranging from medical research to customer access, 
9. $\quad$ specific size of the market and their spending power, and

10. expert discussions on the device and its application in each market segment from a general medicine and specialist medicine perspective.

The six selected markets are based on either customer groups (e.g. farmers) or medical conditions the customer may suffer. This is because the path to market was initially thought to be clearly different from each other and as such we could separate in this way. Through the analysis I have discovered this assumption to be false. Most end user customers are accessed primarily through the same channels. There is proof of efficacy requirements to service customers with specific conditions and to gain public or insurer funding for the device, but the channels to market remain the same.

The diagnosis terms used for the Market Segmentation Analysis don't match perfectly with empirical data from ACC and this imperfection has been carried into the Beachhead Market Identification.

To research this section I:

- interviewed medical and industry experts to gather their measured opinion,

- gathered empirical diagnosis and cost data from the Accident Compensation Corporation, and

- researched the regulatory environment.

The implication of this research on each market segment is discussed in the discussion section.

\subsubsection{Expert Interviews}

\subsection{Kevin Sheehy}

During this process, I have sought the measured opinion from relevant medical experts. Kevin Sheehy has been the primary medical consultant on this project and has provided input across all facets. Kevin is a General Practitioner and holds a PGDip in Health Management. Kevin has recently completed a report on the state of the Health Tech sector in New Zealand, titled "New Zealand Health Technology Review: 2016. New Zealand companies innovating to improve people's health.”. This puts him is a unique position to provide both medical and commercial advice to this project.

Kevin's input, as gathered during several meetings, is discussed throughout this report, and particularly in the expert interview sections in the discussion section titled 7.2.2 Beachhead Market Identification, there his input it critical in evaluating the six market segments identified in the Market Segmentation Analysis. Kevin was asked to provided open-ended comments on each market segment with the conversations focusing around treatment feasibility (likelihood of efficacy), path to market / current treatment providers, types of injury, and regulatory requirements. Highlights of the discussion are also found in the Appendix: Market Segmentation Analysis.

\subsection{Physiotherapists}

I interviewed two physiotherapists to discover their thoughts on the efficacy and uses for the Lifbak device, or a similar device based on the same mechanical principles. The purpose of the interviews was to discover if physiotherapists would consider the device for use in their practise, and to gather additional expert opinions on the efficacy potential of load reduction, and specifically the Lifbak, for accelerating the rehabilitation of spinal injuries. Both physiotherapists viewed and tested the Lifbak prototype during the interview. 
The physiotherapists interviewed were Wayne Roberts and Monty Wawatai. Wayne has nearly 20 years' experience $^{5}$, and Monty has over 30 years' experience ${ }^{6}$. They both have significant experience with sports teams and injuries; Wayne worked for the Wellington Phoenix Football Club, and sports performance and rehabilitation is a particular focus area for Monty.

This is their feedback based on the questions I asked. There was some general discussion at the end of each interview with any outcomes listed after the specific questions.

Q1. Can you please provide some thoughts on the efficacy of load reduction on helping to treat, and support the treatment of chronic lower back pain?

Neither had specific knowledge of how load reduction might help a patient and had not seen studies on the topic.

Based on experience and expertise E-A thought that reducing load would take away pain and allow the patient to exercise and rebuild muscle strength. He was concerned about when load was re-introduced and how the patient's body would react.

E-B had no specific thoughts on the efficacy of load reduction, but did mention that current practice was based around limiting movement and compression.

Q2. What benefit would you see in a load reduction device for your practice? The device is intended to support and accelerate standard rehabilitation methodologies.

Both physiotherapists saw significant potential for a load reduction device which reduces pain, E-A mentioned specifically the L4/L5/S1 vertebra, and allows the patient to regain movement and perform exercises or movement therapy.

E-A was concerned about fitment to patients and a patient's own specific movement patterns. He wanted to make sure that if he was fitting a device to the patient that he knew where the load was being repositioned to by using a mix of sensors. For trials, E-A mentioned using the 3D movement tracker at AUT.

\section{Q3. Do you think that reducing the load on a patient's lower back would help to prevent re-injury during rehabilitation?}

Both were emphatic that reducing load would help to prevent re-injury.

Both E-A and E-B would like to be able to re-introduce load back to the patient over time as they recover. E-B saw the device as providing a margin of error when assigning recovery exercises to the patient.

E-B primarily works with sports injuries and as such sees significant potential for a load reduction device immediately after injury has occurred. This is to quickly stabilise the patient and to prevent further damage; which in turn can lead to significant reductions in overall injury length and cost of treatment.

Q4. Do you think that reducing the load on a patient's lower back would help you to accelerate the rehabilitation of a patient? This could be through things like an increased or more intensive range of prescribed exercises, lowered risk of re-injury, and generally heightened day to day activity?

Both physios agreed that a device that reduces load on the user's spine would be beneficial for recovery from a variety of spinal injuries. Monty specifically mentioned vertebra L4/L5/S1 as key problem areas

\footnotetext{
5 ("Wayne Roberts - Physiotherapist," 2017)

${ }^{6}$ ("About — Wawatai Physio," 2014)
} 
where a device that assisted recovery and reduced rehabilitation time would be highly valuable with a large market of users. Both Monty and Wayne felt that to be successful the device would need to be tailored to each user's body shape. The method of tailoring could be either custom made devices for each user or a single device that was significantly adjustable.

E-A was excited by the potential of reducing load and managing the reintroduction of load, but was concerned about the potential impact of the load reduction on muscle activation and the ability to regain strength.

Monty has a history of working with sporting clients and was interested in testing the device on users immediately after injury with a view to reducing the overall injury length and cost.

E-B was enthusiastic about testing devices in his practice if Lifbak was researching the efficacy of load reduction on reducing the injury length of sporting injuries; given that is who he works most frequently with. He mentioned that he hasn't seen anything similar in the marketplace; but it could be considered an advanced version of the Philadelphia Collar(Wikipedia contributors, 2016a).

\subsection{Christine Bloomfield Interview}

Christine Bloomfield is a Rehabilitation Manager at the Accident Compensation Corporation of New Zealand. Christine is a frequent presenter and expert interview subject on rehabilitation, and is a member of the Expert Advisory Group for the Mobility Action Programme ${ }^{7}$, which is a Ministry of Health programme aimed at improving outcomes for people with musculoskeletal health conditions.

The following are key findings from the interview.

\section{Market Direction}

I questioned Christine on what cohorts of patients she recommends Lifbak focuses on developing the device form. Answers should be from a device efficacy, need gap, and ACC importance perspectives. A key point, repeated a number of times was that we needed to separate out people with pain and those with specific mechanical issues or diagnosis. We should be looking at fractures and other specific mechanical issue diagnosis that patients have and can specifically be treated. It is likely that we'd need to exclude any injuries that include spinal cord damage. Her experience tells us that devices are less helpful for those managing chronic pain rather than a mechanical issue. For fractures, unloading the spine could help them to regain mobility. For other diagnoses, such as lumber sprains, the $10 \%$ who go on to have chronic problems are the costliest. However, for the lumbar sprain cohort the evidence is that they need a multidisciplinary approach to managing their problem that focus on improving function and participation; there is no evidence that passive approaches make a difference.

\section{$\underline{\text { ACC Data Limitations }}$}

When looking to gain direction from ACC data it is important to know the limitations of that data. Because ACC is a compensation organisation, for the treatment to be funded by ACC there needs to be an accident event and a specific diagnosis code that ACC funding supports. These are the codes that are seen in data exports from ACC. Due to this need, the data ACC collects is slightly dirty, and some issues can be overmedicalized to meet diagnosis code requirements. Although the impact this has on the data hasn't been regularly quantified, anecdotally Christine expects it to have a greater impact on the lower range of injuries, i.e. Lumbar Sprains, rather than the more serious diagnosis such as disk prolapse or fractures.

${ }^{7}$ ("The Mobility Action Programme | Ministry of Health NZ," 2017) 
Further to this - most low back sprains/strains/pain is best described as non-specific low back pain but ACC requires an injury diagnosis which in other jurisdictions is not required. This doesn't mean the data is useless, but that we need to keep this fact in consideration.

\section{Outcome Measurements}

When considering outcome measurements and metrics for trials and funding consideration, Christine suggested the following and emailed me a link to a research paper on back injury outcome metrics. The paper looks at how we can build more alignment of outcome measurements in clinical trials in order to better compare benefits. Christine also suggested that ACC's pain management services may have their own outcome measurements they use. She suggested: quality of life, participation measures (social / workplace), time to return to work, percentage of patients who return to work and or independence, pain scores, ease of use, and a decrease in social rehabilitation spend. We want to look at both functional and participation outcomes. ACC Pain Services uses EPPOC ${ }^{8}$ (electronic persistent pain outcome) measures.

\section{Market Entry and ACC Funding}

When looking at purchasing devices ACC tends to be a slow adopter because some of the expensive things are cost prohibitive. They want to see cost effectiveness. ACC gets lots of requests to fund research but generally doesn't do so. They will perform their own literature reviews to look at efficacy of a device put forward to them. Low cost products that make functional gains would be particularly interesting to ACC. Christine mentioned there is a perception that a lot of technology in the field is developed without a view to cost effectiveness. She would like people developing technology to have better understanding that the end products need to be affordable. Some social rehabilitation interventions, such as home equipment, housing modifications, are put in place to increase independence and reduce the need for social rehab e.g. home help, but this doesn't happen or the person's functioning doesn't change. They are perceived to help people but don't have an impact on many of the measures that are important when considered whether there is a benefit to the spend. We need to make sure we don't fall into that trap.

This paragraph needs to be taken as opinion as it depends on a number of factors. Long-term, for devices priced under \$1000 ACC wouldn't closely scrutinize individual requests, however as a whole they would scrutinize why many are being prescribed if they numbers were thought to warrant that scrutiny. ACC has to be fair and manage public expectations around what equipment it will fund. At a trial stage, if a patient was prescribed the device (I gave an example price of $\$ 800$ ) then it would trigger a procurement process. Any basic physiotherapist treatment the patient received alongside the device would be unlikely to attract attention. If we sold directly to patients and they received support to use the device from a treatment provider then unless that patient had a case manager then that treatment would be unlikely to attract attention. Only a very limited number of ACC clients actually have a case manager.

(Bloomfield, 2017)

\footnotetext{
${ }^{8}$ http://ahsri.uow.edu.au/eppoc/index.html
} 


\subsubsection{Accident Compensation Corporation Data Analysis}

\subsection{Lumbar Sprains}

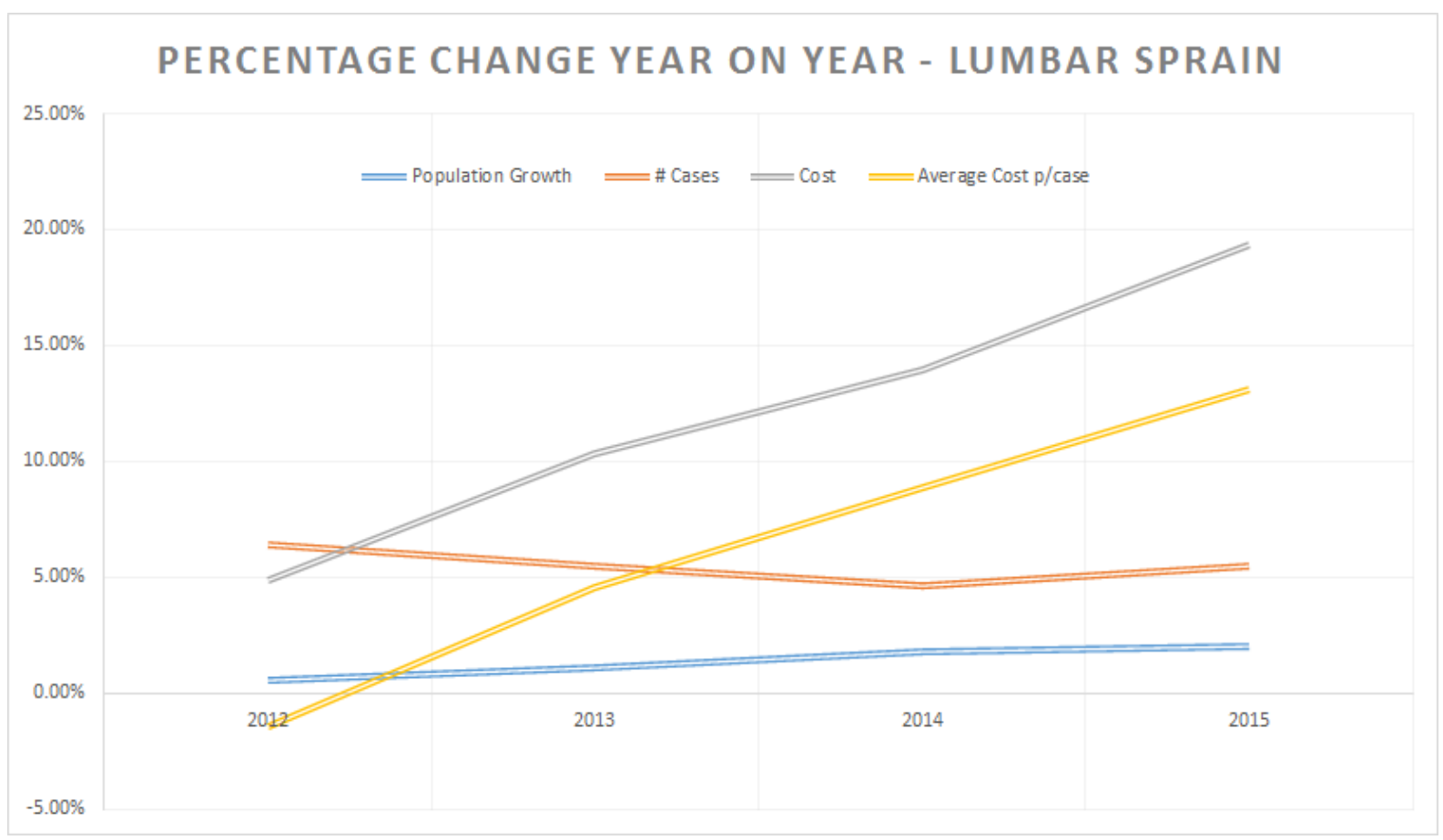

Figure 12 - Lumbar sprain trends (Accident Compensation, 2016)

Lumbar Sprains are the most common types of injuries leading to back pain. The chart above shows the changes in incidence rate, population, total cost, and average cost. Incidence rate (\# Cases) has a reasonably static year on year increase percentage hovering at or just above 5\%. However, when graphed against a lower population growth rate of $0.5-2 \%$ the increase in incidences is exponential against population. Cost of treatment to the ACC is increasing at a far higher rate than any other metric. This exponential increase has led to dramatic increases in total cost to ACC, and therefore New Zealand taxpayers. The full data tables provided by the ACC via Official Information Act requests in September and October 1016 are available in the appendix.

Using an average of these growth rates I can project out how the numbers are likely to look in the near future. Projections for 2020 give us:

- 320,000 patients, up from 243,000 in 2015 ,

- and \$307 Million total cost, up from \$173M in 2015.

These trends are not restricted to New Zealand and can be seen throughout western nations where low back pain has reached near epidemic proportions, being reported by about $80 \%$ of people at some time in their life ("The burden of musculoskeletal conditions at the start of the new millennium," 2003, p. 11). With the peak incidence rates of Nonspecific low back pain, or muscle strains occurring during the peak working years of 27 - 47 years of age we can expect that the impact of this disease on productivity to be significant ("The burden of musculoskeletal conditions at the start of the new millennium," 2003, p. 40) 


\subsection{Top 20 active back claims and their costs by ACC read code description and calendar year.}

\begin{tabular}{|l|l|l|l|l|}
\hline Read Code Description & \multicolumn{2}{l|}{$\mathbf{2 0 1 4}$} & \multicolumn{2}{l|}{$\mathbf{2 0 1 5}$} \\
\hline Lumbar sprain & 231,114 & $\$ 145,613,874$ & 243,792 & $\$ 173,745,244$ \\
\hline Neck sprain & 106,147 & $\$ 42,951,867$ & 110,632 & $\$ 48,048,014$ \\
\hline Thoracic sprain & 40,078 & $\$ 14,440,943$ & 41,534 & $\$ 15,885,453$ \\
\hline Lumbar disc prolapse with radiculopathy & 4,789 & $\$ 49,406,696$ & 4,531 & $\$ 54,762,293$ \\
\hline Contusion, back & 8,178 & $\$ 4,641,857$ & 8,236 & $\$ 4,746,073$ \\
\hline Sciatica & 2,936 & $\$ 7,267,576$ & 2,707 & $\$ 7,120,259$ \\
\hline Whiplash injury & 4,362 & $\$ 3,609,827$ & 4,455 & $\$ 3,489,271$ \\
\hline Back sprain NOS & 3,950 & $\$ 3,283,289$ & 6,142 & $\$ 5,237,101$ \\
\hline Closed fracture thoracic vertebra & 774 & $\$ 9,643,759$ & 739 & $\$ 9,878,418$ \\
\hline Coccyx sprain & 2,666 & $\$ 1,300,113$ & 2,775 & $\$ 1,427,250$ \\
\hline Cervical disc prolapse with radiculopathy & 733 & $\$ 8,300,792$ & 683 & $\$ 10,009,644$ \\
\hline Closed fracture lumbar vertebra & 618 & $\$ 3,998,236$ & 713 & $\$ 4,649,014$ \\
\hline Closed fracture of cervical spine & 316 & $\$ 10,108,613$ & 310 & $\$ 10,679,911$ \\
\hline Lumbar disc displacement & 370 & $\$ 4,043,243$ & 399 & $\$ 3,974,615$ \\
\hline Disc prolapse with radiculopathy & 431 & $\$ 3,736,872$ & 430 & $\$ 4,529,976$ \\
\hline Contusion of lower back & 1,015 & $\$ 967,333$ & 860 & $\$ 1,053,162$ \\
\hline Sprain, lumbosacral ligament & 894 & $\$ 647,517$ & 919 & $\$ 878,259$ \\
\hline Open fracture lumbar vertebra & 201 & $\$ 2,852,168$ & 186 & $\$ 2,241,952$ \\
\hline All & $\mathbf{4 1 9 , 3 1 0}$ & $\$ \mathbf{4 7 0 , 9 3 6 , 7 5 2}$ & $\mathbf{4 3 9 , 3 9 6}$ & $\$ \mathbf{5 3 1 , 1 1 6 , 2 6 6}$ \\
\hline The following were excluded as we do not seek to treat these patients and they are expensive outliers. \\
\hline Quadriplegia & 264 & $\$ 49,040,345$ & 260 & $\$ 48,143,861$ \\
\hline Paraplegia & 293 & $\$ 20,451,085$ & 291 & $\$ 22,559,728$ \\
\hline
\end{tabular}

Figure 13 - Top 20 active back claims $\underline{\text { (Accident Compensation Corporation, 2016) }}$ 


\subsection{Total spend on Back/Spine injuries}

Source: ACC Injury Statistics Tool

Injury sites: Back/Spine

\begin{tabular}{|l|l|l|l|l|}
\hline Financial Year & New Claims & Active Claims & Total Cost & Total ACC Spend \\
\hline Jul 2010 - Jun 2011 & 218,453 & 277,038 & $\$ 316,030,952$ & $\$ 2,211,248,229$ \\
\hline Jul 2011 - Jun 2012 & 225,131 & 284,687 & $\$ 312,434,403$ & $\$ 2,200,541,958$ \\
\hline Jul 2012 - Jun 2013 & 231,247 & 295,515 & $\$ 319,933,977$ & $\$ 2,255,788,993$ \\
\hline Jul 2013 - Jun 2014 & 240,893 & 308,491 & $\$ 353,621,002$ & $\$ 2,505,914,950$ \\
\hline Jul 2014 - Jun 2015 & 253,297 & 324,654 & $\$ 395,909,554$ & $\$ 2,767,282,960$ \\
\hline
\end{tabular}

Figure 14 - ACC Back/Spine Injuries by Year (Corporation, n.d.)

From Jul 2014 - Jun 2015 Back/Spine injuries contributed 14.3\% of total ACC pay-outs.

It can be seen in the data above that the instances of accidents or injury events resulting in back pain in New Zealand is increasing dramatically.

\subsubsection{International Markets}

When looking at what markets to enter one of the measures we'll use is total spend on healthcare. These are the top 20 international markets for expenditure on healthcare.

\begin{aligned} & \hline Country $\begin{array}{c}\text { Annual spend on healthcare in } 2014 \\ \text { Millions of USD }\end{array} \\ &$\hline United States of America $2,985,748 \\ &$ China 574,799 \\ & Japan 470,672 \\ & Germany 437,001 \\ & France 326,475 \\ & United Kingdom 253,041 \\ & Italy 198,013 \\ & Brazil 195,244 \\ & Canada 186,565 \\ & Australia 140,035 \\ & Russian Federation 128,061 \\ & Spain 123,641 \\ & Republic of Korea 103,989 \\ & India 97,140 \\ & Netherlands 95,822 \\ & Mexico 80,571 \\ & Switzerland 78,654 \\ & Sweden 65,654 \\ & Belgium 54,716 \\ & Norway 48,649 \\ & \hline Figure 15 - Global health spend (National Health Account (NHA) indicators - Total spend in USD on health care in 2014, by country., \\ &\end{aligned}


Analysis of the full table tells us that the top 20 countries listed here account for $87.5 \%$ of the total global spend on healthcare in 2014 of USD \$7,588 billion.

I also looked at the global burden of spinal injuries to identify, where possible, international prevalence and trends. Low back pain (LBP) has reached epidemic proportions in developed nations with $80 \%$ of the population reporting symptoms at some stage in their life. The injuries leading to LBP are varied, with $>80 \%$ reported as non-specific. ("The burden of musculoskeletal conditions at the start of the new millennium," 2003) Research on Germany estimates that $30 \%$ to $40 \%$ of Germans experience LBP at any one point in time, with over $80 \%$ experiencing LBP at some point during their life. (Christina M. Wenig, 2009)

LBP doesn't just impact individuals, but also has an impact at a macroeconomic level. A 1998 study estimated LBP cost the German economy 17 billion euros, or $0.7 \%$ of GNP. (Christina M. Wenig, 2009) Other studies have estimated impacts ranging from 0.7\% of GDP in Sweden (Ekman, Jonhagen, Hunsche, \& Jonsson, 2005) and 1.7\% of GDP in the Netherlands (van Tulder, Koes, \& Bouter, 1995).

In the United States LBP contributes to $40 \%$ of all lost work days. (Manchikanti, Singh, Datta, Cohen, \& Hirsch, 2009)

\subsubsection{The Regulatory Environment}

Any medical device that is brought to market by Lifbak will need to meet certain regulatory hurdles depending on the country you are entering. Based on the research into international markets, and the expert opinion of Kevin Sheehy, I have researched the three main markets and regulatory areas we need to consider, New Zealand, the US, and Europe. By meeting the requirements of the US Food \& Drug Administration or the European Medicines Agency we will have achieved regulatory approval for at least half of the top 20 international markets, including four of the top six.

\section{New Zealand}

"Devices that have, or are claimed to have, therapeutic properties must comply with the Medicines Act and Regulations." ("Advertising of a Medical Device," 2011)

"Legal Definition of Therapeutic Purpose: The legal definition of therapeutic purpose is contained in Section 4 of the Medicines Act 1981 and states:

Therapeutic purpose - means any of the following purposes, or a purpose in connection with any of the following purposes:

- preventing, diagnosing, monitoring, alleviating, treating, curing, or compensating for, a disease, ailment, defect, or injury; or

- influencing, inhibiting, or modifying a physiological process; or

- testing the susceptibility of persons to a disease or ailment; or

- influencing, controlling, or preventing conception; or

- testing for pregnancy; or

- investigating, replacing, or modifying parts of the human anatomy." ("Medical Device Definitions," 2015) 


\section{$\underline{\mathrm{US}-\mathrm{FDA}}$}

I was not able to find a similar device in the FDA's devices database, but a search yielded other limb braces which are all Class One, and a powered exoskeleton which is a Class Two device. A Premarket Submission with the FDA prior to entering the marketplace. ("How to Study and Market Your Device," 2015)

\begin{tabular}{|l|l|l|l|l|}
\hline $\begin{array}{l}\text { Product } \\
\text { Code }\end{array}$ & Device & $\begin{array}{l}\text { Device } \\
\text { Class }\end{array}$ & $\begin{array}{l}\text { Regulation } \\
\text { Number }\end{array}$ & Regulation Description \\
\hline HXY & Brace Drill & 1 & {$[888.4540]$} & $\begin{array}{l}\text { Orthopaedic manual surgical } \\
\text { instrument. }\end{array}$ \\
\hline HBD & Handpiece (Brace) Drill & 1 & {$[882.4325]$} & $\begin{array}{l}\text { Cranial drill handpiece } \\
\text { (brace). }\end{array}$ \\
\hline ITW & $\begin{array}{l}\text { Joint Ankle External } \\
\text { Brace }\end{array}$ & 1 & {$[890.3475]$} & Limb orthosis. \\
\hline ITS & Joint Hip External Brace & 1 & {$[890.3475]$} & Limb orthosis. \\
\hline ITQ & $\begin{array}{l}\text { Joint Knee External } \\
\text { Brace }\end{array}$ & 1 & {$[890.3475]$} & Limb orthosis. \\
\hline IQI & Orthosis Limb Brace & 1 & {$[890.3475]$} & Limb orthosis. \\
\hline ITC & $\begin{array}{l}\text { Stirrup External Brace } \\
\text { Component }\end{array}$ & 1 & {$[890.3410]$} & $\begin{array}{l}\text { External limb orthotic } \\
\text { component. }\end{array}$ \\
\hline ITO & Twister Brace Setting & 1 & {$[890.3410]$} & $\begin{array}{l}\text { External limb orthotic } \\
\text { component. }\end{array}$ \\
\hline
\end{tabular}

Figure 16 - Lifbak's FDA classification options (Product Classification: Search Results )

Europe-EMA

Further research is required to discover specific EMA requirements and how they differ from the US's FDA.

\subsubsection{Step Three: Surveying and Problem Interviews}

I conducted primary research to discover more information about the Farmer market segment. This involved a survey help at the Wairarapa Agricultural and Pastoral Show, and one on one Problem Interviews with selected respondents who nominated themselves as available for a follow up interview. The purpose of the survey and problem interviews is discussed in the methodology. Survey respondents were self-selected as they walked past our stall at the show. We had some simple notices naming the company, Lifbak, and that we wanted to talk about back pain. To try and get additional responses we tried to engage passers-by as they walked past the stand. Some respondents referred their partners or friends to us to complete the survey. 


\subsubsection{Wairarapa A\&P Show Survey Results}

We received 22 responses in total. The survey itself can be seen in the Appendix, section 11.1.

Demographics

\section{Gender:}

$60 \%$ of respondents were male, $40 \%$ female.

Age:

\begin{tabular}{lll}
\hline Answer & Count & $\%$ \\
\hline Under 18 & 0 & $0.00 \%$ \\
$18-24$ & 0 & $0.00 \%$ \\
$25-34$ & 1 & $4.55 \%$ \\
$35-44$ & 2 & $9.09 \%$ \\
$45-54$ & 6 & $27.27 \%$ \\
$55-64$ & 5 & $22.73 \%$ \\
$65-74$ & 4 & $18.18 \%$ \\
$75-84$ & 4 & $18.18 \%$ \\
85 or older & 0 & $0.00 \%$ \\
\hline Total & 22 & $100 \%$ \\
\hline
\end{tabular}

The notable takeaway is that $50 \%$ of respondents were between the ages of 45 and 65 and overall the data is skewed towards older ages. This is in line with general demographic trends relating to back pain.

It was noted at the event that many of the younger attendees who looked like farmers had no interest in the survey.

\section{Industry:}

We went into the survey expecting to see a large number of farmers of varying types; but due to the lack of engagement and responses from farmers at the event the results tell us a different story.

\begin{tabular}{lll}
\hline Answer & Count & $\%$ \\
\hline Dairy & 0 & $0.00 \%$ \\
Sheep & 1 & $4.35 \%$ \\
Beef & 1 & $4.35 \%$ \\
Vineyard & 2 & $8.70 \%$ \\
Stable & 0 & $0.00 \%$ \\
Crops & 0 & $0.00 \%$ \\
Vegetables & 0 & $0.00 \%$ \\
Orchard & 0 & $0.00 \%$ \\
Other & 19 & $82.61 \%$ \\
\hline Total & 23 & $100 \%$ \\
\hline
\end{tabular}

The other field was dominated by retired people or complementary services supporting the farming community, including health services. There were also some respondents who were visiting the region from metropolitan areas. 


\section{Occupation:}

Somewhat against expectations, we received a large number of non-farming self-employed people or business owners, as well as managers. We also saw a reasonable percentage of retirees. We did not poll the others for a more specific job description; but these would be considered employees.

\begin{tabular}{lll}
\hline Answer & Count & $\%$ \\
\hline Owner & 8 & $36.36 \%$ \\
Manager & 5 & $22.73 \%$ \\
Other & 6 & $27.27 \%$ \\
Farm Hand & 0 & $0.00 \%$ \\
Milker & 0 & $0.00 \%$ \\
Shearer & 0 & $0.00 \%$ \\
Retired & 3 & $13.64 \%$ \\
\hline Total & 22 & $100 \%$ \\
\hline
\end{tabular}

Questions on Back Pain

\section{Do you or have you suffered from back pain?}

We clearly attracted those who did suffer from back pain, and that was of more benefit to me as I'm seeking information primarily about back pain sufferers. Out of 22 participants, only three didn't suffer back pain, and they were therefore disqualified from the rest of the survey.

A crosstabulation of age against back pain yields no statistically significant findings.

\begin{tabular}{|c|c|c|c|c|c|c|c|c|c|c|}
\hline \multirow[t]{3}{*}{ Age } & & Under & 18 & 25 & 35 & 45 & 55 & 65 & 75 & \multirow{3}{*}{$\begin{array}{l}85 \text { or } \\
\text { older }\end{array}$} \\
\hline & & 18 & - & - & - & - & - & - & - & \\
\hline & & & 24 & 34 & 44 & 54 & 64 & 74 & 84 & \\
\hline \multirow{2}{*}{$\begin{array}{l}\text { Do you or have you } \\
\text { suffered from back } \\
\text { pain? }\end{array}$} & Yes & 0 & 0 & 1 & 2 & 5 & 3 & 4 & 4 & 0 \\
\hline & No & 0 & 0 & 0 & 0 & 1 & 2 & 0 & 0 & 0 \\
\hline
\end{tabular}

\begin{tabular}{|l|l|l|}
\multicolumn{2}{c|}{} & Age \\
\hline \multirow{2}{*}{$\begin{array}{l}\text { Do you or have you suffered } \\
\text { from back pain? }\end{array}$} & Chi Square & $4.73^{*}$ \\
\cline { 2 - 3 } & Degrees of Freedom & 8 \\
\cline { 2 - 3 } & p-value & 0.79 \\
\hline
\end{tabular}

\section{How often, on average, are you impacted by back pain?}

$73 \%$ of respondents said they suffered from back pain at least twice a week, with $58 \%$ reporting daily back pain.

\begin{tabular}{lll}
\hline Answer & Count & $\%$ \\
\hline Daily & 11 & $57.89 \%$ \\
4-6 times a week & 2 & $10.53 \%$ \\
2-3 times a week & 1 & $5.26 \%$ \\
\hline
\end{tabular}




\begin{tabular}{lll}
\hline Answer & Count & $\%$ \\
\hline Once a week & 3 & $15.79 \%$ \\
Less frequently than once per week. & 2 & $10.53 \%$ \\
\hline Total & 19 & $100 \%$ \\
\hline
\end{tabular}

How would you rate the impact of the back pain on your ability to work? When answering this question base the answer on the worst $20 \%$ of the time.

Respondents were evenly split between those who saw a disruption to their work and those who could still continue to complete a full day's work. Disruption errs towards the extreme rather than the moderate.

\begin{tabular}{|l|l|l|}
\hline A great deal (you are able to do very little, if anything) & $21.05 \%$ & 4 \\
\hline A lot (you can do simple things) & $21.05 \%$ & 4 \\
\hline A moderate amount (you can do about 1/2 of what you'd normally be able to do) & $10.53 \%$ & 2 \\
\hline A little (you can do a full day's work but a couple of tasks are beyond you) & $42.11 \%$ & 8 \\
\hline None at all & $5.26 \%$ & 1 \\
\hline
\end{tabular}

Please tell us a little more about how back pain affects your work and the type of jobs around the farm that you are able to do:

The majority of answers in this section are "not applicable". Overall, you can see in the responses below that if someone needs to perform a task for work then they are doing it regardless of their, often, daily pain.

\begin{tabular}{|l|l|l|l|l|l|l|l|}
\hline & \multicolumn{2}{|l|}{$\begin{array}{l}\text { I can do } \\
\text { this. }\end{array}$} & \multicolumn{2}{l|}{$\begin{array}{l}\text { I can do this with some } \\
\text { restrictions }\end{array}$} & \multicolumn{2}{l|}{$\begin{array}{l}\text { I can't do } \\
\text { this. }\end{array}$} & Total \\
\hline Operate a tractor or similar vehicle. & $75.00 \%$ & 3 & $25.00 \%$ & 1 & $0.00 \%$ & 0 & 4 \\
\hline Drive my ATV & $66.67 \%$ & 2 & $33.33 \%$ & 1 & $0.00 \%$ & 0 & 3 \\
\hline Milk the cows. & $100.00 \%$ & 1 & $0.00 \%$ & 0 & $0.00 \%$ & 0 & 1 \\
\hline Shearing & $50.00 \%$ & 1 & $50.00 \%$ & 1 & $0.00 \%$ & 0 & 2 \\
\hline Fencing & $80.00 \%$ & 4 & $20.00 \%$ & 1 & $0.00 \%$ & 0 & 5 \\
\hline Moving animals & $83.33 \%$ & 5 & $16.67 \%$ & 1 & $0.00 \%$ & 0 & 6 \\
\hline Animal handling e.g. calving & $100.00 \%$ & 3 & $0.00 \%$ & 0 & $0.00 \%$ & 0 & 3 \\
\hline
\end{tabular}

There were 0 "I can't do this" responses; which is surprising considering the frequency of pain that respondents were experiencing. To explore this further I have cross tabulated the frequency of pain to these responses to explore whether those who responded here were just at the lower end of the pain spectrum. We found the opposite to be true with the majority of respondents in this section suffering from daily back pain. These results are not statistically significant due to the low quantity of responses, but they are still remarkable in showing that these respondents completed required physical tacks despite their frequent back pain. 
Please tell us a little more about how back pain affects your work and the type of jobs around the farm... \begin{tabular}{l|l}
\hline $\begin{array}{l}\text { How often (on average) are you impacted by back } \\
\text { pain? }\end{array}$ \\
\hline
\end{tabular}

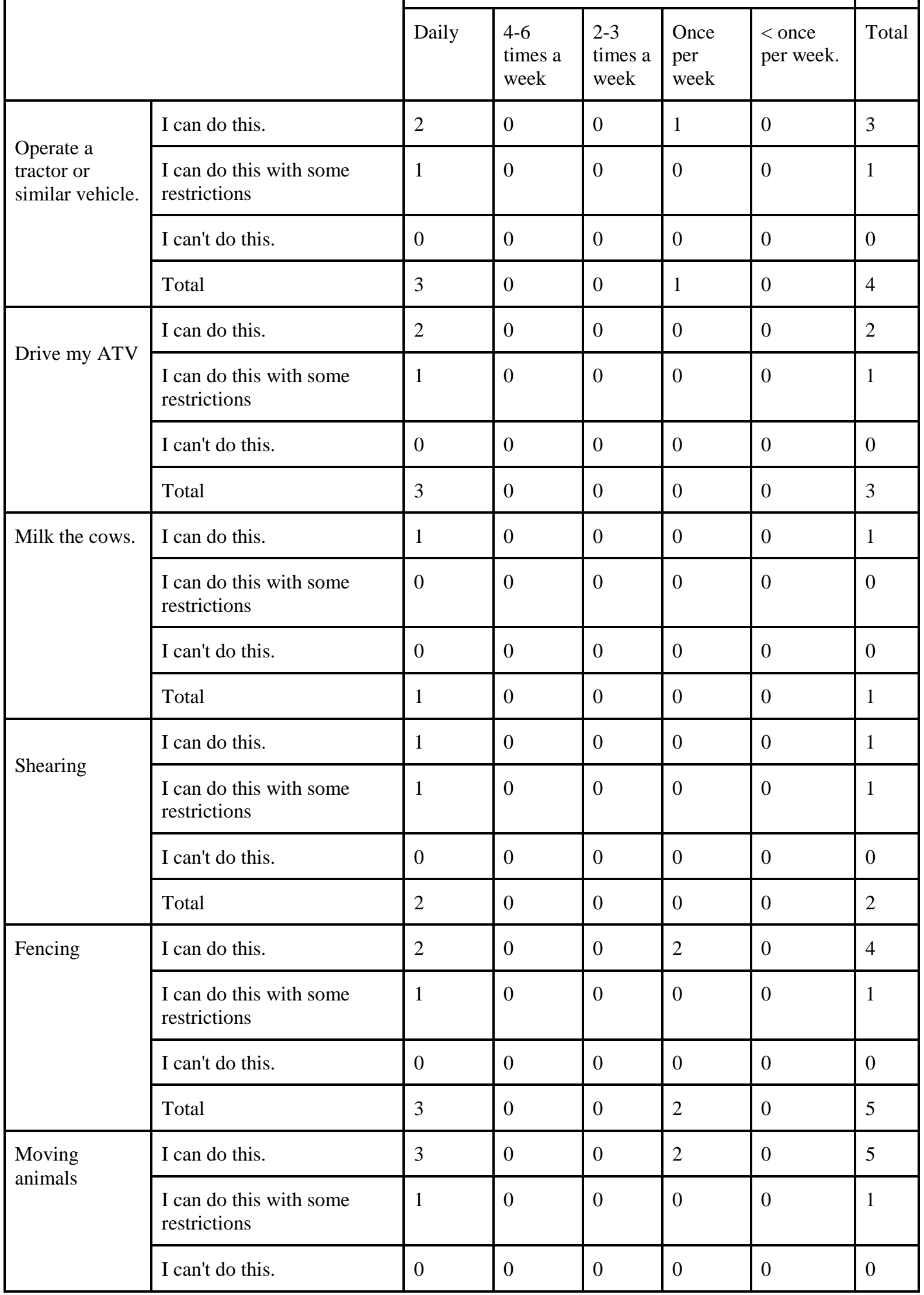




\begin{tabular}{|l|l|l|l|l|l|l|l|}
\hline & Total & 4 & 0 & 0 & 2 & 0 & 6 \\
\hline \multirow{3}{*}{$\begin{array}{l}\text { Animal } \\
\text { handling e.g. } \\
\text { calving }\end{array}$} & I can do this. & 2 & 0 & 0 & 1 & 0 & 3 \\
\cline { 2 - 8 } & $\begin{array}{l}\text { I can do this with some } \\
\text { restrictions }\end{array}$ & 0 & 0 & 0 & 0 & 0 & 0 \\
\cline { 2 - 8 } & I can't do this. & 0 & 0 & 0 & 0 & 0 & 0 \\
\cline { 2 - 8 } & Total & 2 & 0 & 0 & 1 & 0 & 3 \\
\hline
\end{tabular}

If you know and have a specific diagnosis from your doctor or specialist please select or write that here.

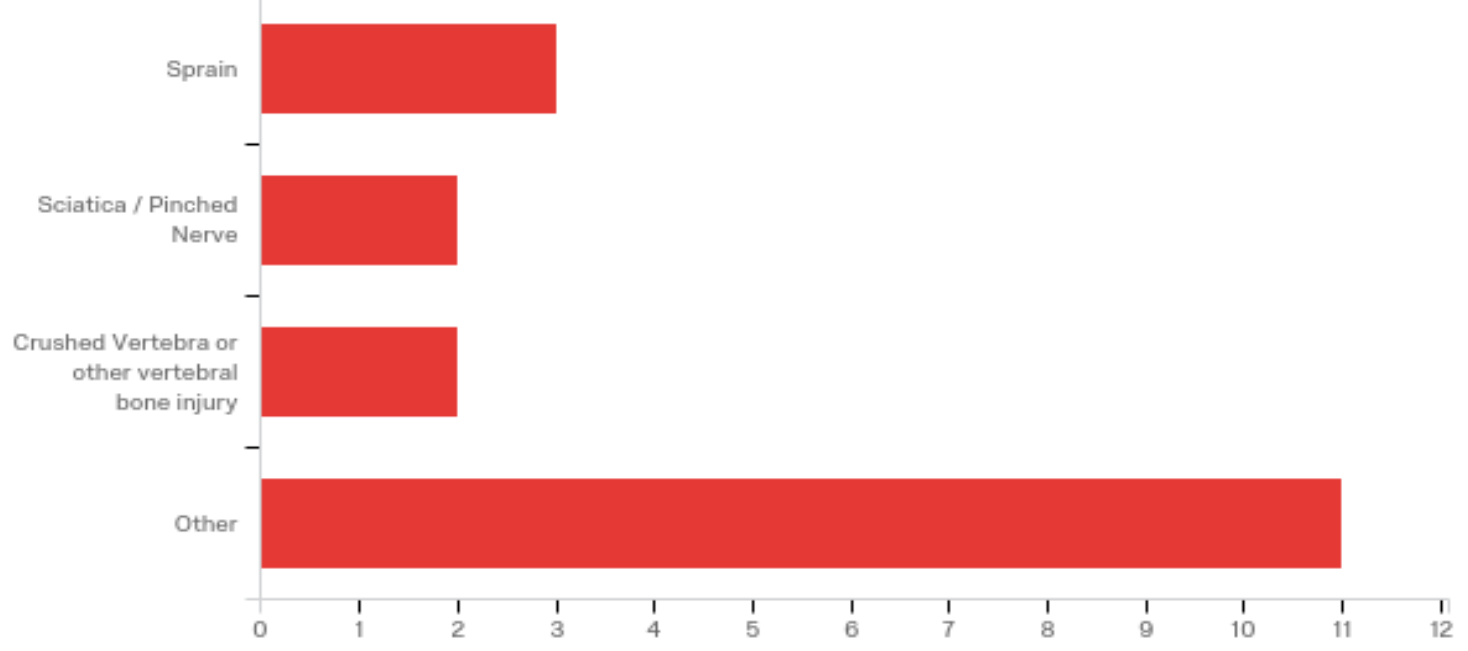

All respondents except one have a diagnosis, or are almost certain of what is causing their back pain. The reasons reached across the spectrum of potential problems and showed no particular bias towards one condition or the other. The full list of issues stated are:

\begin{tabular}{|l|l|}
\hline Sprain & Osteoporosis \\
\hline Sciatica / Pinched Nerve & Degenerative \\
\hline Crushed Vertebra or other vertebral bone injury & Non-diagnosed (likely to be a non-specific injury or strain) \\
\hline Scoliosis & Investigating \\
\hline Slipped disc & Shoulder injury \\
\hline
\end{tabular}

When cross tabulated against frequency of pain we don't see any real trend toward one or other condition. This is primarily due to the high number of "other" responses. In the future, this survey should be completed with the full range of options available to select from. This will allow for better reporting of trends.

\section{Would you see a medical professional about your back pain?}

15 of 19 respondents would see a medical professional about their back pain. 


\section{Would you tell your employer about your back pain?}

When applicable, 7 out of 9 respondents would tell their employer about back pain. Due to the large number of self-employed people, business owners, and managers, 11 answers were not-applicable.

\subsubsection{Problem Interview Results}

In total, four pain sufferers and two physiotherapists were taken through a problem interview. This supplements what was had previously been learnt from discussions with Kevin Sheehy. I aimed for more participants but this didn't occur due to lower than anticipated respondents at the A\&P show further reduced by only three of the eight who agreed to interviews replying to follow up emails seeking to organise an interview. To protect privacy, respondents have been referred to as Back Pain Sufferer (BPS) A, B, C, and D and Expert (E) A and B.

A summary of the responses is stated below. If there is no answer for a select individual then that is because they declined to answer that question or it was not applicable to their case.

Initial questions:

What is your specific condition? (BPS-A was asked what was the initial cause?)

- Varied responses with different conditions diagnosed or left undiagnosed.

- BPS-A suffered from an extrusion of the disk on L5/S1. This was from lifting items at a gym boot camp.

- BPS-B suffered from a slipped disk (prolapsed disk) on L5.

- BPS-C has not had a diagnosis. There was no injury event.

- BPS-D has not had a diagnosis but it is age related and there is no injury event.

How long have you been receiving treatment for this condition?
A. For seven months and ongoing.
B. At the time of the injury four years ago, but none for a while now.
C. Hasn't received any treatment.
D. Hasn't received any treatment.

\section{What sort of support have you received from ACC?}

a. $100 \%$ of expenses covered by ACC for Physiotherapists, osteopaths, orthopaedic surgeon, acupuncture.

b. $\quad$ MRI scan

c. Medication

A. Physio and Osteopath

Are you able to provide specific (or as close as possible) monetary figures for the different types of treatment and financial support ACC has provided?

A. No compensation for being off work, but the cost of MRI and at least 20 appointments isn't low. If surgery is completed (currently on hold due to improvement of the condition) then the cost of that is $\$ 15,000$ 
B. No compensation for being off work, but the cost of 24 visits over the first year.

Who is/was your primary treatment provider?

A. Osteopath.

B. Physiotherapist

Who did you first see when the injury happened?

A. Physiotherapist

B. GP at a $24 \mathrm{hr}$ clinic

Exploratory Questions

In this section, I will combine answers into a summary of overall experiences rather than just provide a repetition of the full interview notes which are available in the appendices.

\section{How do you currently treat your condition?}

None of the back-pain sufferers are currently using analgesics for pain relief. All respondents share common ground in restricting their movement and activity in order to manage pain and reduce the potential for injury or reinjury. This self-management varies from a near complete absence of physical activity to merely limiting the amount of certain activities such as lifting. All respondents perform exercises in some form to help rebuild muscle strength, gain flexibility, and reduce pain. These range from exercises set by a medical professional to simple micro stretches to reduce discomfort.

All respondents shared a similar desire to minimise the amount of analgesics they were taking and might require in the future.

\section{Have you tried anything in the past that you no longer do or use?}

BPS-A and BPS-B both had injury events which they sought medical help for. Both were provided with analgesics and used these for a period. One had a more serious condition and received steroid injections and acupuncture. Exercises were prescribed and performed. One saw value in the physio and one did not. BPS-A was in extreme pain after the injury event and in their own words "I would have paid anything and tried anything to reduce the pain.”. BPS-B used a standing desk for two years post injury to remove the pain of sitting.

Patients BPS-C and BPS-D had not tried anything in the past that they no longer do. This is most likely due to no specific diagnosis or medical direction, and currently doing things that do not pose a break of routine.

\section{Tell me about how your condition affects your life?}

This is a section of responses that is of particular interest as we start to get a picture of the emotional, physical, and economic impact of back pain.

All respondents have experienced an impact on their life and their ability to work.

The emotional impact of back pain in respondents is varied. They include the emotional effects of sleep deprivation, loss of independence, some loss of identity through needing to stop activities they previously enjoyed. The most dramatic emotional impact may have been from BPS-A who cancelled plans to have a baby.

The physical impact of the respondents back pain ranged from: 
- at the top end, extreme pain for six months alongside an almost complete loss of movement due to the pain, and

- at the low end, minor physical disability or pain after performing certain physical tasks, for example moving $15 \mathrm{KG}$ boxes.

We have already assessed to some degree the economic impact to insurers of the respondent's injuries, and you'll see more on that in the section collating statistics from New Zealand's ACC. We can now start to assess the personal economic impact of the respondents' back pain. All respondents are self-employed and they did not receive compensation from ACC. Time off work ranged from six months to none. For BPS-C the pain does not stop him from doing his work, but is a key factor in a pending decision to sell his business. If he didn't have the pain then he would be far less likely to sell. We can easily extrapolate out a loss in productivity and business income due to pain and a reluctance to take on certain required activities that might cause pain.

\section{Would you consider wearing a device to help with recovery? What would it need to look and feel like for you to consider it?}

BPS-C and BPS-D were not deemed candidates for the device in question so were not asked the question.

BPS-A and BPS-B would both consider wearing a device. As stated previously, BPS-A would have tried anything. The aesthetics of the device is a concern if they are expected to wear it in public, but if the pain relief was significant then even the design may be inconsequential.

\subsection{Product Validation and Development}

This section covers research from the Wairarapa A\&P Show that is related to the product that respondents had the opportunity to try on the day. The aim of research in this section is to identify the commercial potential and medical application of the prototype device, and what additional work needs to be done before it will be ready for market. Experts were interviewed in relation to this section with their input already covered in section 6.2.2.1 and expanded on in the discussion and business case. Some information on product development is included in section 6.4.1 of Resource Requirements and Returns.

\subsubsection{Wairarapa A\&P Show Survey}

\section{Questions on the Device}

At the A\&P show we tested the latest prototype of the Lifbak exoskeleton.

These responses seek to discover how we have improved on the previous version and where effort needs to be focussed in the future.

\section{Did you test the device today?}

Seven of the respondents went on to test the device. This was not required and the remaining respondents skipped this section and completed the survey.

There was no correlation seen between any factors and the willingness to test the device. As this is an important commercial factor I have included the full cross tabulation in the appendix.

\section{Please rate the comfort of the device.}

Respondents cluster around the somewhat comfortable/uncomfortable range. This was to be expected with the prototype device that was tested. These results show some improvements on the first version whilst still telling us we have a long way to go to get a market ready product. 


\begin{tabular}{|l|l|l|}
\hline Extremely comfortable & 0 & $0.00 \%$ \\
\hline Somewhat comfortable & 3 & $42.86 \%$ \\
\hline Neither comfortable nor uncomfortable & 2 & $28.57 \%$ \\
\hline Somewhat uncomfortable & 2 & $28.57 \%$ \\
\hline Extremely uncomfortable & 0 & $0.00 \%$ \\
\hline
\end{tabular}

What would be a fair price for a device that helps you to rehabilitate faster from chronic lower back pain? Consider the full value which includes the combination of what you might pay and any coverage from ACC or an insurer.

Although the end user is unlikely to be paying for the product once you have proven efficacy, this does tell you that if you wish to sell direct to consumers in the research phase of Lifbak then you will need to put significant effort into building the consumer facing value proposition for the product to reach the likely required retail price of $\$ 1000$ to $\$ 1500$.

\begin{tabular}{|c|c|c|}
\hline Answer & Count & $\%$ \\
\hline$<\$ 100$ & 1 & $14.29 \%$ \\
\hline$\$ 100-\$ 199$ & 1 & $14.29 \%$ \\
\hline$\$ 200-\$ 499$ & 3 & $42.86 \%$ \\
\hline$\$ 500-\$ 999$ & 1 & $14.29 \%$ \\
\hline$\$ 1000-\$ 1499$ & 1 & $14.29 \%$ \\
\hline$>\$ 1499$ & 0 & $0.00 \%$ \\
\hline
\end{tabular}

\section{Would you wear and use the device as it is today?}

6 of 7 respondents would not wear the device as it was presented at the event. This is not surprising due to the comfort of the device, as seen in the above results and the comments provided further below. The single person who would wear the device as it was is a nice boost to morals but does not hide the fact that much work needs to be done to achieve a market ready product.

\section{Would you purchase the device as it is today?}

With 3 of 7 respondents answering yet, the results of this answer are somewhat contradictory to the immediately prior question; as clearly respondents who wouldn't wear the device would still purchase it. There was some discussion at the event around these questions and I believe that the reasoning for the difference is that after consideration, the reduction of pain and achieving an improved quality of life overtook their desire for comfort and aesthetics. 
I cross-tabulated these responses against questions on pain, work disruption, and comfort. You can see some correlation between the frequency of pain, significance of disruption to work, and an acceptable comfort level with the respondent's willingness to purchase. Due to a small sample size this is not deemed statistically significant with p-values of 0.44 or higher. I do feel that the results are informative and when taken together show a real trend that can be used when building a marketing plan.

\begin{tabular}{|c|c|c|c|c|}
\hline & & \multicolumn{2}{|c|}{$\begin{array}{l}\text { Would } \\
\text { you } \\
\text { purchase } \\
\text { the } \\
\text { device as } \\
\text { it is } \\
\text { today? }\end{array}$} & \multirow[b]{2}{*}{ Total } \\
\hline & & Yes & No & \\
\hline \multirow{6}{*}{$\begin{array}{l}\text { How often (on average) are you } \\
\text { impacted by back pain? }\end{array}$} & Daily & 2 & 1 & 3 \\
\hline & 4-6 times a week & 0 & 0 & 0 \\
\hline & 2-3 times a week & 0 & 1 & 1 \\
\hline & Once a week & 0 & 1 & 1 \\
\hline & Less frequently than once per week. & 0 & 1 & 1 \\
\hline & Total & 2 & 4 & 6 \\
\hline \multirow{6}{*}{$\begin{array}{l}\text { How would you rate the impact } \\
\text { of the back pain on your ability } \\
\text { to work? When answering this } \\
\text { quest... }\end{array}$} & $\begin{array}{l}\text { A great deal (you are able to do very little, if } \\
\text { anything) }\end{array}$ & 1 & 0 & 1 \\
\hline & A lot (you can do simple things) & 1 & 1 & 2 \\
\hline & $\begin{array}{l}\text { A moderate amount (you can do about } 1 / 2 \text { of what } \\
\text { you'd normally be able to do) }\end{array}$ & 0 & 0 & 0 \\
\hline & $\begin{array}{l}\text { A little (you can do a full day's work but a couple of } \\
\text { tasks are beyond you) }\end{array}$ & 0 & 3 & 3 \\
\hline & None at all & 0 & 0 & 0 \\
\hline & Total & 2 & 4 & 6 \\
\hline \multirow{6}{*}{$\begin{array}{l}\text { Please rate the comfort of the } \\
\text { device. }\end{array}$} & Extremely comfortable & 0 & 0 & 0 \\
\hline & Somewhat comfortable & 2 & 1 & 3 \\
\hline & Neither comfortable nor uncomfortable & 1 & 1 & 2 \\
\hline & Somewhat uncomfortable & 0 & 2 & 2 \\
\hline & Extremely uncomfortable & 0 & 0 & 0 \\
\hline & Total & 3 & 4 & 7 \\
\hline
\end{tabular}

Figure 17 - Crosstabulation of purchase intent vs back pain frequency, impact on work, and device comfort 
As a final question, we sought open responses providing feedback with the aim of directing future research and development.

We received four answers from those who said they wouldn't purchase the device as it is today. They are somewhat informative, if still limited. The general trend is around fitment and comfort being the key determining factors.

- Was a little short for my tall posture, and armpit was not quite smooth for me.

- Padding and having it fit correctly

- More streamlined

- We discovered that the device was not helping me at all and was causing some discomfort in my lower back

\subsection{Resource Requirements and Returns}

I have focused resource requirements research on two critical areas for the next stages of the business: product development, and clinical trials.

\subsubsection{Product Development}

\subsubsection{Mark Hildesley Interview}

Mark Hildesley is the inventor of the Lifbak device and my project partner. He is a Professional Engineer with 20 years' experience, specialising in materials engineering. Mark also has a M Phil Eng. in Medical Materials, adding further weight to his input on the future development of the Lifbak device. As an inventor, consultant, and employee, Mark has managed the acquisition of many patents for his own businesses and others, including managing Intellectual Property for Fisher \& Paykel Appliances.

Date: $\quad 14 / 07 / 2017$

Interviewee: Mark Hildesley

Interviewer: Paul Dowd

Topic: $\quad$ Product Development Resource Needs

\section{Notes on Intellectual Property}

\$35-40k would get the NZ patent and the PCT for global pre-registrations. Within 18mths of PCT you have to file in any other countries where you want to expand to and hold patents in. It will cost about another \$10-15k per country; for example, the US, each country in EU (Germany, UK, France), and Australia.

The top 20 countries in the world constitute $80 \%$ of the global health spend, so you look at that list to see which countries are worth investing in IP rights for.

\section{Notes on Product Development}

It will approximately six months of product development and testing to be ready to register the next stage of IP and build the first 10 units that can be used for clinical trials. Non-staff costs during this stage will be $\$ 2000$ in materials. It would cost $\$ 25 \mathrm{k}$ to build the 10 units, excluding staff costs. It may be worth factoring in up to $\$ 10,000$ for equipment access and $3^{\text {rd }}$ party verification activities. E.g. if the device is designed for up to a $120 \mathrm{Kg}$ load then you'd need to make and break one in a suitable test lab to prove it.

Once ready to move to production scale, the injection mold tooling required to produce the first production product will be approximately $\$ 100,000$. 
Mark's experience with additive manufacturing is that it is unlikely to add any value to our product and would significantly increase equipment and manufacturing costs. For now, the incremental improvement from a fully customized manufactured device, over injection molded device, just wouldn't justify the cost.

To get to a production ready product we'll need to hire a product development engineer for around six months at an annual salary of $\$ 100,000$. Mark's project management and design fees would be $\$ 10,000$ per month. An additional $\$ 20,000$ - $\$ 30,000$ of engineering fees can be expected to finalise a production version of the device. On top of these expenses, Lifbak will need to purchase a CAD (computer aided design) station for staff at a cost of around $\$ 15,000$.

\subsubsection{Clinical Trials}

In order to enter most international markets, and in order to make specific health claims in New Zealand, Lifbak will need to run clinical trials to prove the efficacy of the device for one or more conditions.

\subsubsection{Dr. Simon Hinkley Interview}

Dr. Simon Hinkley is the Science Team Leader at the Ferrier Institute at Victoria University of Wellington with significant experience as a researcher and some experience in trials. ("Dr Simon Hinkley | Ferrier Research Institute | Victoria University of Wellington," 2017)

The following are the key findings from the interview.

Simon has some experience in trials and has a product currently undergoing a trial that is also classified as a medical device. However, he has not run one himself or taken a product to market. His experience is typically to hand off the commercialisation (and the clinical trial components required for commercialisation) to organisations that license the technology from the university.

He agrees that the device would be unregulated in New Zealand.

To run a trial, you'd only need one patient and a clinician to begin proving efficacy. This would be a first step to proving efficacy whereby you can expand the trial. At this level, you could operate the trial with a consultant/researcher with prior experience to run the trial and a clinician to develop the proof of efficacy tests. Each person would need to spend approximately $10 \%$ of their time on the trial and as such there is only a small investment required by Lifbak. Once some efficacy is proven the trial can be expanded, which would require more time from the researcher and clinician, but there would also be the opportunity to get grant funding to assist. The clinician is likely to be a GP or Physiotherapist.

Simon isn't up to date on specific organisations in NZ that can assist with developing and running the trial, but he doesn't feel it need to be overly complicated. We just need to prove efficacy and any suitably qualified researcher and clinician should be able to work together in this. Having a researcher who is experienced in trialing medical devices will be beneficial. It is possible that universities could assist with the researcher component. There are some grants available to do co-research with a university or research institute but they are hit and miss with approx. $30 \%$ of applications being successful, so this shouldn't be relied upon and the overhead it imposes may not be worthwhile for what ultimately will be a small investment.

Andrew Harrison from the Malaghan institute may be able to offer more details or assist with a trial. Nancy Yopp from a medical devices committee may also be able to offer more information, although she is more interested in invasive rather than external medical devices.

To get trial participants his experience is to just go out there and find some volunteer who have the right condition for the efficacy we want to prove. One pitfall he has experience, and that we should watch out and control for is the impact of varying clinician performance on trial results. 
Simon mentioned that removing load from bone fractures when they are healing can be detrimental to healing outcomes.

(Hinkley, 2017)

\subsubsection{Crowdfunding}

There are eight equity crowdfunding companies licensed to operate in New Zealand ("Licensed crowdfunding services," 2017). I have not considering non-equity product sales or donation based crowdfunding providers, e.g. Kickstarter, which likely number in the 100s internationally. I interviewed Anna Gunther from Wellington based Pledgeme Limited to get a feel for the requirements when launching an equity crowdfunding campaign seeking to raise at minimum $\$ 250,000$.

\subsubsection{Anna Gunther Interview Findings}

Noted from meeting between Paul Dowd and Anna Gunther, CEO or Pledgeme that took place on September $6^{\text {th }}$, 2016. Supplemented with additional research and clarification post interview.

Pledgeme has a Crowdfunding U programme which takes entrepreneurs through the process of building a successful crowdfunding campaign whilst ensuring all financial market authority requirements are understood and met. This costs $\$ 3,000+$ GST per organization for campaigns aiming to raise over $\$ 100,000$. Some or all of this cost could be covered by capability development vouchers provided by the local economic development agency. ${ }^{9}$ On average, Pledgeme raises around $\$ 250,000$ per campaign, with the maximum allowed being $\$ 2$ million. She felt that with our offering we would be better to aim higher than the average.

When crowdfunding the most important aspect of a successful campaign is the story that you tell about your business, the problem you'll solve, and possibly the product that will solve it if you have one. Real life video testimonials are the most powerful means of conveying the value proposition of your business. Second to this is having an existing base of supporters who will back you as soon as the campaign launches, this generates campaign momentum and tells potential investors who don't personally know you that you are worth backing. With a product like Lifbak's the story shouldn't be hard to build and it will resonate with a larger audience than most campaigns Pledgeme runs.

As part of the crowdfunding process we'll need to develop a business plan, pitch, and prospectus. Crowdfunding $\mathrm{U}$ helps to guide you through this process. An example of a recent high-quality prospectus is Parrotdog's, a company who raised the legislated maximum of $\$ 2$ million through Pledgeme. ${ }^{10}$

There are a lot of other expenses that do come into the equation when crowdfunding, it isn't just Pledgeme's fees. There will be legal feeds, accounting fees, and to optimize success you'll need to spend on building a great campaign. This means brand development, videography, copywriting, and designs.

(Gunther, 2016)

Anna promised to email me details of the costs fundraising through Pledgeme, and those details re included and referenced in the discussion and business case.

\footnotetext{
${ }^{9}$ http://guide.pledgeme.co.nz/crowdfundingu/

${ }^{10}$ https://www.pledgeme.co.nz/investments/234-parrotdog-brewery
} 


\section{Discussion}

\subsection{Business Model Design}

Most organisations aim to have a different business model to their competitors, as this allows them to differentiate themselves in the marketplace and reduce the impact that competition has on their business. I have investigated four business that are building devices in similar fields to Lifbak and analyse the aspects of their business models that were visible to me. This information is then used in the business case to inform what innovation tactics Lifbak might choose to use in order to reduce tactical cross-over.

\subsubsection{Competitor's Business Models}

When looking at the business models of backX, StrongArm Tech, Ekso Bionics, and Rex Bionics we are looking parts of the model that stand out to make them successful and set them apart from their competition. I have assessed the Problem, Customer Segment, Solution, Unique Value Proposition, Unfair Advantage, Channel, and Revenue Streams sections of the Lean Canvas. I am not able to see the Cost Structure or Key Metrics the company has as they are hidden operational elements of the business model.

The business case will seek to utilize those parts of these company's business models which may be critical to success in our market, and differentiate in other parts of the model to reduce competition and allow Lifbak to build their own market.

\subsubsection{Problem:}

backX and StrongArm Tech build products that aim to solve the problem of lower back injuries caused by physical labour at work. Although these products look similar in some ways to Lifbak's device, the perspective of the problem is quite different as they solely focus on prevention rather than rehabilitation.

Ekso Bionics and Rex Bionics build robotic exoskeletons aimed at solving problems in rehabilitating severely disabled patients who need the assistance of a robotic skeleton to walk or exercise

\subsubsection{Customer Segments}

backX and StrongArm Tech both target industrial users, for example manufacturing, distribution, and construction. Ekso Bionics and Rex Bionics targets end users with major spinal injuries, with the economic buyer likely to be health agencies, and possibly insurers.

\subsubsection{Solution}

backX and StrongArm Tech have exoskeleton devices that reduce the amount of working load placed on the lower back with the aim of reducing injury in the workplace. StrongArm Tech also has a software product which allows the organisation to track and model performance data.

Ekso Bionics has developed a software controlled robotic exoskeleton to help patients train their gait and re-learn how to walk. Rex Bionics has a robotic exoskeleton, but theirs is able to stand autonomously so that the user can perform a wider range of rehabilitation exercises.

\subsubsection{Unique Value Proposition}

This is where we see some real differentiation between the organisations. backX places value on the affordability and effectiveness of its device, whereas StrongArm Tech places priority on the cost savings its customers gain. Ekso Bionics has a single value proposition, to get customers walking again, whereas Rex Bionics looks to promote itself across a wider range of rehabilitation activities. 


\subsubsection{Unfair Advantage}

All have their own intellectual property (IP), however, we can learn from this that although IP provides some protection, it does so within a limited scope and there are still ways for competitors to enter the marketplace by solving the problem in a sufficiently different way. Both Rex Bionics and Ekso Bionics run clinical research on their devices, which confers an advantage, if successful, through proven efficacy.

\subsubsection{Channels}

Other than Rex Bionics, who seem at a more advanced stage of market development that the other organisations, none of the competitors have a channel to market, other than direct sales, that was obvious. Even the direct sales methods used seemed difficult and multi-step.

\subsubsection{Revenue Streams}

All competitors derive revenue from product sales, with only one, backX actually publishing a price of USD \$3000 per unit. Ekso Bionics and StrongArm Tech have software products which may also deliver revenue. All of them may derive revenue from training, in particular the robotic exoskeletons which have a hands-on usage pattern where the organisation is likely to be heavily involved in supporting the user post sale.

\subsubsection{Conclusion and Recommendations}

Each of the four competitors have identified a market niche to operate in. backX and StrongArm Tech are the closest competitors in terms of business model overlap.

I recommend Lifbak significantly differentiates their product offering and business model from backX and StrongArm Tech to reduce to chance, and impact, of competition in Lifbak's market. 


\subsection{Market Validation and Development}

\subsubsection{Market Segmentation Analysis}

The market segmentation analysis (Appendix: Market Segmentation Analysis) shows the method that Mark Hildesley and Paul Dowd used to rank a wide range of market options into a few that warranted further investigation. We described 20 potential market segments and ranked them on a scale of 1-5 of how closely the segment matches certain characteristic requirements, such as being well funded (able to afford the product), having a product ready for that customer segment, and whether the market matches the founder's own goals and passions. Because not all of these are equal in the eyes of the entrepreneur we have used a simple weighting system to give more important factors greater weight in the decision-making process. As at this point of the process I was going to co-found Lifbak with Mark my input was equally valuable in determining organizational direction.

Despite slightly different weightings and scores across the decision factors and market segments, Mark and I reached almost identical conclusions on what markets we should further investigate. They were crushed vertebrae, pinched nerve, dairy workers, farmers, sports injuries, and rental devices.

Mark and I found this method to be an effective means of quickly and reasonably robustly whittling down a large number of potential markets into a manageable number that warranted being prioritized for further investigation. Decisions can always be made with more data, but the main priority here was speed, not accuracy. The accuracy comes in the next step, beachhead market identification.

\subsubsection{Beachhead Market Identification}

The outcomes of research into each target market segment we identified during the Market Segmentation Analysis is discussed in Figures 18, \& 19. It is broken into individual market segments and the subquestions we must answer according to the methodology. For some market segments, certain sub-questions have been omitted if there aren't relevant research findings to discuss. All discussion notes are informed by the ACC statistics and expert interview sections of the Findings and Analysis chapter of this report.

Through the research process we identified that the initial market segmentation groups poorly matched the terminology used in the marketplace, and in particular with the records kept by ACC. This can especially be seen in the market size sections where I had to match official diagnosis records with the market segments we described. 


\begin{tabular}{|c|c|c|}
\hline & Crushed Vertebrae & Pinched Nerve \\
\hline End User Profile & Not discussed. & Not discussed. \\
\hline FDA or EMA Requirements & \multicolumn{2}{|c|}{$\begin{array}{l}\text { Lifbak will need to gain FDA and EMA approval to sell in the US and European markets. Further details are discussed in the Product Validation and Development } \\
\text { section. Lifbak will need to maintain a quality dossier documenting any and all information relating to regulatory strategy, clinical information, and reasoning } \\
\text { behind decisions made throughout the design and build of the device. }\end{array}$} \\
\hline Economic Decision Maker & \multicolumn{2}{|c|}{$\begin{array}{l}\text { At a mass market level when we have achieved regulatory approval and approval under relevant health schemes (e.g. ACC in New Zealand and Insurance } \\
\text { Companies in the US) the economic decision maker will be the health professional assessing the user's case. For these conditions, this is likely to be: the surgeon } \\
\text { and/or specialist treating the patient, or medical professionals working with the patient on rehabilitation. In some instances, and at the early stage of the business } \\
\text { this may be essential, the end-user (patient) will be the economic decision maker as they will personally purchase the device. } \\
\text { In New Zealand, for patients who haven't had an accident event and therefore aren't funded via ACC we will need to engage with the Ministry of Health and } \\
\text { District Health Boards to have the device purchased for their patients. Some patients in New Zealand have private health insurance that will cover the cost of our } \\
\text { device if it is recommended by the patient's specialist. The specific efficacy requirements for private health insurers are unknown, but if we meet ACCs } \\
\text { requirements then we should also meet the requirements of any other health insurer. }\end{array}$} \\
\hline $\begin{array}{l}\text { Specific Applications and } \\
\text { Diagnosis / Market Size }\end{array}$ & $\begin{array}{l}\text { In } 2015 \text {, ACC statistics shows } 1638 \text { incidences of thoracic or lumbar } \\
\text { fractures with a total cost to treat of } \$ 16,769,384 \text {. (Accident } \\
\text { Compensation, 2016) }\end{array}$ & $\begin{array}{l}\text { A pinched nerve doesn’t match with the statistics available, therefore I have worked } \\
\text { a market size on injuries that may be similar. These are Lumbar disc prolapse with } \\
\text { radiculopathy, Lumbar disc displacement, and Disc prolapse with radiculopathy. In } \\
2015 \text { ACC funded 5,360 patients with a total cost of treatment, including weekly } \\
\text { payments, of } \$ 63,266,884 \text {. (Accident Compensation, 2016) }\end{array}$ \\
\hline Expected Benefits & Based on ACCs recommended outcome measures & Not Discussed \\
\hline Lead Customers & $\begin{array}{l}\text { Customers will come from specialists and/or physiotherapists. Specific } \\
\text { lead customers haven't been identified but should meet typical lead } \\
\text { customer characteristics of being motivated to try something new right } \\
\text { now, and be able to become a brand evangelist in the future if the Lifbak } \\
\text { device helps them. }\end{array}$ & Not Discussed \\
\hline Partners & $\begin{array}{l}\text { Orthopaedic surgeons are the primary experts and decision makers when } \\
\text { treating this condition. We need to work with and orthopaedic surgeon } \\
\text { during the product development and research stage to prepare a suitable, } \\
\text { specialist backed, device. During market entry and on an ongoing basis we } \\
\text { need to treat orthopaedic surgeons as partners as they are the gateway } \\
\text { through which the device will be prescribed. }\end{array}$ & Not Discussed \\
\hline Expert Interviews & $\begin{array}{l}\text { A long way off having a device and the relevant research required to be } \\
\text { able to enter this market space. We should move away from this market } \\
\text { until research has been completed showing efficacy for this specific } \\
\text { condition and FDA approval has been granted otherwise we are opening } \\
\text { ourselves up for serious legal implications. Kevin mentioned the idea of } \\
\text { surgically implanted exoskeletons in this specific use case. }\end{array}$ & $\begin{array}{l}\text { This is a really strong market because people should keep active and take a } \\
\text { conservative approach to treatment when they suffer a prolapsed disk. Kevin was } \\
\text { most excited by the combination of Farmers and Prolapsed Disk as an initial market. } \\
\text { - Lots of cost to the user; primarily due to their inability to work causing lost income. } \\
\text { - There are lots of diagnosis for this injury. } \\
\text { - Patients are likely to search for treatments at home where there isn't a professional } \\
\text { gatekeeper recommending one or other product. }\end{array}$ \\
\hline
\end{tabular}

Figure 18 - Market Segmentation Analysis pt. 1 

\begin{tabular}{l|l} 
End User Profile & $\begin{array}{l}\text { Older farm workers and farm managers who } \\
\text { experience an injury event, face two critical problem }\end{array}$
\end{tabular}

- They need to keep working as the farm doesn't just stop while they are hurt.

- It isn't easy to get a suitable replacement to do their work for a short time period.

Based on these assumptions we believe that farmers who have a back injury that is preventing them from working, or working at capacity, would be highly motivated to purchase the device as it would show an immediate financial return on investment through improved farm productivity and reduced wage expenses.

The one person I interviewed close to this segment, an owner of a vineyard, suffered from significant back pain that stopped him from being able to work but even so wasn't committed to doing much about it. His situation is not a good representation of this market due to a couple of identifiers we need to be aware of. His lack of need to perform critical work on the vineyard, nearness to and mentality of retirement, and ability and desire to just sell the farm/business. When looking at the farming market you'd need to make sure your leads didn't have these markers.

Assumed profile - not extensively tested due to negative results for this segment at the Wairarapa A\&P show.

FDA or EMA Requirements If we are making any claims for specific conditions then we will need to meet regulatory requirements for those claims. If we maintain a no-claim policy in a similar fashion to the nutraceutical industry then we will be able to enter the market in New Zealand without undergoing any regulatory processes.

Economic Decision Maker

The farm owner/manager is the economic decision maker. If the injury was caused by an accident event, and we have been approved by ACC, then ACC will be able to fund the device once it has been prescribed by a treatment provider.
Users with minor sports injuries could be from any port, but the primary indicators that inform this profile are a recent injury that has resulted in significant pain and loss of movement, and a fast presentation at a treatment provider, most likely a physiotherapist.

My interviews with physiotherapists informs me that the recovery from many sports injuries would benefit from the Lifbak device as a tool that immediately removed load from the injury, preventing the injury from getting worse, and in rehabilitation by allowing the user to perform exercises and increase load to the injured area with reduced re-injury potential.

End users will be motivated to get better fast to either return to the sports field (professional athletes) or get back to work. Generally, we' assume a financial motivation is greater than other factors as that motivation also provides a strong cost/benefit reason to purchase the device.
Physiotherapists and specialists who see patients with conditions where the Lifbak device has shown efficacy in treatment.

\section{End users:}

Patients who have an injury who have been recommended and fitted with the device by their treatment provider.
See left table cell with the addition of:

Due to the likely requirements dictated by specialists and other prescribers I expect Lifbak will need to meet FDA or EMA requirements and/or show research evidence on efficacy for at minimum one specific condition.

In New Zealand, all sports injuries will be classified as accidents and treatments are financed by ACC.

Prior to ACC funding approval being granted the economic decision maker should be the employer who wants to see their employee recover as fast and well as possible.
Two steps and types of EDM:

1. Organisations purchasing the device to rent out are the initial economic decision maker.

2. Once an organisation owns the device the decision maker reverts to ACC, insurers, or health 


\begin{tabular}{|c|c|c|c|}
\hline & & & $\begin{array}{l}\text { boards who are funding rental fees and support } \\
\text { sessions charged by the treatment provider. }\end{array}$ \\
\hline $\begin{array}{r}\text { Specific Applications and } \\
\text { Diagnosis / Market Size }\end{array}$ & $\begin{array}{l}\text { Kevin Sheehy has suggested that the most likely } \\
\text { clinical condition for severe back pain in farmers will } \\
\text { be pinched nerves / prolapsed disk. } \\
\text { We don't have any data on diagnosis by occupation to } \\
\text { specify this market size. }\end{array}$ & $\begin{array}{l}\text { The likely high-potential diagnoses for our device } \\
\text { are lumbar sprains and thoracic sprains. In New } \\
\text { Zealand, there were } 243,000 \text { lumbar sprains and } \\
41,000 \text { thoracic sprains in } 2015 \text {. It is unknown how } \\
\text { many of these were caused by a sporting injury. My } \\
\text { forecasts show this number increasing significantly } \\
\text { every year. We can expect only a few of this large } \\
\text { number of injuries to be the actual market and who } \\
\text { see either a personal financial cost, or ACC cost of } \\
\text { treatment, high enough to justify either party } \\
\text { investing in the Lifbak device. } \\
\text { International trends for lumbar sprains are similar to } \\
\text { New Zealand. International markets will see greater } \\
\text { potential for a market opportunity with professional } \\
\text { athletes. }\end{array}$ & $\begin{array}{l}\text { It is unknown what the exact market size will be for } \\
\text { rental devices as there is no ability to see how many } \\
\text { patients a device would service each year. The } \\
\text { overall market size for patients who need a device } \\
\text { can be expected to be the same as other market } \\
\text { segments with the addition of some users that } \\
\text { wouldn't have met the cost/benefit threshold } \\
\text { previously and would now do so with a lower cost } \\
\text { treatment option. }\end{array}$ \\
\hline Expected Benefits & $\begin{array}{l}\text { We expect to see an immediate increase in patient } \\
\text { productivity and an overall reduction in the amount of } \\
\text { time it takes a patient to return to their before-injury } \\
\text { (or new optimal in the case of there being no full } \\
\text { recovery potential) work abilities. }\end{array}$ & $\begin{array}{l}\text { If patients are able to reduce the load from their } \\
\text { injured area within the first } 24-72 \text { hours then they } \\
\text { should see an immediate reduction in total } \\
\text { rehabilitation time. } \\
\text { After this period, the patient should see improved } \\
\text { rehabilitation times and lower re-injury rates due to } \\
\text { the device reducing the load on the injury site when } \\
\text { they perform rehabilitation exercises. }\end{array}$ & $\begin{array}{l}\text { As with other segments, the expected benefits to the } \\
\text { end user are an immediate increase in ability, a } \\
\text { reduction in rehabilitation time, and an increase in } \\
\text { injury recovery rate. } \\
\text { For the treatment provider, there they should see } \\
\text { benefits in increased customer outcomes, and } \\
\text { therefore brand perception and value, and increased } \\
\text { revenue through billable device rental fees and } \\
\text { appointments. }\end{array}$ \\
\hline Lead Customers & & $\begin{array}{l}\text { Lifbak should look to target professional sports } \\
\text { organisation who are prepared to trial the device to } \\
\text { treat their athletes when they get injured. Having } \\
\text { testimonials and proved efficacy from professional } \\
\text { athletes will allow Lifbak to promote to other } \\
\text { international sports organisations and build a strong } \\
\text { brand story for entering the consumer market. It is } \\
\text { likely that to reach these lead customers Lifbak will } \\
\text { need to form individual relationships with the } \\
\text { clinicians who work for those organisations as } \\
\text { opposed to any treatment centres. }\end{array}$ & $\begin{array}{l}\text { Lead treatment provider customers will ideally fit } \\
\text { two criteria: } \\
\text { 1. Be prepared to work closely with Lifbak in the } \\
\text { development of a device that is suitable for the } \\
\text { rental market. } \\
\text { 2. Be able to become a brand evangelist and } \\
\text { example treatment provider when the device is } \\
\text { launched to the wider market }\end{array}$ \\
\hline Partners & $\begin{array}{l}\text { To access this channel, we will need to partner with a } \\
\text { distributed group of physiotherapists who are both } \\
\text { able to access the market for product sales, and } \\
\text { provide ongoing training and support to device users. }\end{array}$ & $\begin{array}{l}\text { Physiotherapists are essential partners to access and } \\
\text { treat this market segment. }\end{array}$ & \\
\hline
\end{tabular}




\begin{tabular}{|c|c|c|c|}
\hline & $\begin{array}{l}\text { We can sell directly to this market using the channel } \\
\text { or digital marketing methods. }\end{array}$ & & \\
\hline Expert Interviews & $\begin{array}{l}\text { Rural GP network for market access, check if they } \\
\text { have affiliated Physios etc. } \\
\text { - ask them questions on who, why do they get injuries, } \\
\text { and how are they currently treated } \\
\text { - find someone with a special interest in back injuries } \\
\text { - find a way to talk to farmers directly } \\
\text { - Field Days, see if they are able to provide some } \\
\text { information / research, just go along and ask some } \\
\text { questions } \\
\text { - check out farmers social networks and survey them" }\end{array}$ & $\begin{array}{l}\text { Most sports injuries won't be back related. The most } \\
\text { common back injury in sports is probably sprained } \\
\text { muscles in the lower back and this sort of treatment } \\
\text { is unlikely to have a dramatic impact on recovery } \\
\text { time and user quality of life. } \\
\text { If we were to enter this market we would need to } \\
\text { find a high performance expensive sport that does } \\
\text { have back injuries and where players need to get } \\
\text { back to the game quickly; or where there is a high } \\
\text { cost to a sports person being unable to play. }\end{array}$ & $\begin{array}{l}\text { The avenue into District Health Boards in New } \\
\text { Zealand (and other similar institutions worldwide) } \\
\text { would need to be a clinical department who } \\
\text { recommends the institution stocks this device for } \\
\text { their patients to use/hire. The device would still } \\
\text { need to be prescribed by a nurse, doctor, or } \\
\text { specialist. } \\
\text { - We could try and find some specialists who could } \\
\text { support it, want to prescribe it, and therefore would } \\
\text { use their influence to get their institution to } \\
\text { purchase units. } \\
\text { - We still need to bring all activity back to the } \\
\text { disease or condition that we are treating. The } \\
\text { medical professional needs a reason to prescribe the } \\
\text { device, likely based on research results. }\end{array}$ \\
\hline
\end{tabular}

Figure 19 - Market Segmentation Analysis pt. 2 


\subsubsection{ACC Discussion}

Indications from ACC are that there are several likely markets that Lifbak can target with a clear preference shown for us to look at specific mechanical diagnosis. Out of the initial beachhead markets we identified the closest matches to mechanical diagnosis codes that ACC uses are Crushed Vertebrae and Pinched Nerve. However, any group where we can show a benefit at reasonable cost would be a market that ACC would fund. Because many of the diagnosis codes show average costs to ACC that are at a similar level to or less than the expected price of the Lifbak device we need to do more research to identify specific cohorts within these segments who will allow us to achieve enough benefit for the device to make financial sense to ACC. After receiving the initial datasets from ACC in mid-2016 I requested decile breakdowns so that I could identify these more expensive cohorts; however, I never received the data. It should be available if we request it again and follow it up.

Mechanical diagnoses are by far the smaller of the customer segments that ACC has, however they do see a significantly higher average cost than many of the non-mechanical diagnosis. This means that although there is small number in the cohort, because the average cost of treatment is high it is likely that a far greater proportion of those patients are candidates for Lifbak's device. There are approximately 7000 patients in these segments. If we were to provide devices to $5 \%$ of this market then that would represent 350,000 in sales at a price of $\$ 1000$ per unit. It is likely that once efficacy and cost benefit has been shown with any of these market segments then the uptake will be far greater than 5\% as ACC would recommend our device as a means of reducing their overall cost.

A strong example of the potential in non-mechanical injuries is lumbar sprains. Lumbar sprains are the single largest injury diagnosis but have an average cost of just over $\$ 700$, which is too low for Lifbak to be viable. However, when looking at the deciles, specifically the most expensive $10 \%$ of cases, the product is very likely to be viable. This would still represent 24,000 patients in 2015, a significant market. Lumbar sprains are also a fast-growing market in terms of volume of patients and the cost of treatment with my forecasts showing the total market increasing to 320,000 patients and an average treatment cost of around $\$ 950$ by 2020 .

\subsubsection{Conclusion and Recommendations}

Through this process I learnt that the method we used to identify the beachhead market was relatively fast, but not particularly effective at accurately picking the right segment to target. It allowed us to investigate and learn about multiple options without a large investment of time and resource. The research dis-proved a hypothesis of farmers as a target market, and further research is required to find the correct beachhead market. Due to this failure, I had to pivot away from farmers as a market segment and Lifbak needs to find a new market segment.

Through my research into ACC's needs and the potential of using them as a path to market, I concluded that, even though the end user has not been identified yet, a pivot to ACC as the economic customer is the right path to take. ACC has a clear need to find rehabilitation solutions to a variety of diagnoses where their compensation and treatment costs are high and/or rising. Once efficacy has been shown for a diagnosis then ACC will most likely fund it, much reducing the barrier to sales through the likely channel to market options of Physiotherapists and specialists.

I recommend that:

- Lifbak undertakes additional market research to identify a select group of diagnoses where Lifbak could have the greatest impact.

- Lifbak undertakes clinical trials to prove efficacy for one or more diagnoses. 
- Works with ACC during market research and trials to ensure the smoothest possible path to market once the device is ready for production.

\subsection{Product Validation and Development}

\subsubsection{Wairarapa A \& P Show}

When we attended the Wairarapa A\&P Show we took the opportunity to test our prototype device on some willing participants. These tests formed an optional part of the survey.

We found that the device was neither comfortable or uncomfortable, which on the surface appears to be a significant improvement on previous reports from the inventor. This result needs to be taken in the context of the participant only wearing the device for a short period (usually less than 5 minutes), whereas in a real-life setting the device would be worn for an extended period of time (up to a full day).

Participants were asked about price, and erred towards the lower end of the options we offered, with the most common selection being $\$ 200-\$ 499$, and the middle one in the list. It is possible that the bias of going with the middle option occurred. Given I recommend Lifbak pivots to a different economic customer this question is no longer relevant due to the decision-making processes of health insurers, health agencies, and ACC being significant different to those of consumers.

When asked whether they would use/wear or purchase the device as it was presented to them at the show I saw a strange occurrence of dissonance. Despite only one person saying they'd wear it as it was presented, an additional two people said they'd purchase it, which would necessitate the wearing of it if they hoped to gain any benefit from the purchase. I believe this difference is down to the first question triggering a thought response about the design and aesthetic of the device, whereas the second question triggered the desire to remove their pain, which ultimately overcame their reservations from the previous question. I believe that we discovered that those with significant pain will try something to remove that pain even if it isn't ideal; something that was shown through the crosstabulation of pain frequency and impact, and purchase intent.

\subsubsection{The Regulatory Environment}

\subsubsection{New Zealand}

During the initial stages of development, if Lifbak is sold without claim then it can avoid coming under the conditions of the Medicines Act and Regulations.

Based on the definitions of therapeutic purpose the Lifbak device should not come under the remit of the Medicines Act. This means that you can promote and sell Lifbak in New Zealand without meeting set regulatory requirements. When promoting any products you must still meet New Zealand advertising standards.("The burden of musculoskeletal conditions at the start of the new millennium," 2003) A prevetting service is offered by the Advertising Standards Authority which seeks to help advertisers of therapeutic and other products meet a high level of advertising standard.

Regardless of this, if you wish to get funding from Pharmac or ACC, the nation's primary funders of healthcare, you will need to perform formal medical trials to show efficacy. The business case has more details on how to be funded by these agencies.

\subsubsection{US - FDA}

Based on the device types discovered in the research, the Lifbak device could be classified as a Class One - Lowest Risk, or a Class Two - Moderate Risk medical device. Given the Lifbak device is closer in form 
and function to a brace than an exoskeleton, I am hopeful that Lifbak would be classified as Lowest Risk. Lifbak will need to complete a Premarket Submission with the FDA prior to entering the marketplace. ("How to Study and Market Your Device," 2015)

Kevin Sheehy has recommended that to streamline the FDA (and EMA) application process Lifbak should maintain a quality dossier documenting all information relating to regulatory, strategic, and clinical reasoning behind decisions made throughout the design and build of the device. (Sheehy, 2016)

\subsubsection{Conclusion and Recommendations}

Results from product testing at the A\&P show, indicate that patients presenting with frequent back pain will consider using the device, even if other aspects of it don't appeal. Three of the seven people who tested the device indicated they would purchase it as it was at the event. This is a very strong validation of the product concept; with that validation enhanced by the device presented lacking aesthetic appeal, and clearly being an industrial prototype.

Meeting regulatory requirements is a critical step for market entry in New Zealand and Internationally. Although Lifbak can sell the device in New Zealand with limited regulation and no approvals required, proving efficacy will mean additional promotional and market segment opportunities become available. With the US being the largest health market in the world, meeting FDA requirements is essential and its requirements should be considered throughout product design and development.

I recommend:

- that, over the long term, Lifbak works with customers to discover an aesthetically pleasing device, but this should not be at the risk of reducing performance, which is more important.

- that significant research is continued on improving the comfort of the device.

- that Lifbak maintains a quality dossier of all decisions and actions pertaining to the development of the Lifbak device as support for future FDA and EMA applications.

- that Lifbak runs clinical trials to determine efficacy of the device for at minimum one diagnosis.

\subsection{Resource Requirements and Returns}

\subsubsection{Product Development}

Discussion with Mark Hildesley, the original inventor and an experienced engineer, informs us that Lifbak will need approximately $\$ 100,000$ in capital, over a six-month period, to fund the research and development required to build a device ready for patenting and clinical trials. It is expected that development will take six months to complete. Half of the cost is labour, with the remainder split between materials, equipment, contingency, and facility/consulting fees. These numbers are not exact and are based on Mark's experience in the industry running similar projects. If the product takes longer to develop then this cost will increase significantly due to the labour component's high weighting.

On top of these costs, Mark Hildesley will want to draw a salary for his time which will come to $\$ 240,000$ over the two years required to develop the product and run clinical trials.

Mark Hildesley recommends following method for protecting IP in New Zealand and abroad: 
1. Perform a Patent Cooperation Treaty (PCT) application in New Zealand ${ }^{11}$. Upon granting the patent the device will be protected in New Zealand, and Lifbak will be able to apply for protection in any PCT country within 31 months of earliest priority date. Although the listed fees aren't high, in reality this process will cost up to $\$ 40,000$ to complete.

2. Research those countries that you may wish to expand to in the future and register in those countries within the priority period. Only 20 countries make up nearly $90 \%$ of international expenditure on health. Once these countries are mapped against international back injury data you'll have a clear indication of what markets to enter. Based on existing knowledge from my WHO research, any western nation should be considered. With an expected cost of \$10-15,000 per additional country, and around 15 countries in total needing to be protected, this represents an additional $\$ 200,000$ in IP protection costs. These costs are only incurred if efficacy is proven and funds don't need to be raised prior to trials.

\subsubsection{Clinical Trials}

Discussions with Christine Bloomfield and Simon Hinkley show that the clinical requirements for entering New Zealand and being funded by ACC should not be arduous, or expensive. This needs to be weighed against the need to prepare for future international expansion where there is a greater need to prove efficacy in preparation for FDA and EMA applications.

The first priority is to meet the efficacy needs of Lifbak's initial target economic customer, ACC. We don't know how many people ACC will need to see in a trial, but we know it will need to be more than one and that the metrics ACC will use to assess efficacy and fundability need to be included in trial metrics.

A clinical trial will need a clinician, at a cost of approximately $\$ 20,000$, and a trial manager who will cost from $\$ 20,000$ to $\$ 30,000$ depending on the length of the trial.

\subsubsection{Funding Methods}

I have only investigated Crowdsourced funding in this report. Other options are mentioned in the business case based on my personal experience.

There are two options for crowd-funding, product sales, and equity investment. In New Zealand Lifbak could do one, or both of these options to raise working capital if they used a local company that has been approved by the financial markets authority. I talked with Anna Gunther, CEO of Pledgeme, who is one of the crowdfunding companies authorised to raise capital in New Zealand. The maximum value of equity that can be raised through this method in New Zealand is $\$ 2$ million.

Based on Anna's recommendations, and the prices listed on the Pledgeme website, crowdfunding will cost $\$ 3000$ in direct training fees and $6.5 \%{ }^{12}$ of all funds raised. Lifbak will also need to factor in costs associated with building a successful campaign, including legal, design, videography, and other consulting fees.

${ }^{11}$ https://www.iponz.govt.nz/about-ip/patents/ ("Patents - Intellectual Property Office of New Zealand,")

${ }^{12}$ https://www.pledgeme.co.nz/about/equity\#equity-crowdfunding ("Equity campaigns,") 


\subsubsection{Conclusion and Recommendations}

With the focus, right now, on product development and clinical trials, funding should be limited to these activities and not extended to non-essential market development activities, for example branding. Product development will cost approximately $\$ 100,000$ to produce a device ready for patenting and clinical trials, and an additional $\$ 40,000$ for patenting. Clinical trials will cost approximately $\$ 50,000$. Management salaries for Mark Hildesley will come to $\$ 240,000$ over the two years. I have not investigated other options for raising capital, but crowdsourced funding through Pledgeme would cost over $10 \%$ of raised capital if Lifbak raised $\$ 400,000$.

I recommend:

- that Lifbak immediately raises $\$ 340,000$ to fund product development, patenting, and clinical trials.

- that Lifbak investigates other funding methods to reduce the time and financial burden a crowdsourcing campaign will impose.

- that Mark Hildesley reduce his salary requirements to $\$ 60,000$ per annum as a 3/5-time employee. 


\section{References}

About — Wawatai Physio. (2014). Retrieved from http://www.wawataiphysio.co.nz/about/

Accident Compensation, C. (2016). 37364 - Back claims by Read code. In: Accident Compensation Corporation.

Advertising of a Medical Device. (2011, 10 May 2011). Retrieved from http://www.medsafe.govt.nz/regulatory/DevicesNew/12Advertising.asp

Aulet, B. (2013). Disciplined Entrepreneurship: 24 Steps to a Successful Startup. New Jersey: John Wiley \& Sons.

backX | suitX. (2017). Retrieved from http://www.suitx.com/backx

Bloomfield, C. (2017, 11 July 2017) Interview on ACC Outcome Measurements/Interviewer: P. Dowd. Master of Innovation and Commercialisation.

BPS - A. B. C. and D. (2016) Lifbak Problem Interviews/Interviewer: P. Dowd. Master of Innovation and Commercialisation.

The burden of musculoskeletal conditions at the start of the new millennium. (2003). World Health Organ Tech Rep Ser, 919, i-x, 1-218, back cover.

Christensen, C. M. (1997). The innovator's dilemma: when new technologies cause great firms to fail. Boston, MA: Harvard Business School Press.

Christina M. Wenig, C. O. S., Thomas Kohlmann, Bernd Schweikert. (2009). Costs of back pain in Germany. European Journal of Pain, 13, 7.

Dowd, P. (2015). Key Metrics Modelling for Devilish Growth. Retrieved from http://growthdevil.com/keymetrics-modelling-devilish-growth/

Dr Simon Hinkley | Ferrier Research Institute | Victoria University of Wellington. (2017). Retrieved from http://www.victoria.ac.nz/ferrier/about/staff/simon-hinkley

Ekman, M., Jonhagen, S., Hunsche, E., \& Jonsson, L. (2005). Burden of illness of chronic low back pain in Sweden: a cross-sectional, retrospective study in primary care setting. Spine (Phila Pa 1976), 30(15), 1777-1785.

Ekso Bionics - An exoskeleton bionic suit or a wearable robot that helps people walk again. Retrieved from http://eksobionics.com/

Equity campaigns. Retrieved from https://www.pledgeme.co.nz/about/equity\#equity-crowdfunding

Gunther, A. (2016, 06 September, 2016) Pledgeme / Lifbak crowdfunding discussion/Interviewer: P. Dowd.

Hinkley, D. S. (2017, 11 July 2017) Interview with Dr Simon Hinkley about clinical trials for medical devices./Interviewer: P. Dowd. Master of Innovation and Commercialisation.

How to Study and Market Your Device. (2015, 09/16/2015). Retrieved from http://www.fda.gov/MedicalDevices/DeviceRegulationandGuidance/HowtoMarketYourDevice/default. htm

Keeley, L., Walters, H., Pikkel, R., \& Quinn, B. (2013). Ten types of innovation: The discipline of building breakthroughs. New Jersey: John Wiley \& Sons.

Licensed crowdfunding services. (2017). Retrieved from https://fma.govt.nz/compliance/lists-andregisters/licensed-crowdfunding-services/

Magretta, J. (2002). Why Business Models Matter. Harvard Business Review, 80(5), 86-92.

Manchikanti, L., Singh, V., Datta, S., Cohen, S. P., \& Hirsch, J. A. (2009). Comprehensive review of epidemiology, scope, and impact of spinal pain. Pain Physician, 12(4), E35-70.

Maurya, A. (2012). Running Lean: Iterate from Plan A to a Plan That Works. Sebastapol: O'Reilly Media, Inc.

Maurya, A. (2016). Scaling Lean: Mastering the Key Metrics for Startup Growth: Penguin UK.

Medical Device Definitions. (2015, 15 January 2015). Retrieved from http://www.medsafe.govt.nz/regulatory/DevicesNew/1Definition.asp

The Mobility Action Programme | Ministry of Health NZ. (2017, 30 March 2017). Retrieved from http://www.health.govt.nz/our-work/preventative-health-wellness/mobility-action-programme

National Health Account (NHA) indicators - Total spend in USD on health care in 2014, by country. (2014). Retrieved from: http://www.who.int/health-accounts/ghed/en/

Patents - Intellectual Property Office of New Zealand. Retrieved from https://www.iponz.govt.nz/aboutip/patents/

Rex Bionics - Step into the future. (2017). Retrieved from http://www.rexbionics.com/

Ries, E. (2011). The lean startup : how today's entrepreneurs use continuous innovation to create radically successful businesses (First edition. ed.).

Sheehy, K. (2016, 2016 and 2017) /Interviewer: P. Dowd.

Strategy. Methods, Models and Theories. (2017). Retrieved from https://www.12manage.com/i_s.html

StrongArm ${ }^{\circledR}$ Technologies, Inc. Retrieved from https://www.strongarmtech.com/ 
Taplin, M. (2011). Business Plans, Business Models or KPI Models? KPI Models. Retrieved from http://kpilibrary.com/topics/business-plans-business-models-or-kpi-models

Thiel, P., \& Masters, B. (2015). Zero to One: Notes on Start Ups, Or How to Build the Future: Virgin Books.

Turner, D. W. (2010). Qualitative Interview Design: A Practical Guide for Novice Investigators. The Qualitative Report, 15(3), 754-760.

van Tulder, M. W., Koes, B. W., \& Bouter, L. M. (1995). A cost-of-illness study of back pain in The Netherlands. Pain, 62(2), 233-240.

Wayne Roberts - Physiotherapist. (2017). Retrieved from http://www.habit.co.nz/rehabilitation/physiotherapists/wayne-roberts

\section{Figures}

Figure 1 - 24 Steps to a successful startup. (Aulet, 2013)

Figure 2 - Problem interview script deconstructed (Maurya, 2012, p. 85) .

Figure 3 - The Solution interview script deconstructed (Maurya, 2012, p. 103)

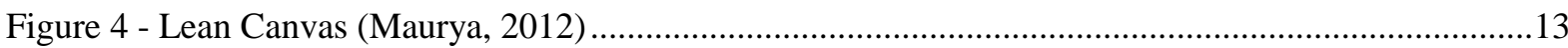

Figure 5 - Ten Types of Innovation Tactic Overview............................................................................14

Figure 6 - Lots of business strategy tools ("Strategy. Methods, Models and Theories," 2017) ....................17

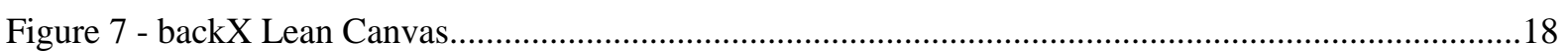

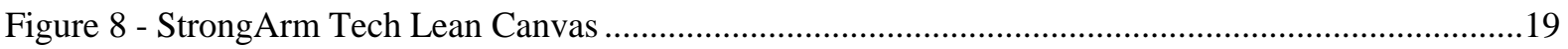

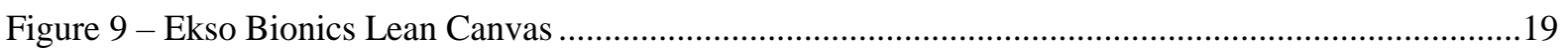

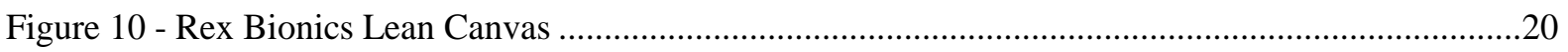

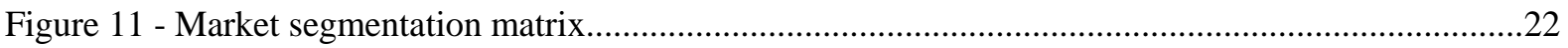

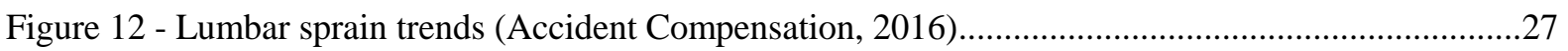

Figure 13 - Top 20 active back claims (Accident Compensation Corporation, 2016).................................28

Figure 14 - ACC Back/Spine Injuries by Year (Corporation, n.d.) …………………………..................29

Figure 15 - Global health spend (National Health Account (NHA) indicators - Total spend in USD on health care in 2014, by country., 2014)

Figure 16 - Lifbak's FDA classification options (Product Classification: Search Results )..........................31

Figure 17 - Crosstabulation of purchase intent vs back pain frequency, impact on work, and comfort .......41

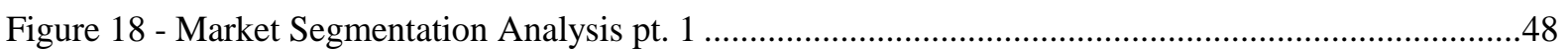

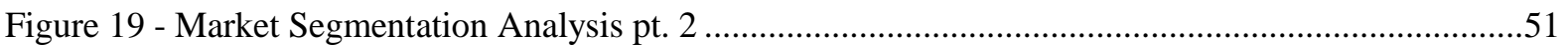

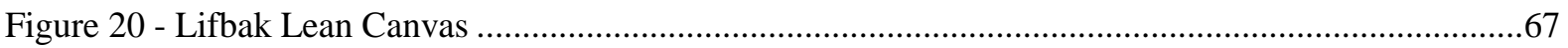

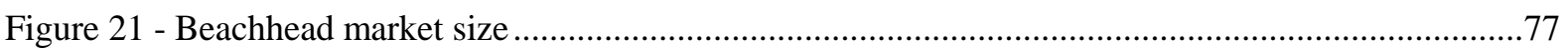




\section{Appendix}

\subsection{Survey Questionnaire}

\section{DEMOGRAPHIC QUESTIONS}

- Gender

- Age

- Industry

- Occupation

\section{PRIMARY RESEARCH QUESTIONS:}

- Do you or have you suffered from back pain? (If they answered no to this question then they skipped to contact details.)

- How often (on average) are you impacted by back pain?

- How would you rate the impact of the back pain on your ability to work?

- How does back pain influence your ability to do certain jobs around the farm?

- A selection of typical farm activities was made available.

- What was the specific diagnosis (if any) for your back problem?

- Would you (or did you) see a medical professional about your back pain?

- Would you tell your employer about your back pain?

\section{SECONDARY RESEARCH QUESTIONS IF THEY TESTED THE DEVICE}

- $\quad$ Did you test the device today?

- Please rate the comfort of the device?

- What would be a fair price for a device that helps you to rehabilitate faster from chronic lower back pain? Consider the full value which includes the combination of what you might pay and any coverage from ACC or an insurer.

- Would you purchase the device as it is today?

- What would need to be different for you to purchase the device today?

\section{FOLLOW UP AND CONTACT DETAILS}

- Would you be interested in trialling the device for a month and providing feedback to our researchers?

- Are you happy to be contacted for a follow up 30-minute in-depth interview where we will seek to get a better understanding of your condition and how it impacts your life?

- Can we provide your contact information to Lifbak in order to send you product announcements once the device is ready for the market?

- What are your contact details? 

- Name
- Email address
○ Phone number

\subsection{Problem Interview Script for Back Pain Sufferers}

After introducing myself, the purpose of the research, and setting the scene for the interviewee, I asked the following questions:

INITIAL QUESTIONS:

- What is your specific condition?

- How long have you been receiving treatment for this condition?

- What sort of support have you received from ACC?

- Are you able to provide specific (or as close as possible) monetary figures for the different types of treatment and financial support ACC has provided?

- Who are your primary treatment providers?

- Who did you see first when the initial injury happened?

EXPLORATORY QUESTIONS:

- How do you currently treat your condition?

- Have you tried anything in the past that you no longer do or use?

- Tell me about how your condition affects your life?

EXTRA SOLUTION QUESTIONS IF TIME AND INTERVIEWEE PERMITS.

- Would you consider wearing a device to help with recovery?

- What would it need to look and feel like for you to consider it? 


\subsection{Market Segmentation Analysis}

Worksheet One: Paul Dowd's opportunity assessment.

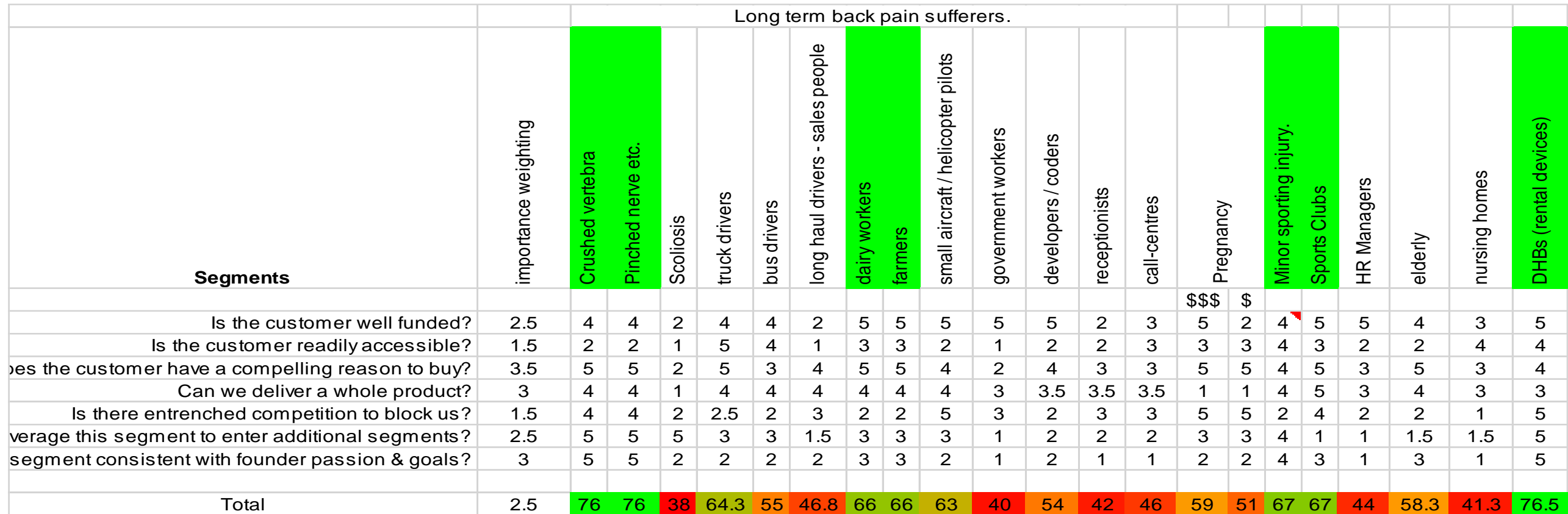


Worksheet Two: Mark Hildesley's opportunity assessment

\begin{tabular}{|c|c|c|c|c|c|c|c|c|c|c|c|c|c|c|c|c|c|c|c|c|c|c|c|}
\hline & \multirow{3}{*}{ 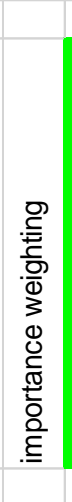 } & \multicolumn{13}{|c|}{ Long term back pain sufferers. } & & & \multirow[b]{2}{*}{ 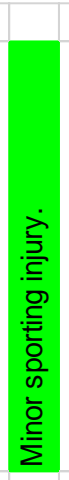 } & \multirow[b]{2}{*}{ 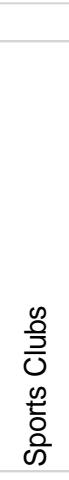 } & \multirow[b]{2}{*}{ 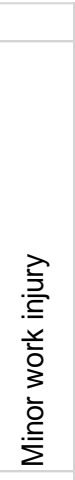 } & \multirow[b]{2}{*}{ 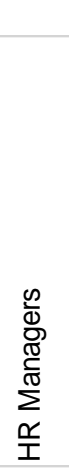 } & \multirow[b]{2}{*}{$\begin{array}{l}\frac{\lambda}{\frac{1}{d}} \\
\frac{0}{0}\end{array}$} & \multirow[b]{2}{*}{ 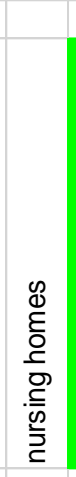 } & \multirow[b]{2}{*}{ 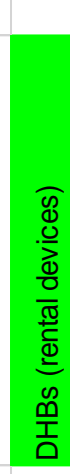 } \\
\hline \multirow[t]{2}{*}{ Segments } & & $\begin{array}{l}\frac{\pi}{0} \\
\frac{0}{0} \\
\frac{0}{0} \\
\frac{1}{0} \\
\frac{0}{0} \\
\frac{5}{0} \\
\frac{2}{0}\end{array}$ & $\begin{array}{l}\frac{0}{0} \\
0 \\
\frac{0}{0} \\
\frac{0}{0} \\
\frac{0}{0} \\
\frac{0}{0} \\
\frac{0}{0} \\
0\end{array}$ & $\begin{array}{l}\frac{\infty}{\mathscr{D}} \\
\frac{0}{\bar{O}} \\
\dot{\mathcal{D}}\end{array}$ & 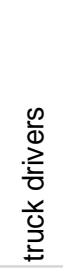 & 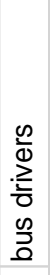 & 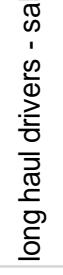 & $\begin{array}{l}\frac{0}{0} \\
\frac{1}{0} \\
\frac{1}{0} \\
3 \\
\frac{1}{0} \\
\frac{\pi}{0}\end{array}$ & & 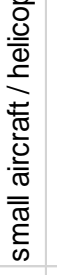 & 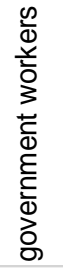 & $\begin{array}{l}\frac{\omega}{d} \\
\frac{0}{0} \\
0 \\
\frac{\omega}{0} \\
\frac{0}{0} \\
\frac{0}{0} \\
\frac{\partial}{0}\end{array}$ & 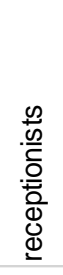 & 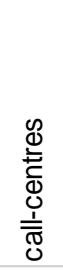 & \multicolumn{2}{|c|}{ 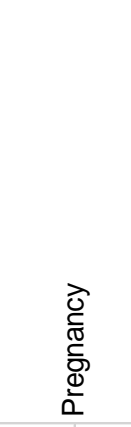 } & & & & & & & \\
\hline & & & & & & & & & & & & & & & $\$ \$ \$$ & $\$$ & & & & & & & \\
\hline Is the customer well funded? & 3 & 4 & 4 & 2 & 4 & 4 & 2 & 5 & 5 & 5 & 5 & 5 & 2 & 3 & 5 & 2 & $4^{\top}$ & 5 & 4 & 5 & 4 & 3 & 5 \\
\hline Is the customer readily accessible? & 2 & 2 & 2 & 1 & 5 & 4 & 1 & 3 & 3 & 2 & 1 & 2 & 2 & 3 & 3 & 3 & 4 & 3 & 4 & 2 & 2 & 4 & 4 \\
\hline Does the customer have a compelling reason to buy? & 3 & 5 & 5 & 2 & 5 & 3 & 4 & 5 & 5 & 4 & 2 & 4 & 3 & 3 & 5 & 5 & 4 & 5 & 2.5 & 3 & 5 & 3 & 4 \\
\hline Can we deliver a whole product? & 2.5 & 4 & 4 & 1 & 4 & 4 & 4 & 4 & 4 & 4 & 3 & 3.5 & 3.5 & 3.5 & 1 & 1 & 4 & 5 & 4 & 3 & 4 & 3 & 3 \\
\hline Is there entrenched competition to block us? & 1 & 4 & 4 & 2 & 2.5 & 2 & 3 & 2 & 2 & 5 & 3 & 2 & 3 & 3 & 5 & 5 & 2 & 4 & 2 & 2 & 2 & 1 & 5 \\
\hline Can we leverage this segment to enter additional segments? & 3 & 5 & 5 & 5 & 3 & 3 & 1.5 & 3 & 3 & 3 & 1 & 2 & 2 & 2 & 3 & 3 & 4 & 1 & 4 & 1 & 1.5 & 1.5 & 5 \\
\hline Is the segment consistent with founder passion \& goals? & 3 & 5 & 5 & 2 & 2 & 2 & 2 & 3 & 3 & 2 & 1 & 2 & 1 & 1 & 2 & 2 & 4 & 3 & 4 & 1 & 3 & 1 & 5 \\
\hline
\end{tabular}


Worksheet Three: Top six segments

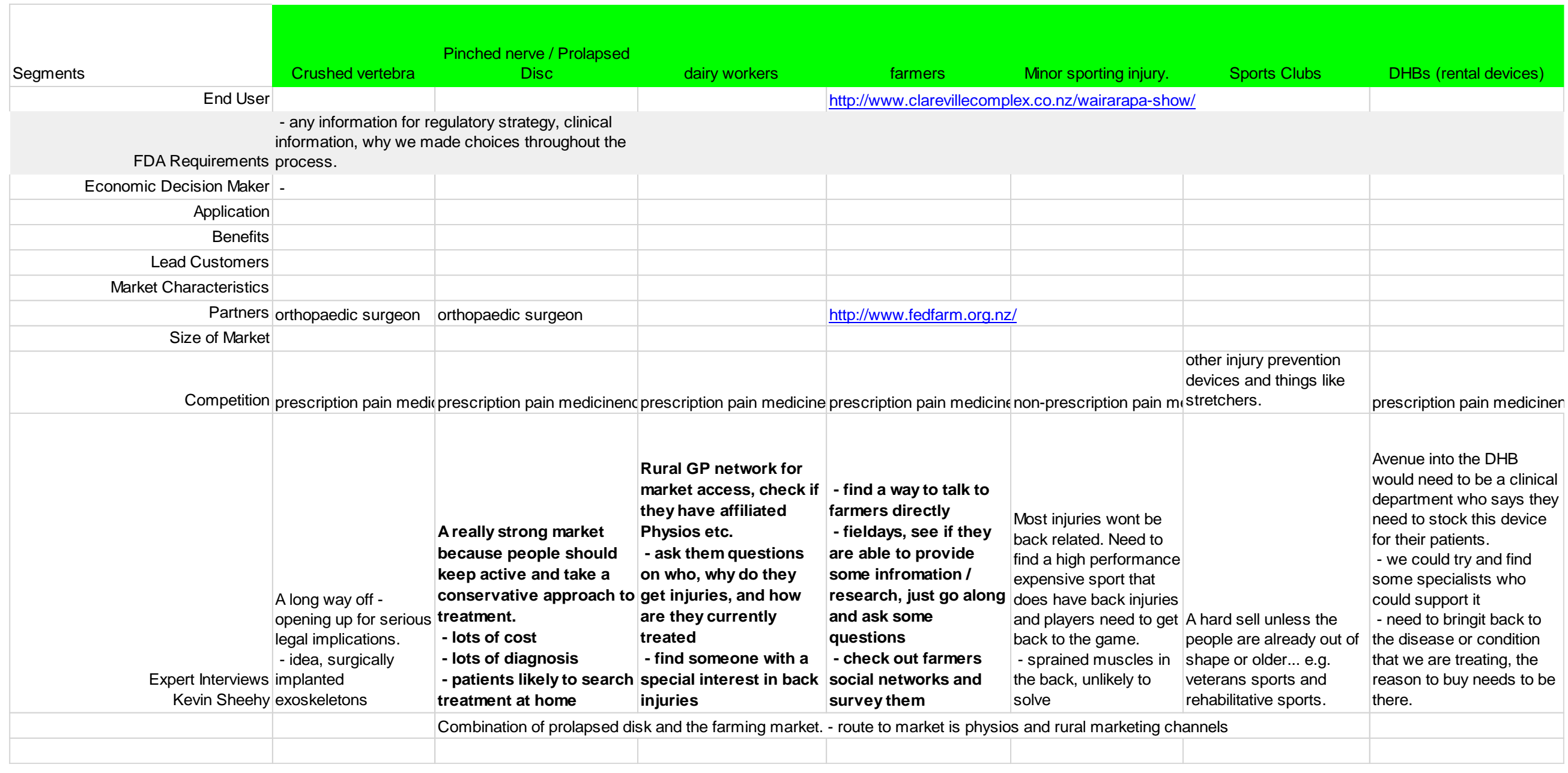


10.4 Low grade medical device competition.
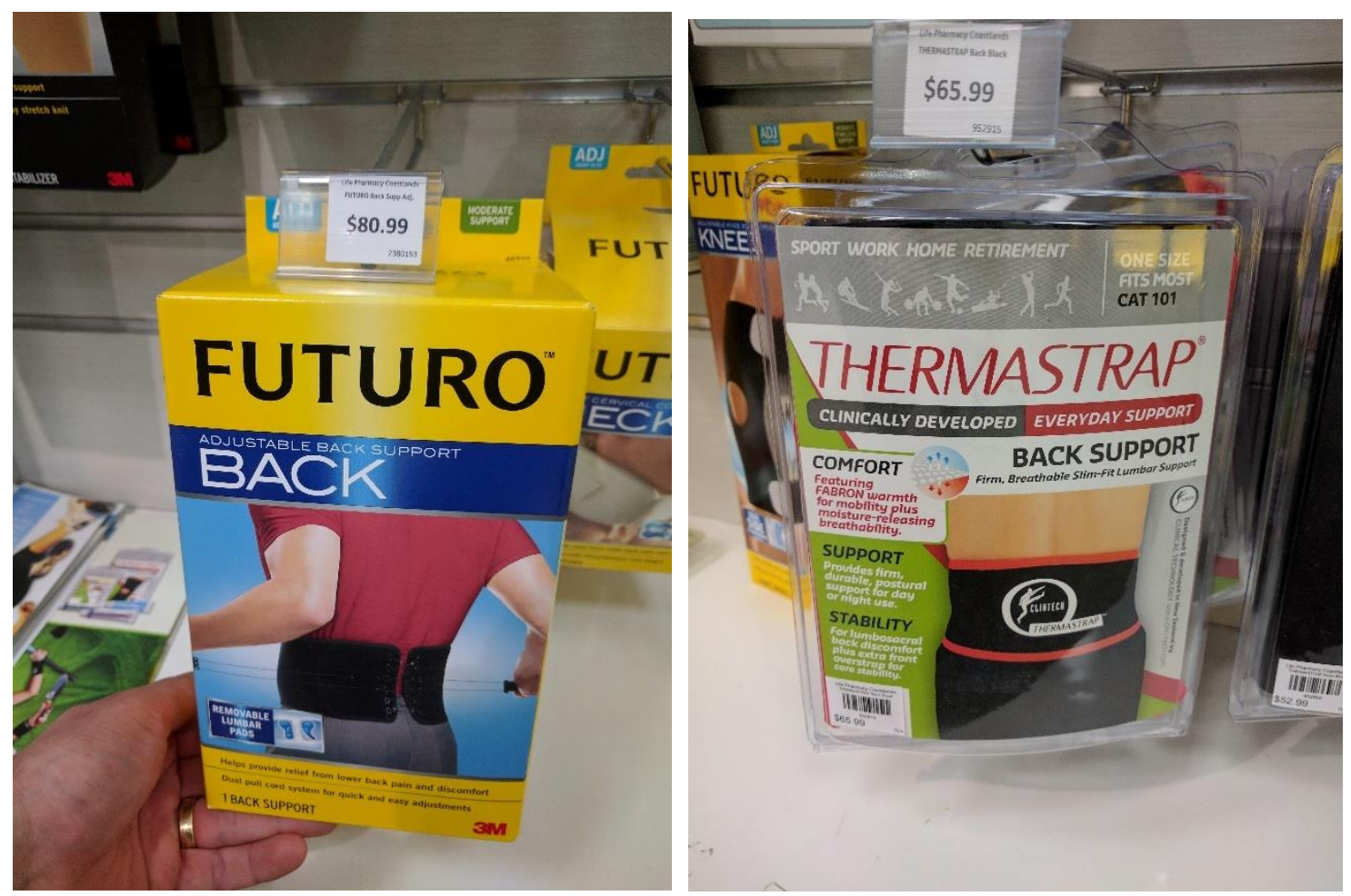


\section{Lifbak}

\section{BUSINESS CASE}

\section{CONTENTS}

1. Business Model Design

2. Market Validation and Development

3. Product Validation and Development 


\section{Business Model Design}

\subsection{Business Model Goals}

The business model is there to provide a simple framework to describe core business functions that the entrepreneur and organisation management can use to build strategies upon. At the entrepreneurial stage we are fixated on testing and exploring different aspects of the business model to discover one that is viable.

Each segment of the Lean Canvas described in Figure 20 needs to be thoroughly tested by the entrepreneur. Some of this can be done by using the strategies and tactics outlined in this business case.

In order of importance, the following aspects of the business model need to be tested and proven.

1. Problem AND Customer Segments

2. Unique Value Proposition

3. Solution

4. Channels

5. Revenue Streams

6. Cost Structure

7. Key Metrics

8. Unfair Advantage

Through the research to date we have weakly qualified the first parts of the business model (Problem and Customer Segments) and reached Customer/Problem Fit. C/P Fit is a state where we deeply understand a problem and have identified and validated a customer group that recognises, and is motivated to solve, the problem. Due to the pivot in market segments, additional validation research is needed to correctly identify the correct customers. I have described beachhead customers and tactics to reach them further on in this business case, but it is important to remember to always be testing and validating as the journey to be certain about customer problem fit hasn't been completed yet.

Some preliminary work has been done to describe and validate the third, fourth, seventh, and eighth aspects of the business model. Significantly, due to pivots in audience and a lack of market testing, work still needs to be done to discover the value propositions that will resonate with end users (patients), and the economic decision makers (ACC, health insurers). 


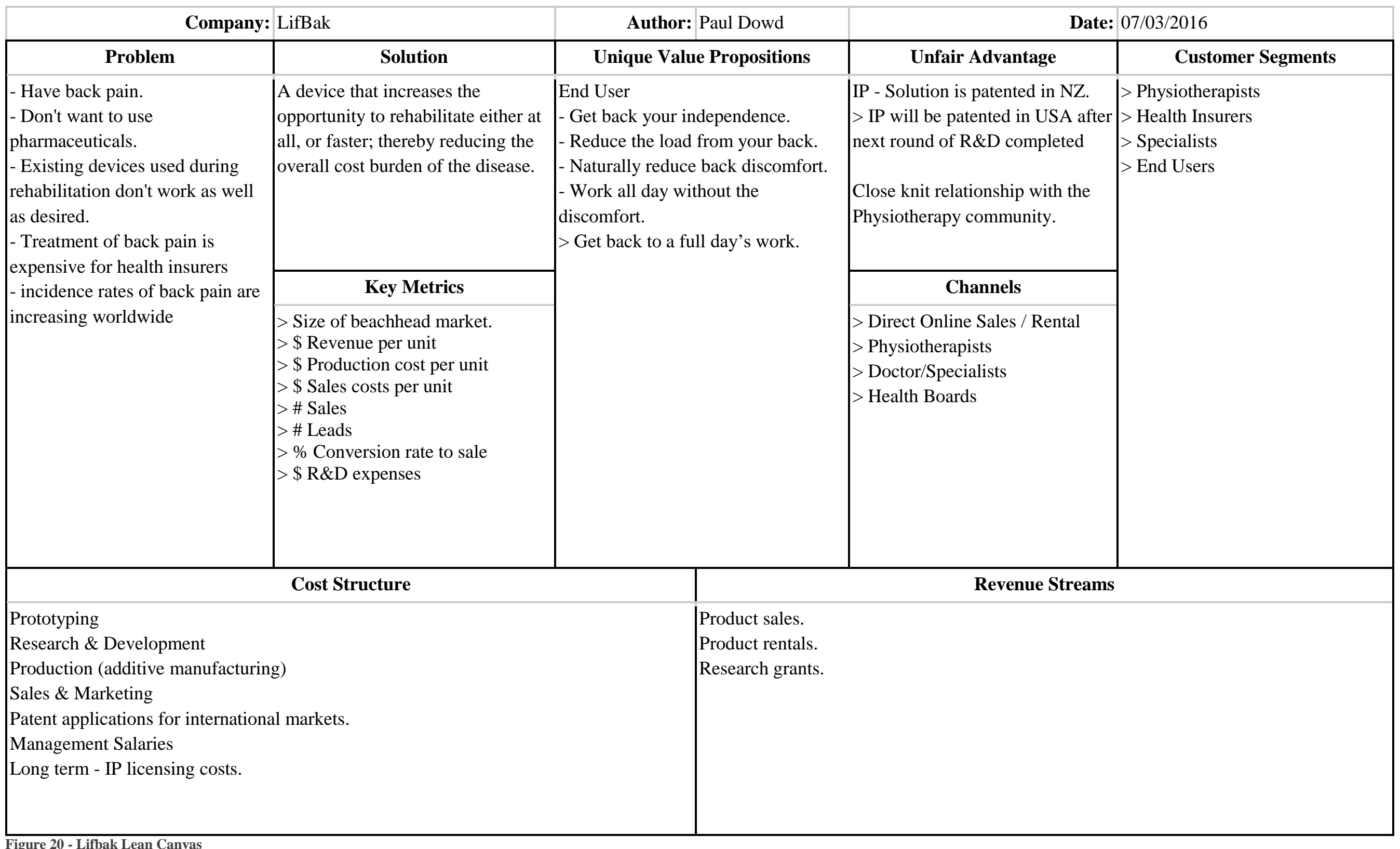




\subsection{Innovation Model}

I have developed an Innovation Model that touches each major business area. These pull from and expand the core business model sections described in the Lean Canvas. The recommendations made in this section are based on learnings from Larry Keeley's Ten Types of Innovation (Keeley, Walters, Pikkel, \& Quinn, 2013), a leading book on innovation thinking based on research gathered over the last two decades.

The ten types of innovation are split into three categories concerning the configuration or inner workings of the business (profit model, network, structure, and process), the product or service offering (product performance and product system), and the experience delivered to customers (service, channel, brand, and customer engagement). The future will most likely see the innovation model revised and improved as more is learnt about the competitive environment and how the business must be built. The aim is to test and settle on innovation factors that provide us with a point of difference and competitive advantage.

\subsubsection{Profit Model}

I recommend you pursue the Float, Financing, and Subscription profit models. These are the definitions from Ten Types of Innovation.

"Float: Receive Payment prior to building the offering; earn interest on that money prior to delivering the goods.

Financing: Capture revenue not from the direct sale of a product but from structured payment plans and after-sale interest.

Subscription: Create predictable cash flows by charging customers upfront (a one time of recurring fee) to have access to the product or service over time." (Keeley et al., 2013, p. 144)

By focussing on building products customised or partially customised for the end user you will be able to request payment prior to incurring manufacturing and distribution costs. You will be able to reduce the level of working capital required and improve profit margins. Earning interest on those funds will be only a small component of the reasoning here, but it may well be a contributor to long term profit margins. Bulk sales with government or private health insurers could deliver significant financing gains through boosts to working capital, and reducing the reliance on and cost of investor funds.

Higher value products designed to be leased out by medical practitioners may be considered a significant cost as most of these practitioners operate in a small business. You should offer financing options to these practitioners to reduce barriers to entry and increase market penetration. There will be small profit gains available in the financing of sales. An alternative to financing for these businesses could be a subscription model whereby products are offered to practitioners on a subscription basis. This could take the form of the following example.

Subscription model example:

- $\quad \$ 100$ per month per patient using a device.

- Ongoing support provided by Lifbak to the practitioner and their patients.

- $\quad$ Ongoing maintenance of the device.

- Upgrade or replacement of the device as new versions are released. 


\subsubsection{Network}

I recommend you pursue Alliances and Collaboration as your network models. These network models are chosen because working together with channel partners is essential for the successful development, introduction, and ongoing sales of Lifbak products. They are defined as:

"Alliances: Share risks and revenues to jointly improve individual competitive advantage.

Collaboration: Partner with others for mutual benefits.” (Keeley et al., 2013, p. 145)

Channel partners are key in defining who the best end user customers are and selling or prescribing to those customers. The partners identified through research to date are:

- Physiotherapists

- Orthopaedic Surgeons

- General Practitioners

- Osteopath (Excluding the USA, they should be considered a supplementary market as is it a pseudo-scientific practice)

- Chiropractor (They should be considered a supplementary market as is it a pseudo-scientific practice)

I have noted Osteopaths and Chiropractors at a lower standing because working with pseudo-scientific practitioners from the outset may harm your ability to get penetration to the mainstream medical market who don't want to be associated with products those practitioners use and recommend.

Alliances need to be made in key areas that secure funding from sources other than the end user. Important alliances will be with state funded health insurers such as the ACC in New Zealand, or private insurance companies which constitute the majority of the US market. Without the agreement of these partners to fund Lifbak devices for their patients you will find it difficult to get any level of market penetration.

\subsubsection{Structure}

Possibly Organisational Design...

"Organizational Design: Make form follow function and align infrastructure with core qualities and business processes.”(Keeley et al., 2013, p. 145)

No recommendations at this point.

\subsubsection{Process}

I recommend that you begin with the Flexible Manufacturing, Intellectual Property, On-Demand Production, and Logistics Systems tactics. As Lifbak grows in production volume they should consider removing Flexible Manufacturing as a tactic and adding in Lean Production and Process Standardisation. These are defined as:

"Flexible Manufacturing: Use a production system that can rapidly react to changes and still operate efficiently.

Intellectual Property: Use a proprietary process to commercialize ideas in ways that others cannot copy.

On-Demand Production: Product items after an order has been received to avoid carrying costs of inventory. 
Logistics Systems: Manage the flow of goods, information, and other resources between the point of origin and the point of use.

Lean Production: Reduce waste and cost in your manufacturing process and other operations.

Process Standardisation: Use common products, procedures, and policies to reduce complexity, costs, and errors." (Keeley et al., 2013, p. 145)

As Lifbak develops builds, tests, and introduces multiple early stage product versions you will need to have a high degree of flexibility in manufacturing methods. During this stage you should use methods ideal for small volume or one-off production. I envisage some components of Lifbak devices, and almost certainly prototypes, will be manufactured using additive manufacturing technology. Keeping production flexible, likely outsourced, will keep up front capital costs down whilst maintaining product and company nimbleness as you enter the marketplace and discover currently unknown requirements.

When you test and build your products it must always be with a view to building and securing patentable Intellectual Property. This IP, at least initially, creates the core value in the business and is what shareholders and investors will want to see and will invest in. This IP will also help to protect your position in the marketplace.

It has previously been recommended that there is a focus on getting orders and payment prior to production and potentially the customisation of those products to be produce. This will mean that you'll be best placed to practise On-Demand production methods. To do this you will need to maintain strong relationships with suppliers and outsourced manufacturers.

\subsubsection{Product Performance}

Ï recommend Lifbak develops products based on the Customisation, Ease of Use, Focus, and Engaging Functionality strategies. They are defined as:

"Customization: Enable altering to suit individual requirements of specifications.

Ease of Use: Make your product simple, intuitive, and comfortable to use.

Focus: Design a product or service for a particular audience.

Engaging Functionality: Provide an unexpected or newsworthy feature that elevates the customer interaction from the ordinary." (Keeley et al., 2013, p. 146)

These aspects cut to the core of what I believe Lifbak should strive to be: a device, with proven efficacy for select conditions, that users love to use. I take the focus and customisation aspects as to mean meeting the requirements of specific conditions and therefore proving efficacy for that condition.

\subsubsection{Product System}

I recommend that Product/Service platforms are built. It is defined as:

"Product/Service Platforms: Develop systems that connect with other partner products and services to create a holistic offering." (Keeley et al., 2013, p. 146)

The Lifbak device requires significant upfront and ongoing support to ensure the patient end user receives the right initial fitting and training in the device so that the patient has the highest possible chance of getting a positive treatment result. I recommend that training systems are built for prescribing medical practitioners and end users. One on one in person training backed up with comprehensive written and video training documentation is essential for medical practitioners. Video training will be ideal for end 
users in the understanding that their medical practitioner is also able to provide a deeper level of support if required.

Medical practitioners will need to have a deep understanding of:

- Assessing patients that are likely to receive benefit from Lifbak products.

- Measuring the patient for either custom manufacture or product fitment.

- Fitting Lifbak products on patients and training the patient in how to use the device.

End users will need to know how to:

- $\quad$ Fit the device.

- Actively wear the device for maximum comfort and support.

- Assess their own body in respect to the device to ensure they wear it only for the recommended period or to cease wearing it if required.

\subsubsection{Service}

I recommend that Lifbak pursues the service innovation strategy of Personalised Service. This is defined as:

"Personalized Service: Use the customer's own information to provide perfectly calibrated services." (Keeley et al., 2013, p. 146)

By offering personalised services, Lifbak can maximise the customer experience. Better service may also be a factor in greater efficacy.

\subsubsection{Channel}

I recommend that you use Indirect Distribution supported by Pop-Up Presences where strategically appropriate. These are defined as:

"Indirect Distribution: Use others as resellers who take responsibility for delivering an offering to the final user.

Pop-Up Presence: Create a noteworthy but temporary environment to showcase and/or sell offerings." (Keeley et al., 2013, p. 147)

Lifbak should sell through the channels described in section 2. A pop-up presence may be needed when/if Lifbak needs to build market awareness and/or provide training and support for the device.

\subsubsection{Brand}

I recommend using Brand Leverage and Certification tactics to enhance the delivery of Lifbak products and services. These are defined as:

"Brand Leverage: Allow others to use your brand name to lend them your credibility and extend your company's reach.

Certification: Develop a brand or mark that signifies and ensures certain desirable characteristics in thirdparty offerings." (Keeley et al., 2013, p. 147)

Because Lifbak will primarily sell through the channel, it will be beneficial to build a brand that makes the process of prescribing the device easier for the clinician. Certification will be necessary to maintain quality 
standards through the channel, and inform customers about who is able to support them when using the device.

\subsubsection{Customer Engagement}

I recommend we keep things simple for customer engagement and only use the Experience Simplification tactic. In the future, as the company grows, it would likely be beneficial to supplement this with the Community and Belonging, and Experience Enabling tactics. These tactics are defined as:

"Experience Simplification: Reduce complexity and focus on delivering specific experiences exceptionally well.“ (Keeley et al., 2013, p. 147)

This is important for two reasons: using the device should be an exceptional experience, and to help Lifbak focus on the core benefit customers want and appreciate.

\subsection{Key Metrics Model}

\subsubsection{Our Key Metrics}

For each stage of the business there will be different key metrics that need to be met. This model is for the market introduction stage of the plan. The trial stage metrics are specified in detail in section 8.3.1 in the Product Validation and Development section of the business case.

I have broken each section of the customer factory into metrics that have been used to direct operational activities that Lifbak needs to undertake. All organisational activity should all aim to influence one or more of these metrics. The primary outcome metrics are what all activities within the section should aim to influence and the input metrics are the outputs from the various operational and marketing activities recommended in this business case.

\subsubsection{Acquisition Metrics}

Acquisition is all activity that drives new user leads. There are core outcome metrics we will use to measure performance, as well as input metrics that are influenced by the marketing and promotion efforts we undertake. As I am recommending acquiring and engaging users through therapeutic channels I have focused the metrics around this. Any other acquisition tactics the company may wish to undertake need to identify the metrics the tactic will influence and then model that to the outcome metrics we need to perform against.

\section{Outcome Metrics:}

- Number of new leads (\#Leads)

\section{Input Metrics:}

- Physiotherapy Channel

- Number of physiotherapists signed up (\#Physio)

- Average number of clients per physio (\#PhysioAvgClients)

- Pain Clinic Channel

- Number of clinics signed up (\#Clinics)

- Number of specialists signed up (\#Specialists)

- Average number of clients per clinic (\#ClinicAvgClients) 
- $\quad$ Direct Sales

- Number of website visits. (\#WebVisits)

- Website conversion rate. (\%WebConvertToLead)

\subsubsection{Activation}

This is where we turn leads into new users.

\subsubsection{Retention}

In order to keep a flow of happy users, revenue, and new leads we'll need to perform against the needs of end users and economic customer.

\subsubsection{Revenue Metrics}

I don't have enough visibility to identify exactly how we can and will measure and track revenue metrics from ACC and health insurers. If we don't need to continuously prove and report on efficacy then the metrics are simple sales metrics; but if we have ongoing assessment requirements dictated by funders then Lifbak will need to record more detailed impact and outcome metrics as exampled below:

These are the metrics that can be used to deliver value to end users that the financial customer will monetise for us.

1. Time to return to work.

2. Number of hours that the user can work per week.

3. Cost of treatment.

These are additional metrics that are important value factors for end users and will likely impact the final monetizable factors.

- Pain

- Ability to perform normal activities.

- Quality of life.

- Time to rehabilitate.

The above metrics are critical to monetisation at the early stage and need to be part of any trials, however it is uncertain whether they are relevant long term. It is more likely that

\subsubsection{Referral Metrics}

At this point I am not recommending any activity around customer referrals. 


\section{Market Validation and Development}

\subsection{The Problem}

Back pain is a resulting condition associated with a variety of medical diagnoses. Back injuries of all types are increasing worldwide and are reaching epidemic proportions with $80 \%$ of the population expected to suffer from a back injury at some point in their lifetime. ("The burden of musculoskeletal conditions at the start of the new millennium," 2003) This increase of incidence rate coincides with the rapidly rising cost of treating individual patients; leading to exponential increases in cost to insurers, individuals, and taxpayers. This is all before we consider the human costs of dealing with chronic or short-term back pain. In New Zealand, the cost to ACC of treating just Lumbar Sprains is expected to reach $\$ 307$ Million by 2020, an increase of $77 \%$, or $15 \%$ per annum, on the 2015 cost of $\$ 173$ Million. These statistics tell us that the current method of treating this condition is not sustainable. We need to invest in finding alternatives to the status quo.

\section{Patients with chronic back pain and their treatment providers have limited options when seeking to accelerate rehabilitation from injury.}

For more detail on the specific statistics referenced above see the Findings and Analysis.

\subsection{Existing Solutions / Competitors}

There are no direct competitors for the Lifbak device. We are building a new market. This creates complications when building a business as we don't have a successful leader to follow who has already invested heavily in the market and experienced failures that we could learn from. We have to both build the demand for the product (the market) and then become the best solution for that demand.

However, there are indirect competitors that Lifbak needs to be aware of.

- The "do nothing" group are probably the largest competitor or roadblock to successfully building and entering the market. Lifbak will need to develop efficient means of filtering these people when assessing markets and potential users.

- For now, I'm including those happy to take pain medication as part of the "do nothing" market. In time, we may develop marketing funnels that are able to transition some of this cohort to potential Lifbak customers.

- Our channel partners (Physiotherapists, chiropractors, osteopaths, etc.) are also competitors in that they provide services for the same problem to the same users.

- Compression bands and similar devices that are sold through pharmacies and health stores are not a direct competitor but may be seen as a lower cost alternative to our product/s. We will need to effectively differentiate Lifbak from these products. It may be that this differentiation includes trialling some devices alongside ours to show increased comparative efficacy.

- Non-medical exercise treatments exist that potential customers may choose to perform instead of using the device. These include yoga, pilates, and other types of exercise methodologies that focus on core strength, flexibility, and movement.

\subsection{The Beachhead Customer}

Based on the outcomes of the A\&P Show I recommend that the Beachhead Market Segment pivots.

Discussions to date shows that patients accessed via the Physiotherapy and Pain Clinic channels should be the new beachhead customer segment. The ideal physiotherapists and pain clinics will have client lists that 
include patients experiencing problems our device has shown efficacy in treating. Being willing to run trials with their patient/s will be a significant bonus and should be sought for at minimum the first 10 channel customers.

At this point we are assuming thoracic vertebrae injuries as the most likely candidates for efficacy, and these will be the focus end-user segment.

\subsubsection{Ideal Physiotherapist Customer Profile}

\subsubsection{Customer Base}

A strong, stable physiotherapy practice with a minimum of 10 patients who are prime candidates to whom they'd recommend the device. Customers need to be sufficiently insured, or have sufficient disposable income, to be able to entirely or partially pay for the device. Although we don't need many customers to trial with, it is preferable to have early adopters with a large customer base that the device can be introduced to once trials are completed.

\subsubsection{Location}

Due to a need to engage the Physiotherapists in formal trials it is beneficial, but not essential, that our customers are located close to Auckland where the head office is likely to be located. If a Physiotherapist is sufficiently experienced in running trials with their patients then this need could be reduced.

\subsubsection{Profile}

Target early adopters need to be enthusiastic about trialling and promoting new technologies that they believe will help their patients. Early adopters should show characteristics that indicate they can grow into being effective brand evangelists. Some attributes we should seek:

- Willing to take a controlled risk on a new method and device.

- Ability to promote and organise trials with their patients.

- Good relationship with ACC, preferably with experience working with ACC on funding new therapies.

- Willing to invest time and money into learning about and purchasing the device.

- Ability to invest the time required to provide critical diagnostic feedback to Lifbak about device performance and patient experience.

\subsubsection{End User Profile}

Actual end users will show the following characteristics:

- Motivated to try something new to help or accelerate their rehabilitation.

- An injury that will be helped by a load-reduction device.

- An ability to invest time and money into using the device.

The source of end users will need to be located near the clinician running the initial trial/s. Because the founder CEO is based in Auckland, and Auckland is the biggest market in New Zealand, I recommend that Lifbak focuses on this single market for the initial trial period.

Users will be found via the trial clinician, early stage channel partners, and specialist treatment centres. 
During the trial, users won't need to purchase the device and all appointments with the clinician should be covered by ACC if their injury was caused by an accident. Post-trial, users will need to be prescribed the device by their clinician, but they still won't need to pay for it as we'll have been approved by ACC. Users will need to be able to fund the non-funded portion of clinician appointments. I recommend that during the trial Lifbak covers this expense.

A "nice to have" characteristic of all trial participants is an ability and willingness to become a brand evangelist for Lifbak and be featured in articles, reports, and videos.

Note:

At this stage, we don't know enough about what diagnoses the device will help and the customer types that accept the device as helping with their problem to more accurately identify and describe end users. Once Lifbak has started to prove efficacy and have tested the device with various end user groups then you'll be in a position to revisit creating customer profiles.

\subsubsection{Looking to the Future}

What customer segments will we look to after gaining traction in the Beachhead market segment?

Bring in viable segments from the market segment matrices that have been reinforced by data.

\subsection{Market Entry Plan - New Zealand}

\subsubsection{Strategic Overview}

Entry into New Zealand will occur in three stages trial, introduction, and maturity. One could make a case to skip New Zealand entirely and go to a larger marketplace, however I consider the time and cost benefits of being able to develop and test the device in a less regulated environment far outweighs the benefit of being in a more complicated international market $1-2$ years earlier.

\subsubsection{Trial:}

Timeline:

18-24 Months

This timeline is based on six months for development of the next version of the device, registration of IP, and a twelve-month clinical trial. Efficacy for one diagnosis needs to be shown in this time for the next stages of the strategic plan to come into effect. If efficacy is not immediately shown then design, development, and trialling will need to repeat until we are able to show enough efficacy to meet the requirements of $\mathrm{ACC}$ in New Zealand.

Strategic Outcome: $\quad$ Single product approved by a major funder, ideally the ACC.

Metric Outcomes: Whichever metrics are confirmed for the trial.

\subsubsection{Introduction:}

Timeline: $\quad 2-5$ years

Once efficacy has been shown for at minimum one diagnosis and the product has been accepted by the ACC as a device they will pay compensation for, the formal introduction to market begins.

The focus for this 2-3-year period is on educating the channel about our device, what it has been funded for, and when it should be prescribed. 
Strategic Outcome: $\quad$ Achieved 20\% market penetration for one diagnosis, and $>80 \%$ market awareness within our target channels to market.

Metric Outcomes: $\quad$ Number of registered channel partners, number of clinicians trained.

\subsubsection{Maturity:}

Timeline: $>4$ Years

Once Lifbak has achieved the following two things we will have reached maturity in the New Zealand market. At this stage Lifbak should be looking to maintain profitability in the market with existing products and invest in new products to ensure market leadership.

1. The device has been accepted and approved for purchase by ACC, the Ministry of Health (or DHBs, whichever is appropriate), and private health insurers in New Zealand.

2. Lifbak has market recognition amongst specialists and key channels nearing $80 \%$. Achieving this level of market awareness is not trivial, but if Lifbak can prove efficacy then it should be able to demand significant attention in this market and utilise existing (largely free) methods of promotion.

I expect us to reach maturity in New Zealand within a few years for those markets where we have proven efficacy and cost/benefit. I believe a quick jump to maturity is achievable due to a lack of competitors in our specific market, a large unmet market need, and cost-efficient price point.

Additional markets that have additional proof of efficacy requirements will see a similar, but slightly shortened, market entry curve as each new market goes through their own clinical trials and market introduction.

\subsubsection{Beachhead Market Size}

In 2015 ACC funded treatment for 440,000 back injuries with an average cost of treatment of $\$ 1200$. Due to this treatment cost being too low to make our product viable we need to further refine the market to only a few injury types that have high average costs to ACC. I have used only used injury types defined in the discussion by expert recommendation and ACC needs analysis. The beachhead market of ACC funded major thoracic injury patients consists of just two patient groups: closed fracture thoracic vertebra, and disc prolapse with radiculopathy. There may be additional groups identifiable through expanding into similar injuries in the lumbar region, and by performing more in-depth market analysis of other diagnoses to identify the number of patients who go on to have long term chronic problems.

\begin{tabular}{|r|l|l|l|}
\hline \multicolumn{1}{|c|}{$\mathbf{2 0 1 5}$} \\
\hline Read Code Description & Patients & \multicolumn{1}{|c|}{ Total Spend } & \multicolumn{1}{|c|}{ Average Spend } \\
\hline Lumbar disc prolapse with radiculopathy & 4,531 & $\$ 54,762,293$ & $\$ 12,086.14$ \\
\hline Closed fracture thoracic vertebra & 739 & $\$ 9,878,418$ & $\$ 13,367.28$ \\
\hline Closed fracture lumbar vertebra & 713 & $\$ 4,649,014$ & $\$ 6,520.36$ \\
\hline Lumbar disc displacement & 399 & $\$ 3,974,615$ & $\$ 9,961.44$ \\
\hline Disc prolapse with radiculopathy & 430 & $\$ 4,529,976$ & $\$ 10,534.83$ \\
\hline Open fracture lumbar vertebra & 186 & $\mathbf{\$ 2 , 2 4 1 , 9 5 2}$ & $\$ 12,053.51$ \\
\hline Total: & $\mathbf{6 , 9 9 8}$ & $\mathbf{\$ 8 0 , 0 3 6 , 2 6 8}$ & $\mathbf{\$ 1 1 , 4 3 7 . 0 2}$ \\
\hline
\end{tabular}

Figure 21 - Beachhead market size

Post-trial, this beachhead market would represent the following revenue opportunities. These figures are based on an average sale price of $\$ 950$. 
$5 \%$ market penetration:

$10 \%$ market penetration:

$20 \%$ market penetration:
$\$ 332,000$ / 350 units

$\$ 665,000 / 700$ units

$\$ 1.3 \mathrm{Mil} / 1400$ units

$20 \%$ market penetration should be realistic once proof of efficacy is shown.

\subsubsection{Trial Tactics}

See section 3.1.2 for detailed information on clinical trials.

\subsubsection{Market Introduction Tactics}

Details individual tactics I have identified with a focus on the "Customer Factory" and the specific metrics we will be looking to get traction in at each stage of the business.

For market introduction, we are focusing on the following metrics:

- Number of channel partners.

- Number of clinicians trained.

\subsubsection{ACC Funding and Trials}

In New Zealand, public funding for the device would come via ACC paying for the device based on requests from various intermediaries who recommend the device to their patients. To ease this process, we need to ensure we are working with ACC to provide them the information they need to make a funding decision in our favour, and this means proof of efficacy.

Because of the growth rate in back injuries and back pain related compensation claims that ACC is facing, I believe that they will look favourably at working with Lifbak to run a small trial. They are constantly seeking better treatment methods that can return their customers to work faster, and therefore reduce the overall cost of treatment to ACC. To build this business case for ACC we will need to focus on a group of customers who are in the higher brackets of treatment costs, and importantly will be receiving weekly income compensation payments.

The Rehabilitation Manager at ACC, Christine Bloomfield, has recommended that we look at their clients with thoracic spinal injuries who have been off work long term and are high cost customers for ACC. This is a group where ACC's motivation and need is high. They are looking for new ways of accelerating or even just achieving, the rehabilitation of this cohort to a place where they are able to work again.

\subsubsection{Market Validation and Introduction to Physiotherapists}

To attract physios, and perform market validation and research at the same time, I recommend that Lifbak runs a nationwide research project to learn more about the treatment options Physiotherapists have and use when rehabilitating back injuries. We want to frame this in a way that shows we are seeking their input on patient and clinician need for additional device options when treating back injuries.

The survey should be supplemented with information on the device and a summary of the relevant research on the efficacy of using load reduction in the rehabilitation of back injuries. Testimonials from NZ physios who have personally reviewed and tested the device should be used to back up our research and bring real life relevancy.

The primary outcome this should deliver are further information or trial requests (sign-ups) by the participating Physiotherapists. 


\section{Proposed survey questions:}

- What are their current short-term treatments for back pain? You may wish to offer options for both chronic pain and acute pain.

- It has been highlighted in discussions with Kevin Sheehy and Monty Wawatai that the device may be better suited to treating acute back pain.

- What type of patient would you use this device on? Please provide as detailed a description of the patient and their condition as you are able to provide.

- How many patients do you currently see who re-injure themselves during recovery?

○ Would you consider using the device with those patients?

- When would you use the device and when would it be most effective?

- Do you see an overuse of analgesics, in particular opiate painkillers, in you patients?

- Do you see this device as offering you an option you can use to help patients off using analgesics?

(Sheehy, 2016)

\section{Method of distribution:}

- Scrape physiotherapists from various website to build a database that can be used to email out a survey designed to initiate a discussion as well as better validate the market and its needs. The ideal tool for scraping internet based lists is www.ParseHub.com.

○ Physiotherapy New Zealand, http://physiotherapy.org.nz/about-physiotherapy/find-aphysio/

- Review and then import the scraped list into an email marketing system that is able to track all typical email marketing metrics.

- Send a small campaign of emails introducing the concept and requesting responses to the survey.

- Send an introductory email with information on Lifbak, load reduction, and the survey.

- After one week, send all those who haven't completed the survey to date a follow up email requesting the survey be filled out

- After another week review the list of non-responses and pull out a list of people who are worth calling to try and get a survey response.

- After someone has completed the survey they should be thanked for doing so.

The responses of this survey will give you a strong indication of the potential for distributing the Lifbak device through the Physiotherapy channel. It will also provide you with a list of warm leads who are likely to want to learn more and potentially trial the device. These leads should then be placed into an appropriate Customer Relationship Management system for future follow up. 


\subsection{Market Entry - International}

Entry into international markets are not the priority right now, however due to the importance of these markets to future growth, the intellectual property security and regulatory requirements of these markets needs to be taken into account early on in product design and development.

The key markets Lifbak should target are the United States of America, Germany, France, and the United Kingdom. Regulatory requirements of these markets should be met by gaining FDA and EMA approvals. It is currently uncertain how Brexit may impact the regulatory environment for medical devices in the UK. Other markets that should be considered, but have yet to be investigated are Japan, Canada, Australia, and South Korea.

I recommend the first international market Lifbak expands to is the largest one, the USA. It is possible that by the time Lifbak is ready to enter the market in the USA the market will have increased exposure to mass-produced exoskeleton devices from backX and StrongArm Tech, which will reduce some of the barriers to entry.

\section{Product Validation and Development}

Developing a validated product is the most important next stage of activity for Lifbak. The two areas of validation that need to be found through the medical research are one of more conditions that the device has efficacy to treat, and a viable market where the customer has demonstrated an unmet need that an economic decision maker, e.g. ACC, is willing to fund the device to fill. The future regulatory requirements for the USA and Europe need to be considered throughout product development and trials to ensure the process can be completely smoothly when the time comes to apply for approval in those regions.

\subsection{Product Development}

The next six months needs to be committed to developing a product and is suitable for patenting and ready for the clinical trial.

Development will require a suitable product engineer, under the guidance of Mark Hildesley. This is an iterative process built around continuous testing with select users who have signed non-disclosure agreements. Once Lifbak is satisfied that the device will be both acceptable to the user to wear for long period, and has the highest possible probability of proving efficacy, then it will be ready for patenting.

Specialist CAD equipment and a workshop will be required. On occasion Lifbak may need to contract external parties to run specific diagnostic or performance tests on the device; for example, if Lifbak needed to formally test its strength under load.

Lifbak will need approximately $\$ 100,000$ to fund the staff and resources required to develop the product.

\subsection{Medical Research}

Medical research on the benefits of load reduction for the rehabilitation from back injuries has suffered from limited research, likely because of limited devices being invented in this area that would necessitate the research being done. In order to prove the worth of Lifbak's products they will need to undertake clinical trials that prove the benefits of load reduction on the rehabilitation of specific back injuries, specifically with the Lifbak exoskeleton. The research will need to meet the requirements of the FDA and EMA to ensure future market opportunities are enabled. 
Lifbak will need approximately $\$ 50,000$ to run the trials over an 18 -month period. This excludes product development costs.

\subsubsection{Key Metrics for Trials}

To meet ACC proof of efficacy requirements, Lifbak should measure outcomes that closely align with those that ACC uses internally when making decisions on both efficacy and cost effectiveness. At the end of the trial we need to be able to tell a story that shows the improvement in recovery caused by our device, and how that improvement can be achieved at an economical cost. The trial will need to measure:

- EPPOC (electronic persistent pain outcome) Measures.

- Quality of life.

- Social participation.

- Economic / workplace participation.

- Time to return to work (i.e. speed of rehabilitation).

- Likelihood of returning to work. (i.e. incremental improvement in return to work instances due to Lifbak)

- All cost points related to using the device.

The clinician in charge of designing the trial measures needs to take these needs into consideration, but will have the final say on what outcomes are appropriate and possible to be measured.

\subsubsection{Clinical Trial}

It has been stated that the first trial could include just a single participant with more being added part way through the trial if there are early signs of success. However, as we don't want to run to many trials and speed to market is important, I recommend running the first trial with 10 patients to give ourselves the greatest opportunity to learn from the trial, achieve the desired outcomes, and more robust proof of efficacy standards.

The trial needs to be designed and managed by a researcher experienced in running clinical trials on medical devices, and a clinician experienced and expert in treating thoracic vertebrae injuries. We should expect to require up to $20 \%$ of a full time equivalent person for each professional during the entirety of the trial.

A GP or specialist (consulting clinician) running the trial will cost around $\$ 20,000^{13}$ to run the trial parttime for the year. They may receive additional remuneration by billing patient appointments for the trial participants they see in a clinical capacity.

The research designer and manager (researcher manager / researcher) will cost $\$ 20-30,000^{14}$ for the period of the trial design, operation, and reporting.

I don't expect we'd need any special facilities for the duration of the trial as appointments and training can be done at the consulting clinician's practice. However, we should factor in a possible need to hire specialist kinesiology testing equipment if required. A $\$ 5000$ fund for this type of testing should be appropriate.

${ }^{13}$ https://www.careers.govt.nz/jobs-database/health-and-community/health/physician/

${ }^{14}$ https://www.careers.govt.nz/jobs-database/health-and-community/health/biomedical-engineer/ 


\subsection{Regulatory and Intellectual Property Considerations}

\subsubsection{Intellectual Property Protection}

The new version of the product, once developed, will need to be patented in New Zealand and other international markets we wish to sell in. Without this, the Lifbak device could be easily replicated.

\subsubsection{US - FDA Regulations}

Lifbak will need to complete a Premarket Submission with the FDA prior to entering the marketplace.

\section{Resource Requirements and Returns}

\subsection{Required Team}

What team members do we need to have to execute on the business plan? List what/who we need and why we need them. These should tie back to the business model and the customer factory metrics. I will need to outline additional team members that we'll need to find as we move through the go to market strategy and need to work on different metrics.

- $\quad$ CEO / Mark Hildesley

- Trial Manager

- Trial Clinician

- Lead Product Designer / Engineer

\subsection{Financial Plan}

\subsubsection{First 24 Months}

Lifbak will need $\$ 340,000$ to $\$ 460,000$ for the first 24 months of operations to invest in product development, research, and market development.

\begin{tabular}{|r|r|}
\hline Expense & Amount \\
\hline IP Protection & $\$ 40,000.00$ \\
\hline Clinical Trials & $\$ 50,000.00$ \\
\hline Product Development & $\$ 100,000.00$ \\
\hline Management & $\$ 120,000.00-\$ 240,000.00$ \\
\hline Consultancy fees (engineering, testing etc.) & $\$ 30,000.00$ \\
\hline
\end{tabular}

\subsubsection{Funding Options}

There are multiple options available when considering funding a new enterprise. The methods used have pros and cons that need to be considered. I have outlined the options below, and my recommendation is to raise as much capital now to allow for rapid market entry. Because the aim is for Lifbak to be a high growth company, and they will need to hold additional capital fundraising rounds in the future, I recommend diluting to $20 \%$ of the company in the first funding round.

With a capital requirement of $\$ 340,000$ to $\$ 460,000$, this means a post-money valuation of $\$ 1.7-\$ 2.3$ million. 
This should be done as a mix of angel investment, grants, and crowdfunding, with crowdfunding being the primary source if possible. I have only discussed crowdfunding here, but research and development grants via Callaghan Innovation should be sought, and angel investment should also be investigated if it can reduce the costs associated with crowdfunding. Research and development grants could return up to $40 \%$ of expenditure to the organisation to invest in future activities.

\subsubsection{Crowdfunding}

Crowdfunding is an exercise in both market development and fundraising. In order to crowdfund we must first fully understand the market segments we are selling to and the value propositions that will appeal to them. This will include having at least 5 devices in the market being used by customers that value stories and testimonials can be built around. Crowdfunding would directly target end-users rather than the physiotherapist channel. It is possible to target investors via crowdfunding, but typically crowd funders look to invest in something they have a personal connection to or need for.

Crowdfunding, done well, could deliver a significant proposition of the capital requirements for Lifbak. You should run a crowdfunding round with multiple options funders can select from. These are:

- Investment Only

- Pre-purchased product only.

There are costs associated with setting up and running a crowdfunding campaign, as well as some ongoing costs of managing the interests of those shareholders.

\subsection{Investment Only}

Investors will purchase newly issued shares in blocks of $\$ 500$ with a maximum of $\$ 300,000$ to be raised in this way.

\subsection{Product Only}

Customers who want to pre-purchase a product will be provided a discount rate to the set retail price, and will also be rewarded with a small shareholding. This is the cheapest form of capital for us and has the highest upside as we are also creating customers and evangelists for our brand.

The Lifbak exoskeleton will have a retail price of $\$ 1,200.00$, and crowdfunding customers will be able to purchase this at a reduced early bird price of $20 \%$ off.

\subsubsection{Seed Equity Funding Round}

Depending on Mark's salary needs Lifbak will need to raise $\$ 340,000$ to $\$ 460,000$ to fund two years of product development and trials. I expect that Mark's salary draw would be a factor in any funding negotiations if non-crowdsourcing methods were used.

I recommend targeting investors who are able to invest in future funding rounds and can provide additional value through market access and expertise, especially into the US. Because Lifbak is currently only raising capital for product development and trials, significant further investment will be required to enter the marketplace in New Zealand, secure international IP rights., and gain regulatory approval in international markets. It is beneficial to keep the same group of investors if it is possible. 